\title{
Enhanced Sludge Washing Evaluation Plan
}

R. D. Jensen

Date Published

September 1994

Prepared for the U.S. Department of Energy Office of Environmental Restoration and Waste Management

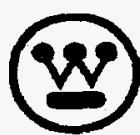

Hanford Operations and Engineering Contractor for the

U.S. Depertment of Energy under Contract DE-AC06-87RL10930

Approved for Public Release 


\section{DISCLAIMER}

This report was prepared as an account of work sponsored by an agency of the United States Government. Neither the United States Government nor any agency thereof, nor any of their employees, make any warranty, express or implied, or assumes any legal liability or responsibility for the accuracy, completeness, or usefulness of any information, apparatus, product, or process disclosed, or represents that its use would not infringe privately owned rights. Reference herein to any specific commercial product, process, or service by trade name, trademark, manufacturer, or otherwise does not necessarily constitute or imply its endorsement, recommendation, or favoring by the United States Government or any agency thereof. The views and opinions of authors expressed herein do not necessarily state or reflect those of the United States Government or any agency thereof. 


\section{DISCLAIMER}

Portions of this document may be illegible in electronic image products. Images are produced from the best available original document. 


\section{RELEASE AUTHORIZATION}

Document Number: WHC-EP-0805

Document Title: Enhanced Sludge Washing Evaluation Plan

Release Date: $\quad 9 / 30 / 94$

This document was reviewed following the procedures described in WHC-CM-3-4 and is:

APPROVED FOR PUBLIC RELEASE

***************

WHC Information Release Administration Specialist:

Christino Prellexgham

C. Willingham

$9 / 30 / 94$

(Signature)

(Date) 
CONTENTS

1.0 ENHANCED SLUDGE WASHING EVALUATION PLAN $\ldots \ldots \ldots$. . . . . 1-1

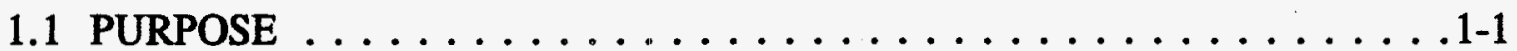

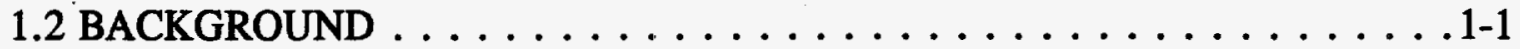

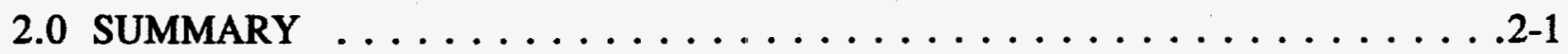

3.0 TECHNICAL WORK SUPPORTING ENHANCED SLUDGE WASHING

EVALUATION . . . . . . . . . . . . . . . . . . . . . . . .

3.1 LOGIC FOR TECHNICAL WORK $\ldots \ldots \ldots \ldots \ldots \ldots \ldots \ldots \ldots$

3.2 WASTE CHARACTERIZATION . . . . . . . . . . . . . . . 3-3

3.3 ENHANCED SLUDGE WASHING PROCESS DEVELOPMENT . . . . . 3-7

3.4 ADVANCED SEPARATION $\ldots \ldots \ldots \ldots \ldots \ldots \ldots \ldots \ldots$

3.5 TANK AZ-101 SLUDGE WASHING TEST . . . . . . . . . . . . . . 3-9

3.6 HIGH-LEVEL WASTE FEED COMPOSITION AND WASTE FORM

SELECTION . . . . . . . . . . . . . . . . . . . 3-10

3.7 BLENDING STUDIES/RETRIEVAL SEQUENCE . . . . . . . . . . . . 3-12

3.8 FLOWSHEET DEVELOPMENT . . . . . . . . . . . . . . . . . . . . . . . . . . . . . . . . . .

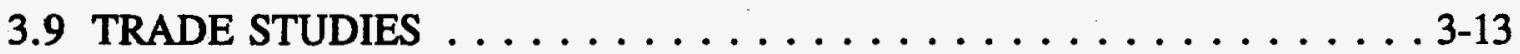

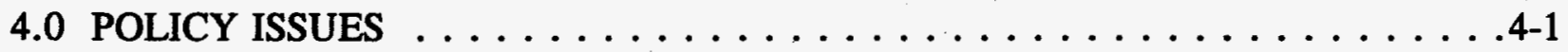

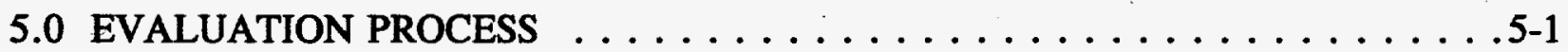

5.1 EVALUATION METHOD . . . . . . . . . . . . . . . . . .

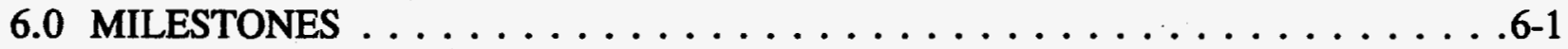

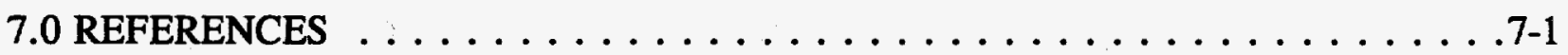

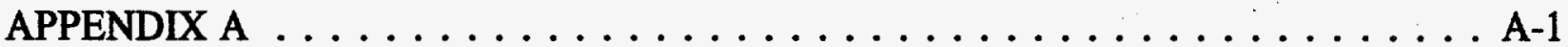

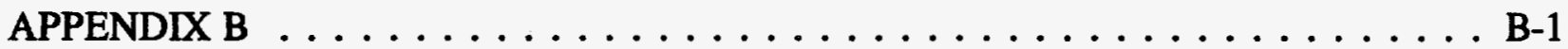




\section{LIST OF FIGURES}

1-1 Waste Pretreatment Block Diagram $\ldots \ldots \ldots \ldots \ldots \ldots \ldots \ldots \ldots \ldots \ldots$

3-1 Logic for Enhanced Sludge Washing Technical Work . . . . . . . . . . 3-2

5-1 Program Systems Engineering Process $\ldots \ldots \ldots \ldots \ldots \ldots \ldots . . \ldots .5$ 5-2

6-1 Summary of Enhanced Sludge Washing Evaluation Schedule . . . . . . . . . 6-4

\section{LIST OF TABLES}

6-1 Enhanced Sludge Washing Evaluation Related Milestones . . . . . . . . . . 6-2

Special thanks to the people that contributed to this document; J.N. Appel, R.A. Kirkbride, P.S. Shaus, I.E. Reep, K.A. Gasper, and M.R. Cushing (WHC); J.T. Slankas (PNL); S.L. Derby (Scientific Decisions Group); K.M. Liikala and J.R. Lawson (BCSR). 


\subsection{ENHANCED SLUDGE WASHING EVALUATION PLAN}

Enhanced sludge washing was chosen as the baseline process for separating Hanford tank waste sludge into a high-level waste (HLW) fraction and low-level waste (LLW) fraction to facilitate waste disposal. Section 1.0 briefly discusses the purpose of the evaluation plan and provides the background that led to the choice of enhanced sludge washing as the baseline process. Section 2.0 provides a brief summary of the evaluation plan details. Section 3.0 discusses, in some detail, the technical work planned to support the evaluation of enhanced sludge washing. Section 4.0 briefly discusses the potential importance of policy issues to the evaluation. Section 5.0 discusses the methodology to be used in the evaluation process. Section 6.0 summarizes the milestones that have been defined to complete the enhanced sludge washing evaluation and provides a summary schedule to evaluate the performance of enhanced sludge washing. References are identified in Section 7.0, and additional schedule and milestone information is provided in the appendices.

\subsection{PURPOSE}

This report has been prepared to present an evaluation plan that will permit a rational, comprehensive evaluation determining if enhanced sludge washing performs satisfactorily and will lead to the best possible decision on whether advanced separation processes are required. The evaluation process will facilitate evaluation of all aspects of enhanced sludge washing within the context of available technical and cost information, policy issues, and stakeholder values and their associated level of uncertainty. The evaluation process is also capable of providing guidance on the allocation of available resources to reduce uncertainty in key technical, cost, and policy issue factors.

This plan will complete Hanford Federal Facility Agreement and Consent Order (Tri-Party Agreement) (Ecology et al., 1994) Milestone M-50-03A, "Define Additional Milestones for Waste Pretreatment Leading to the Decision Whether Advanced Sludge Separation Processes are Required."

\subsection{BACKGROUND}

The Tank Waste Remediation System (TWRS) Program mission is to store, treat, and immobilize highly radioactive Hanford Site waste (current and future tank waste and the strontium/cesium capsules) in an environmentally sound, safe, and cost-effective manner.

The scope of the TWRS Waste Pretreatment Program is to treat tank waste and separate that waste into HLW and LLW fractions and provide additional treatment as required to feed LLW and HLW immobilization facilities. The intent is to dispose of the 
LLW fraction containing the bulk of the chemical constituents near surface and the HLW fraction containing the major fraction of radionuclides in a deep geologic repository.

This overall separations strategy was contained in the Hanford Final Environmental Impact Statement (EIS) (DOE 1987) with the associated Record of Decision (DOE 1988). The strategy contained in these documents served as the basis for the waste tank milestones in the 1989 Tri-Party Agreement that defined a 30-year cleanup program for the Hanford Site.

A number of significant policy changes affecting tank waste occurred subsequent to the publication of these documents. The changes that have significant impact on pretreatment and disposal of Hanford tank waste include:

- The U.S. Department of Energy (DOE) has changed the planning basis to include retrieval of the waste from all single-shell tanks (SST) as well as the double-shell tanks (DST). This increases the planned quantity of waste to be pretreated approximately four-fold.

- Upgrading B Plant for use as a pretreatment facility to bring it into compliance with current environmental and safety requirements was not found to be cost effective. This required building a pretreatment plant for supplying the feed to the LLW immobilization facility.

- Concerns with near-surface disposal of LLW in grout vaults as planned, resulted in the preferred approach being production of a vitrified form with further radionuclide removal. This requires building a LLW vitrification plant for immobilizing the waste for disposal.

The strategy incorporating these changes served as the basis for the waste tank milestones in the Fourth Amendment to the Tri-Party Agreement. Pretreatment processes to achieve the objectives of the Tri-Party Agreement are being identified, technology and processes are being developed, processes are being designed and tested, and facilities will be constructed and operated.

Currently the Pretreatment Program is performing process development activities on LLW and HLW pretreatment processes. Processes that are included in the baseline workscope include separation of liquids from solids to remove supernate and dissolved salts, removal of cesium (also strontium and technetium if necessary) from these alkaline liquid wastes, evaporation of water to concentrate the wastes, and feed to a facility for vitrification as LLW. The solids in the tank will be washed to dissolve salts to the extent practical and those salt-bearing liquids will be added to the supernatant stream going to cesium removal. The sludge remaining in the tanks will be washed further to remove additional solids and to minimize the volume of the feed going to the facility for vitrification as HLW. 
During the negotiations in 1993 leading to the Fourth Amendment to the Tri-Party Agreement, three basic pretreatment methods for waste tank sludge pretreatment were considered: 1) simple sludge washing, 2) enhanced sludge washing, and 3) advanced separations. Simple sludge washing consists of washing the sludge with water with corrosion inhibitors added in existing DSTs. Enhanced sludge washing consists of simple washing followed by leaching of chemical constituents with caustic and other chemicals either in existing DSTs, if possible, or in new specially designed processing equipment. Advanced separations consists of complete dissolution in acid, if possible, followed by extensive chemical and radionuclides separation. Advanced separation would result in the least volume of HLW and simple sludge washing, the most. Based on information available at the time of the negotiations, it was concluded that simple sludge washing would result in a volume of HLW that was "unreasonably" large in terms of cost and federal repository capacity. Advanced separations, which would result in the least HLW, would require extensive technology development, and complex facilities, and the implementation date was uncertain.

The redefined program (see Figure 1-1) resulting from the negotiations was a program that would rely on existing technologies as much as possible (Wodrich 1994). Pretreatment of tank waste using simple processes that could be done within tanks or relatively simple new facilities and require only limited development was preferred over processes requiring complex facilities and extensive technology development. The idea of getting on with the cleanup was far more important to the public stakeholder than minimizing the volume of waste to be sent to the federal repository particularly in light of the uncertainty of when the repository would be available to receive waste (Pacific Northwest Laboratory [PNL] 1994). The level of radioactivity in the LLW planned for near-surface storage at the Hanford Site was felt to be adequately controlled with retrievable storage of an improved waste form.

Therefore, enhanced sludge washing was selected as the pretreatment baseline method with the expectation that it would result in a "reasonable" volume of HLW and the LLW stream would have radionuclides removed to the same extent required for the DSTs only (Bernero 1989): LLW disposal requirements include:

- Nuclear Regulatory Commission's (NRC) "incidental waste" classification (Bernero 1993).

- Does not exceed the comparable limits for commercial LLW (10 CFR 61 Class C Waste).

- Will result in an acceptable disposal system performance assessment.

- Will comply with DOE's As Low As Reasonably Achievable (ALARA) policy. 
Figure 1-1. Waste Pretreatment Block Diagram.

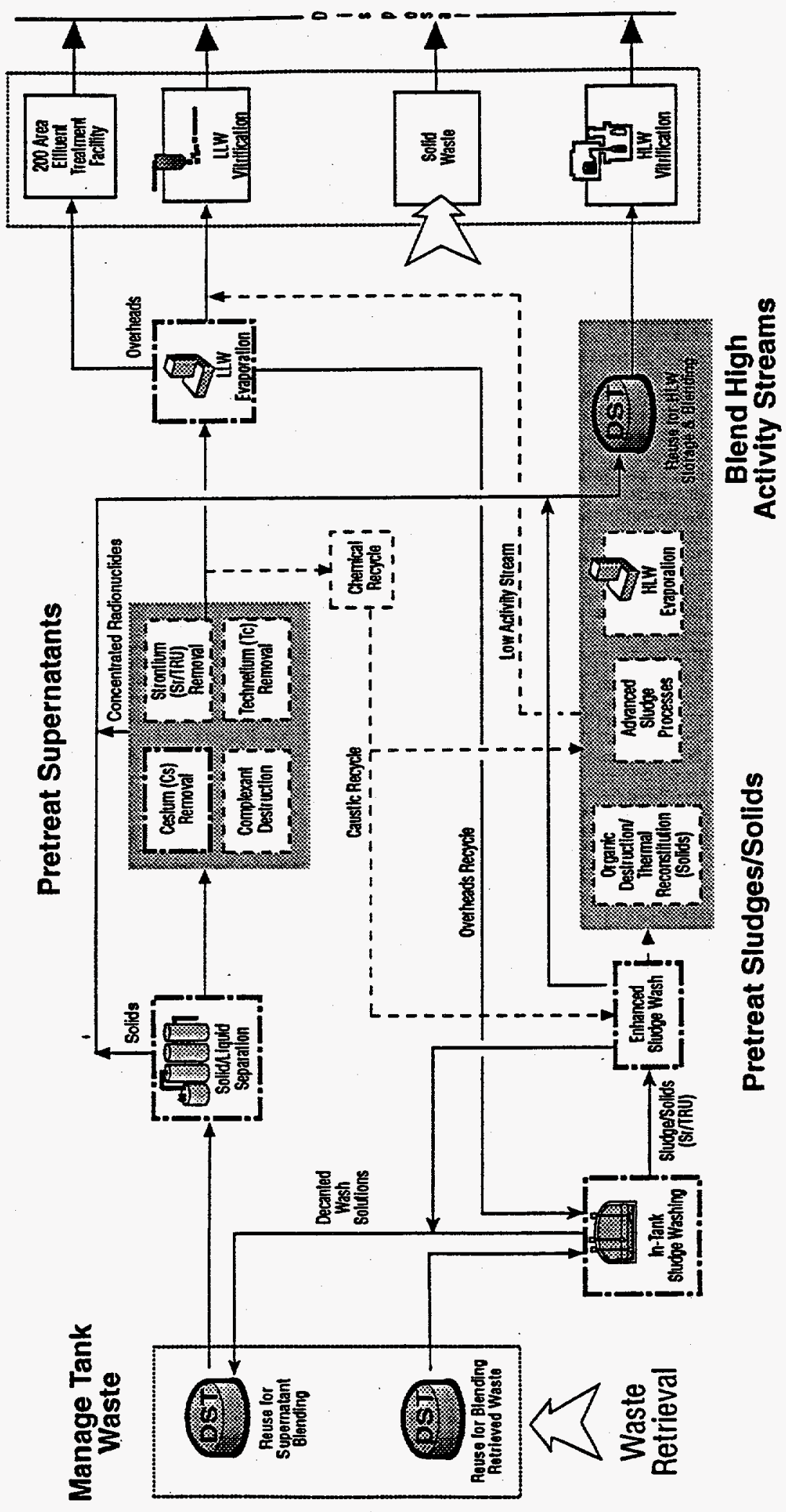


To that end, testing and selective technology development to enhance the simple processes were continued as the major thrust of the technical baseline. In parallel, a limited amount of technology development on other activities such as acid dissolution of sludge, advanced radionuclide removal, and organic destruction were continued as contingencies. Some of these may be necessary, or they might result in significant cost reductions or schedule improvements.

To support the schedule of the disposal program it was agreed that determination of the adequacy of the simple enhanced sludge washing processes to meet program requirements should occur by mid-1998. Consequently, the Tri-Party Agreement Milestone M-50-03, "Complete Evaluation of Enhanced Sludge Washing to Determine Whether Advanced Sludge Separation Processes are Required, " was established and scheduled for completion on March 31,1998 . The following additional milestones were established to monitor progress toward evaluation of enhanced sludge washing:

Number

M-50-03A

M-50-03-T01

M-50-03-T2A

M-50-03-T2B

M-50-03-T2C

(formerly M-50-03-T02)
Milestone

Define Additional Milestones

for Waste Pretreatment Leading

to the Decision Whether Advanced

Sludge Separation Processes are

Required (M-50-03).

Issue Report on Current Status

of Tank Waste Enhanced Sludge

Washing.

Submit a Report Summarizing the Testing of Enhanced Sludge Washing and Related Tank Waste Sludge Pretreatment Methods for Samples of Tank Waste Sludge.
Due Date

9/30/94

$10 / 31 / 94$

9/30/95

$9 / 30 / 96$

9/30/97 


\section{WHC-EP-0805}

This page intentionally left blank. 


\subsection{SUMMARY}

As a result of significant changes to plans for disposal of Hanford tank waste subsequent to the original signing of the Tri-Party Agreement in 1989, the tank waste disposal program was redefined during negotiations in 1993 to accommodate the changes and expedite cleanup. The redefined program was structured to rely on simple processes as much as possible. Enhanced sludge washing was selected as the baseline method for pretreating sludge tank waste. Testing and selective technology development work on enhanced sludge washing was initiated. Other development work on more complex advanced sludge separation processes was continued primarily as a contingency in case enhanced sludge washing will not satisfy disposal mission requirements. A milestone was defined to complete the evaluation of enhanced sludge washing by March 31, 1998. Two (recently modified to four) milestones were defined to monitor the testing and development work. An additional milestone called for development of a plan to evaluate enhanced sludge washing and to define additional milestones that would lead to a decision on its adequacy. This plan will complete that milestone.

This plan discusses the technical work that is underway, planned, and proposed, which is intended to improve the decision on enhanced sludge washing adequacy by reducing uncertainty in key technical areas. Eight areas of technical work are discussed: waste characterization, enhanced sludge washing process development, advanced separations process development, in-tank sludge washing testing, HLW feed composition and waste form selection, blending studies/retrieval sequence, flowsheet development, and trade studies. Logic is provided to illustrate how the technical work supports the enhanced sludge washing evaluation. Schedule details for the technical work are included as an appendix. Those policy issues that are recognized as having potential for major impacts on the adequacy of enhanced sludge washing are also addressed.

Decision analysis was chosen as the method for evaluating enhanced sludge washing. It was chosen because it is an iterative, structured process that can deal effectively with complex systems. Decision analysis provides a methodology for rational choice in systems facing uncertainty in policy issues, costs, technical information, and stakeholder values. The evaluation process schedule leading to completion of the evaluation is presented. A total of 29 new milestones have been defined. A chronological listing of enhanced sludge washing evaluation related milestones, including existing and newly defined milestones, is presented. 
WHC-EP-0805

This page intentionally left blank. 


\subsection{TECHNICAL WORK SUPPORTING ENHANCED SLUDGE WASHING EVALUATION}

This section describes the logic and technical work for providing technical input to the enhanced sludge washing decision analysis (Figure 3-1). The technical workscope consists of eight major tasks; waste characterization, enhanced sludge washing process development, advanced separations process development, Tank AZ-101 sludge washing test, HLW feed composition and waste form selection, blending studies/retrieval sequence, flowsheet development, and trade studies. The logic shown in Figure 3-1 is iterative in that the results of trade studies and decision analysis that feeds the preliminary recommendations made in fiscal year (FY) 1995 and FY 1996 also feed back into the logic process. This can result in future changes to the type and amount of waste samples needed and the plan for enhanced sludge washing process development.

Summary information on milestones for the technical work supporting the enhanced sludge washing evaluation is provided in Table 6-1 of Section 6.0, Milestones. A Summary schedule is also provided on Figure 6-1 of Section 6.0. Detailed schedules are provided in Appendix A for each of the technical work tasks described in this section. Milestone Description Sheets (MDSs) for the key milestones are provided as Appendix B. The schedules and MDSs contained in this plan are a subset to the TWRS FY 1995 - 1997 MultiYear Work Plan (Westinghouse Hanford Company [WHC] 1994b).

\subsection{LOGIC FOR TECHNICAL WORK}

The logic for performing technical work to feed the decision analysis for evaluating enhanced sludge washing is shown in Figure 3-1. The front-end work (Sections 3.2 to 3.7) described in the following paragraphs of Section 3.0 is funneled into flowsheet development (Section 3.8) to provide flow rates and feed stream compositions to the LLW and HLW vitrification facilities. In turn, flowsheet information is fed into trade studies (Section 5.9) to evaluate process alternatives and process baselines for the TWRS. Outputs from the trade studies include total life-cycle cost, relative technical risk, baseline schedule impacts and volume of HLW produced for the baseline and alternatives to the baseline. These data provide an important input to the decision analysis (Section 5.0) and the recommendation that documents the enhanced sludge washing evaluation. 
Figure 3-1. Logic for Enhanced Sludge Washing Technical Work.

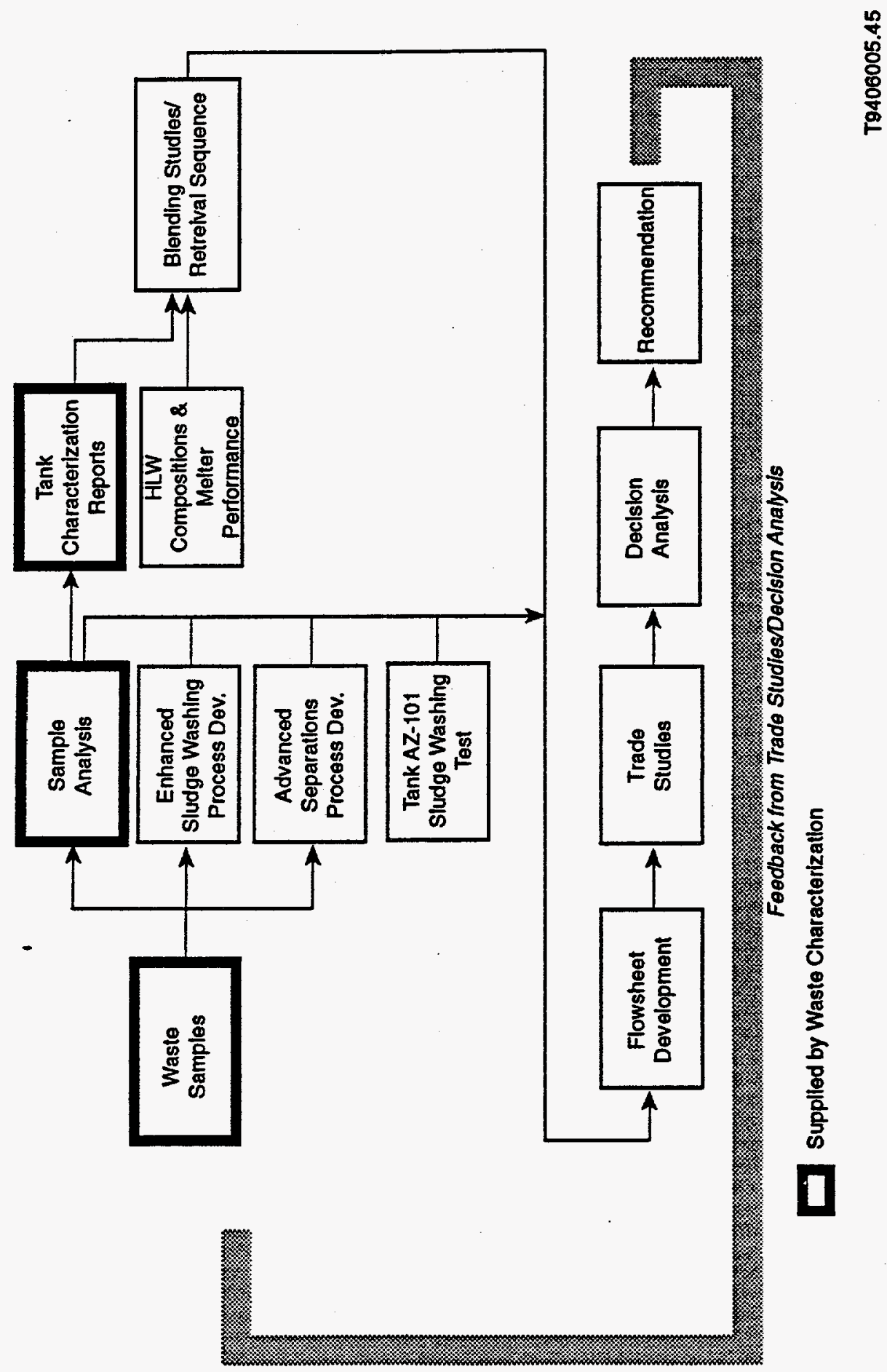




\subsection{WASTE CHARACTERIZATION}

The Waste Characterization Program has two primary functions in support of enhanced sludge washing: 1) assay the tank sludge wastes to provide inventories of the chemical and radiochemical (radionuclide) constituents, 2) provide samples of the tank sludge wastes for process development investigations (and also retain sample portions of the tank wastes for archive purposes). Chemical and radionuclide inventories are critical to estimating the scope of potential pretreatment processes, both in volume and complexity of effort. Actual tank waste samples ensure that laboratory studies are realistic, addressing the actual physical properties and chemical constituents found in Hanford tank waste sludges. These laboratory studies provide the information to determine process feasibility, to develop a process technology baseline, and to provide scaling data for design. The process technology baseline with its associated developed scaling data, in turn, permits engineering assessments and trade studies that will provide the technical basis for the evaluation of enhanced sludge washing. A number of infrastructure support items affect the ability of the Waste Characterization Program to provide adequate samples.

Over the next 3 years the Waste Characterization Program will provide samples for the Waste Pretreatment Program in accordance with formal procedures and will also archive sample portions for possible future use. A formal Data Quality Objectives (DQO) process that represents a disciplined, logical approach to effectively plan, define, obtain, and use samples is guiding sample selection and analysis. The samples requested represent the input and coordinated review of many people, including TWRS Process Engineering, Waste Pretreatment Program, and numerous principal investigators from national laboratories. The cost and difficulty in obtaining samples from tanks are recognized and factored into the sample requests. Principal investigators will submit test plans for all samples requested in accordance with guidelines provided by the Waste Characterization Program.

The samples requested for enhanced sludge washing studies will provide the basis of process technology through a series of laboratory investigations. Studies will be done on approximately 16 different tank/sludge samples in FY 1995, 30 in FY 1996, and 30 in FY 1997. Efforts will be equally divided between PNL and Los Alamos National Laboratory (LANL). Including the five sludge samples already investigated, a process technology baseline covering approximately 70 different sludges will be available for assessments and trade studies by July 1997. Data from these sludge samples will represent nearly 70 percent of the total sludge volume and include the significant waste streams currently identified.

The Waste Characterization Program has developed a draft sampling schedule that considers rotary, push, auger, and grab modes of sampling sludge; that incorporates new sampling hardware as it is planned to become operational; and that incorporates personnel qualification training. The draft sampling schedule provides enough samples in FY 1995, 1996, and 1997 to meet the above requirements. The milestones identified in Table 6-1, and the MDSs included in Appendix B document the Waste Characterization Program's 
commitment to provide rotary core, push mode, and auger sludge samples in quantities sufficient to support enhanced sludge washing process development and evaluation.

\section{- Samples for Process Development/Enhanced Sludge Washing}

Actual tank waste samples are required for pretreatment studies that provide the necessary technical baseline of experimental data to allow realistic assessments of the proposed pretreatment processes. In more detail, pretreatment technology development: 1) provides the technical basis to support the technical approach in preparing acceptable waste feeds for HLW and LLW disposal, 2) fills the technical gaps in current technology to allow enhanced sludge washing evaluation with a minimum of uncertainty, and 3) provides sub-scale design data.

The pretreatment development program plans enhanced sludge washing studies for a number of different sludges. The following criteria represent the basis for sludge sample selection: 1) HLW glass loading especially aluminum, phosphate, and chromium content of the sludge, 2) total oxides in HLW and definition of actual pretreatment process behavior, 3) waste type using Sort On Radioactive Waste Volume (SORWT) model, which is the broadest survey of known variables in sludge waste compositions, 4) investigation of alternative pretreatment processes if enhanced sludge washing does not satisfy TWRS program goals and performance standards, and 5) development of tank selection and blending information to avoid forming hard-to-treat precipitates, if constituents of different tanks were to be mixed improperly.

\section{- Inventories of Tank Constituents}

Other information on the history of the tank waste, independent of the limited analysis data on tank waste constituents, must also be used. Such information includes process information, such as flowsheets on the various operations that occurred; recorded waste stream volumes to establish waste generation rates; and amounts of chemicals used during the various operations (to include process modifications/changes over each operation). These historic analyses require verification to enhance their defensibility and credibility. Such efforts are underway by a joint ICF-Kaiser Hanford/LANL team. Assessment of all available information can lead to more realistic tank waste inventories when augmented by judicious comparison with new waste sample analyses results.

\section{- Infrastructure Support}

Oak Ridge National Laboratory (ORNL) and LANL have stated they can handle sludge samples. LANL has already received small amounts of waste and plans to enhance its capability by putting a glove-box addition on a hot cell, which will facilitate handling of samples. There are serious concerns at PNL because of the Building 325 shutdown and difficulties in establishing alternatives such as other PNL facilities or the Plutonium-Uranium Extraction (PUREX) Laboratory. Nevertheless, the November to December 1994 time period appears reasonable for resumption of many operations. 
Sandia National Laboratory (SNL) Transportation Department personnel have been continuing their support and evaluation efforts to assess support for pretreatment sampling by addressing the entire process from requesting samples, to taking samples, to handling and shipping samples, to receiving samples for process studies, to regulatory documentation (NEPA, DOT, NRC, etc.). Their initial assessment showed some short-term problems that they are working. A final letter report is due the end of September 1994 detailing the SNL findings and conclusions.

\section{- Outstanding Issues and Potential Problems.}

Direct determination of tank waste composition by sampling and analysis has severe limitations. Chemical and physical interactions of different waste streams as tanks were filled often caused the solid wastes in tanks to have large inhomogeneities both in the horizontal and the vertical directions, particularly for tanks that were partially sluiced. Riser access for sampling is limited, and often the sampling riser was previously used as a fill line riser, which may lead to bias in the waste components sampled. Consequently one or two core samples from a tank may not provide a true representation of a tank's actual average contents. Limited access, sample recovery issues, and the difficulty in obtaining these radioactive core samples make any statistical sampling procedure extremely difficult if not essentially impossible, both from a physical and economic standpoint.

The two major issues confronting enhanced sludge washing studies are: 1) whether the Waste Characterization Program can provide the tank sludge samples required for pretreatment in a timely manner (this includes both taking sample from a tank and doing the initial extrusion from the sampler and mixing segment extrusions from a core as necessary), and 2) whether the samples can be investigated to develop the necessary process technology baseline in a timely manner. A third and lesser issue exists concerning infrastructure support for shipping samples, handling samples, and analyzing samples onsite at each laboratory. This third issue should only represent a near-term perturbation.

The Waste Characterization Program has encountered serious difficulty in the tank farms this past year in obtaining samples. Additionally, much of the sampling support equipment has not been deployed to the tank farms yet. Considerable crew training requirements also remain. Consequently the sampling schedule currently being finalized depends upon a number of actions still being planned or implemented.

Alternatives and enhancements to both the means of sampling and sample selection are under consideration. Increased and improved auger mode sampling, which is relatively inexpensive and simple, is one consideration and using larger samplers is another. The grab mode provides sludge samples well within the desired time frame. However, grab sludge samples are only acceptable for pretreatment needs if each segment of the sludge core can actually be sampled, which has been a problem previously. Improved definition of tank waste constituents and streams through enhanced use of existing data and analyses offers potential to sample less but acquire more and better information. 
The ability of the research laboratories to study enough sludge samples by July 1997 is a concern. Currently, the Building 325 facility at PNL is in a stand down because of safety problems in handling radioactive materials. This represents approximately 20 to 30 percent of the planned laboratory capacity for initial sample processing and 50 percent of the laboratory capacity for enhanced sludge washing studies. This situation has existed since April 22, 1994, (i.e., almost 5 months). Although there is a tentative start up date targeted for early November 1994, there is no definite date when PNL can resume normal enhanced sludge washing studies in the Building 325 facility.

PNL has investigated alternative sites for enhanced sludge washing and has found that the PUREX laboratory at Hanford could accommodate these studies. They have also found that the Building 324 facility could accommodate more limited studies. RL has directed that PNL should place all emphasis on the safe restart of the Building 325 facility at this time. If PNL cannot restart the Building 325 facility in November 1994 and other Hanford laboratories are not used, the enhanced sludge washing process technology base line planned to be available by July 1997 may be delayed. LANL is planning to start sludge washing studies in October 1994. As a backup, the Pretreatment Technology Development Program is soliciting a contingency proposal from ORNL to perform sludge washing studies.

Shipping samples offsite to LANL and ORNL, initial preparation of core samples from the tank, and onsite analyses may all be problems in FY 1995. Initial assessment by SNL Transportation Department personnel indicate that nominally $\mathbf{5 0}$ grams of all sludges can be shipped using a Type A container. WHC Transportation and Packaging has indicated that the SAFESEND Type A container that contains limited shielding should be available in November 1994, which would enable shipping 10 to 12 different sludge samples of 50 to 70 grams each year. Additionally, WHC has obtained approximately 20 small, nominally 30 gram Type A shipping containers from LANL. WHC has also acquired 2 PAS-1 Type B containers that could be used for 1 liter samples of sludge when NRC/DOT approval is granted for PAS-1 use, currently projected for January through March 1995. Consequently transportation of samples is currently only a concern and not anticipated to be a problem.

The limiting factor in the current draft sampling schedule proposed by the Waste Characterization Program is laboratory capacity both for initial preparation of core samples directly from the tank and for initial analyses of samples. Initial analytical requirements defined by the current DQOs for pretreatment represent an upper, most conservative limit. The amount of initial analyses required is being reviewed in response to a August 1994 Pretreatment Technical Advisory Panel (TAP) recommendation. The TAP recommended considerable relaxation in the initial analysis required, even to the extent of total elimination. Reduction in the amount of initial analysis of sludge samples for pretreatment may help alleviate the current schedule bottleneck, but total resolution depends on other actions since pretreatment represents only about 14 percent of the total Waste Characterization Program laboratory efforts. This is a near-term FY 1995 problem to resolve. 


\subsection{ENHANCED SLUDGE WASHING PROCESS DEVELOPMENT}

The purpose of this work is to support flowsheet development by gathering data on the effectiveness of solid/liquid separation, sludge washing, and alkaline leaching through laboratory testing using actual tank waste. Annual status reports (TPA M-50-03-T01, T2A, T2B, and T2C) will be issued to document progress on enhanced sludge washing process development. These are identified in Table 6-1 and are described in the corresponding MDSs included in Appendix B.

- Sludge washing using corrosion inhibited water and sludge leaching using sodium hydroxide

This activity will consist of conducting laboratory tests on small samples (approximately 5 grams) of actual waste to determine the extent of removal of water and caustic soluble components when washed with inhibited water and sodium hydroxide. Component material balances will be determined as part of this effort. A wide variety of actual wastes will be tested over a range of concentrations and time conditions to estimate the effectiveness on solubilizing phosphates, aluminum and chromium, and other waste constituents near the limiting concentration for acceptable glass formulation. The number of waste types tested each year will depend on an evolving characterization sampling plan.

- Selective sludge leaching

Experiments using test-tube amounts of waste that are leached/reacted with dilute acid mixes, alkaline oxidants such as potassium permanganate and carbonate/hydroxide mixes will be conducted to determine if sludge leaching can be further enhanced. Tests in which the reaction time and temperature are varied will also be conducted. Component material balances should be determined as part of this effort.

\section{- Settling tests}

Liter amounts of actual waste will be used to study settling characteristics of washed sludge, alkaline leached sludge, and sludge rewashed with water. Settling times, the degree of sludge compaction and particle size/distribution in the supernatant will be measured in these tests. Effectiveness of settling agents will also be assessed if settling rates or degree of compaction are not acceptable. Characterization of the particles in the supernate is necessary to evaluate/test techniques to remove the suspended particle matter.

\section{- Extend sludge processing science}

Basic understanding of the chemical and physical properties that govern the leaching and metathesis of Hanford tank waste sludges is critical to project the effects of these unit operations over the entire range of sludges with limited testing of actual sludges. Experimental testing and modeling will investigate solubility mechanisms including chemical kinetics, ion interactions in solutions and on surfaces and transport processes. Information 
on tests of actual sludge will provide input to this activity. The results of this activity will be used to update either the integrated flowsheet or variations of flowsheets used in trade studies.

\section{- Nonthermal reconstitution tests}

These tests are aimed at reproducing a sludge that is more amenable to caustic leaching than the original aged sludge. Small amounts of acid-dissolved sludge will be neutralized and caustic leached over a range of concentration and time conditions to estimate the effectiveness on solubilizing phosphates, aluminum and chromium and other waste constituents near the limiting concentration for acceptable glass formulation. Component material balances will be determined as part of this effort so that glass volumes may be projected for an integrated flowsheet and subsequent trade study.

\subsection{ADVANCED SEPARATIONS PROCESS DEVELOPMENT}

The purpose of this work is to develop alternatives to enhanced sludge washing if further reduction in HLW volume is required. A potential alternative being investigated is: acid dissolution followed by radionuclide separation using solvent extraction and/or ion exchange. Actual tank wastes will be used in the laboratory tests and results will be used for preliminary flowsheet development. In FY 1996 and FY 1997 acid dissolution and subsequent radionuclides removal will be pursued only if more simple pretreatment processes are unsuccessful. No milestones have been identified for this activity because only limited funding is available from EM-30 for advanced separations process development.

\section{- Acid dissolution tests}

Batch testing will be conducted on test-tube quantities under a wide range of time and temperature conditions using nitric acid, nitric/oxalic acid mixtures, and nitric/hydrofluoric acid mixtures. Component material balances will be determined so that better projections of the assumed HLW undissolved sludge and resulting glass volume can be made. This activity will be continued at a reduced level in FY 1995. Uncompleted FY 1994 work will be completed in FY 1995 with EM-30 funding.

\section{- Radionuclide separation of batch solvent extraction}

Laboratory testing of batch solvent extraction using test-tube quantities will result in preliminary separation coefficients determination for strontium and transuranics. The results of these tests will be used to confirm the generic Transuranic Extraction (TRUEX) Model or to update the model. Uncompleted FY 1994 work will be completed in FY 1995 with EM30 funding. 
- Bench scale solvent extraction

Continuous testing of an integrated solvent extraction using $2 \mathrm{~cm}$ contactors will be accomplished with simulated waste. Improved separation coefficients for strontium and transuranics will be determined as part of this activity. This activity is not funded by EM-30 in FY 1995.

\section{- Alternatives to solvent extraction}

Laboratory scale testing of strontium, cesium, and transuranics extraction methods other than solvent extraction will be investigated on test-tube quantities of acid dissolved sludge. This activity is not funded by EM-30 in FY 1995.

\section{- Cesium solvent extraction}

A solvent extraction process for cesium removal from acid dissolved sludge will be developed. This process will be combined with a strontium removal solvent extraction process that has previously been developed. This activity is not funded by EM-30 in FY 1995.

\section{- Update generic TRUEX model}

The TRUEX Computer Model developed by Argonne National Laboratory will be updated with new test data to aid in flowsheet development. The expanded version will include a model of Strontium Extraction (SREX) and Cesium Extraction (CSEX). This activity is not funded by EM-30 in FY 1995.

\section{- Silicotitanate tests for cesium removal}

Removal of cesium from acid dissolved sludge using crystalline silicotitanates will be investigated using test-tube quantities of actual wastes. Preliminary separations coefficients will be determined. This activity is not funded by EM-30 in FY 1995.

\subsection{TANK AZ-101 SLUDGE WASHING TEST}

This activity involves the performance of a process test to verify the effectiveness of in-tank sludge washing. Laboratory tests are performed on small samples of simulated and actual tank waste sludge to obtain design data on the effectiveness of sludge washing. However, the small scale of the laboratory testing leaves a large uncertainty regarding the implementation of sludge washing in Hanford tanks. An in-tank process test is the most expeditious way to test the effectiveness of in-tank sludge washing. 
The process test will be performed by initially sludge washing tank AZ-101. The supernate from tank AZ-101 will be removed and tank AZ-101 will be filled with dilute waste, condensate, or conditioned process water and mixed during a mixer pump process test in support of the Waste Retrieval Program. The AZ-101 mixer pump will be installed as part of Project W-151, AZ-101 Process Test. The sludge washing process test in tank AZ-101 will be conducted in parallel with the Project W-151 mixer pump process test. During the mixer pump/sludge washing process test, measurements will be taken from previously installed instrumentation and sludge samples will be taken and analyzed for future reporting. After several months of mixer pump testing in tank AZ-101 the solids will be allowed to settle for several months during which time measurements will be taken from previously installed instrumentation and sludge samples will be taken and analyzed. Some specific data desired from the test that supports the evaluation of in-tank enhanced sludge washing is supernate clarity and settling times. The data from the test will be used to update the reference flowsheet and to prepare pretreat sludges/solids functions and requirements documents. Results of the sludge washing process test will be reported at the end of FY 1997.

After completion of the tank AZ-101 mixer pump/sludge washing process test, the washed solids from tank AZ-101 will be combined with the unwashed sludge in tank AZ-102 and the combined mixture will be washed and allowed to settle. The results of this second process test will not be available in time to provide input to the March 1998 M-50-03 TriParty Agreement milestone but will support planned sludge washing demonstrations is the late 1990s. Completion of this second process test will provide a demonstration of sludge washing, prepare all of the aging waste sludge for vitrification, and contain all of the washed aging waste sludge in one tank. The wash solutions will be concentrated and stored in one tank ready for cesium removal in the Initial Pretreatment Module (Project W-236B) scheduled for start-up in December 2004 (TPA M-50-02).

\subsection{HIGH-LEVEL WASTE FEED COMPOSITION AND WASTE FORM SELECTION}

The volume of the HLW glass waste form is ultimately determined by one primary factor, the volume of pretreated waste and one secondary factor, the waste loading. In order to attain the optimum volume of a HLW glass waste form that meets the waste acceptance specifications as defined by the Civilian Radioactive Waste Management System (CRWMS), the Pretreatment Program is working closely with the HLW Program to jointly define the feed stream requirements for pretreated HLW that will be immobilized in the HLW vitrification plant. Definition of the requirements are scheduled as shown in Table 6-1 and Figure 6-1 documented in the MDSs included in Appendix B.

The HLW Program is also working with the CRWMS by providing input to the advanced conceptual design effort at the geological repository. Input on the possible range of standard canisters has been requested (Sheridan 1994) and provided (Powell 1994). Future input will include information on alternate waste forms and canister size. The HLW 
Program is working with the Office of Civilian Radioactive Waste Management (OCRWM) to establish optimized canister configuration for the Hanford HLW glass. Trade studies are being performed and reviewed with the OCRWM to evaluate the variables affecting canister handling in the HLW vitrification plant, storage of the canisters at Hanford, shipment of the canisters to the repository and handling of the canisters at the repository. Shipment of the canisters to the repository and their handling at the repository are paid by the disposal fee charged by the OCRWM. This fee has been estimated as several billion dollars and varies greatly with the canister configuration. Thus, these trade studies are important in determining the cost of the disposal program. A report on the results of the trade studies is due in April 1996.

Based on the Pretreatment Program's initial predictions of the range and variability of the HLW feed streams, chemical simulants of pretreated HLW will be used in a series of laboratory-scale, small-scale, and pilot-scale tests. The HLW testing program will evaluate and select a melter system, formulate optimum glass compositions that are compatible with the selected melter, and identify those chemical constituents that are of particular concern to the long-term performance of the waste glass. Data generated by the testing program will provide input to the Pretreatment Program for further updating of its feed processibility and blending studies and other process development activities. Subsequent updates of HLW feed stream ranges and variability by the Pretreatment Program and test results from the HLW Program using chemical simulants will further refine the iterative optimization of HLW feed streams and specification of compatible glass formers.

Small quantities of radioactive pretreated wastes will be required from the Pretreatment Program to confirm early test results obtained through the use of simulants. These confirmatory tests will be performed on a small-scale and will be used to validate the predictive glass formulation models. This combination of simulant testing, glass formulation modeling, and confirmatory radioactive tests will ultimately define the glass composition envelope that provides acceptable long-term performance in accordance with the waste acceptance specifications defined by the CRWMS. Definition of the glass composition envelope is an iterative process that attempts to optimize the waste oxide loading for the range of pretreated HLW feed streams.

A major parameter in achieving an acceptable glass composition envelope is the selection of a reliable and predictable glass melter system. Glasses with higher melting temperatures than those associated with borosilicate glasses can accommodate a broader range and higher volume of waste constituents, while maintaining acceptable levels of durability. The generally higher waste loadings per unit volume and the increased solubility of specific chemical constituents associated with higher melting temperature glasses have significant implications with regards to the amount of HLW produced. If waste oxide loadings approaching 45 percent are achievable for the higher melting temperature glasses it will result in approximately half the volume of glass that would be produced for the nominal 25 percent waste oxide loadings achieved with borosilicate glasses. 


\subsection{BLENDING STUDIES/RETRIEVAL SEQUENCE}

Previous studies have shown that blending waste into homogeneous batches prior to immobilization may result in a significant reduction in HLW volume (Geeting and Kurath 1993). The reduction occurs because the blended waste can have several chemical constituents near the limiting concentration for acceptable glass formulation rather than a single constituent. However, the ability to blend waste and its effectiveness is integrally tied to the tank waste retrieval sequence, waste transfer capability, and lag storage capacity. Blending studies to evaluate different retrieval and processing sequences will be continued as integrated retrieval and pretreatment efforts.

The blending studies will use a decision-analysis approach involving a team comprised of key personnel from several of the major TWRS program elements. An overall goal of the work is to develop a retrieval sequence and blending strategy that supports successful execution of the TWRS mission and to provide estimates of immobilized LLW and immobilized HLW feed composition versus time. The major drivers affecting the retrieval sequence and blending strategy will be identified and system models will be prepared as needed to understand and evaluate which factors affect retrieval sequences and blending strategies. Computer tools will be developed as needed to aid in understanding these factors. The work will identify which TWRS performance measures, measures of effectiveness, or other criteria should be used in evaluating retrieval and blending sequences and strategies. Blending options to be considered include:

- Blending by tank farm.

- Blending by waste type.

- Blending to provide a minimal number of feeds to LLW and HLW vitrification facilities.

The blending studies described here are identified in Table 6-1, and the corresponding MDSs are included in Appendix B. These studies directly support the Tri-Party Agreement Milestone M-45-02 annual reports on SST retrieval sequence. Completion of the M-45-02 milestones is the responsibility of the Retrieval Program. This work will provide the technical basis and rationale for the sequences documented in the retrieval sequence documents that satisfy the M-45-02 milestones. Retrieval sequences identified will also be incorporated into preliminary flowsheets and updates of the TWRS reference flowsheet.

\subsection{FLOWSHEET DEVELOPMENT}

This work covers the development and maintenance of process flowsheets for the pretreatment of Hanford tank wastes. The flowsheets document the reference process for pretreating Hanford tank waste and provide flow rates and compositions for feed streams to the LLW and HLW vitrification facilities. A reference flowsheet has been prepared, TWRS 
Process Flowsheet (Orme 1994), based on the use of caustic (sodium hydroxide) and water to wash aluminum, phosphate, and soluble species out of the Hanford tank waste sludges. This approach is part of the processes termed "enhanced sludge washing" in the Fourth Amendment to the Tri-Party Agreement. The wash waters are routed to LLW pretreatment for removal of cesium and, possibly, strontium and technetium before feeding the liquid stream to the LLW vitrification facility. The radionuclides removed in LLW pretreatment are stored in the tank farm until they are vitrified in the HLW vitrification facility.

The reference flowsheet will be updated annually to incorporate information from ongoing pretreatment development work, blending and retrieval strategy developments, and recommendations from preliminary process flowsheets. These updates are identified on the detailed schedules in Appendix A. The FY 1996 update is included on Figure 6-1 and described in the MDSs included in Appendix B. The reference flowsheet and its updates will support The Tri-Party Agreement Milestone M-50-03 by providing part of the basis for decision making. Information obtained each year from sludge washing and caustic leaching laboratory tests will be incorporated into the reference flowsheet by updating the wash factors used to model the partitioning achieved during washing. Information obtained from laboratory settling tests and in-tank process tests will also be incorporated into the flowsheet in the form of settling times and separation efficiencies.

Some preliminary flowsheets that will support updates to the reference flowsheet include the cesium removal flowsheets for CS-100 and resorcinol-formaldehyde resins (TriParty Agreement Milestone M-50-01-T01), a cesium removal flowsheet using crystalline silicotitanate resin, preliminary strontium and technetium removal flowsheets, a time-phased retrieval flowsheet, and a "strawman" advanced processing flowsheet (and updates). As other technologies or needed separations are identified, other flowsheets will be prepared to aid in selection of the Hanford tank waste pretreatment processes. All the preliminary flowsheets will be incorporated into the reference flowsheet after a trade study is performed to establish the need and benefit of adding a proposed process to the overall pretreatment strategy, or a formal process evaluation and selection is performed to choose between alternatives. While these other flowsheets do not directly address the sludge processing portion of the reference flowsheet, the secondary waste generation from these can impact the HLW vitrified product volumes and the canister count.

\subsection{TRADE STUDIES}

This work includes the evaluation of process alternatives through trade studies that establish the technical and process baselines for Hanford tank waste pretreatment. The trade studies will be used to identify alternate configurations for the LLW and HLW pretreatment processes. Advantages and disadvantages of the various options will be identified and a preferred option recommended. The work is performed by identifying facility functions and requirements, identifying and reviewing alternate options, and preparing preliminary cost estimates for each option. Engineering studies will be performed to assess the performance of the options and identify the best option. In addition, assessments of specific systems, 
subsystems, and component implementations will be conducted to optimize plant performance and adapt to changing operating conditions or requirements.

A key trade study planned for FY 1995, with updates in FY 1996 and 1997, is determination of the waste processing strategy for tank waste. The FY 1995 trade study will provide technical input to the TWRS EIS on alternatives for processing tank waste that are (1) no pretreatment, (2) extensive pretreatment, and (3) Tri-Party Agreement preferred. The no pretreatment and extensive pretreatment alternatives were addressed in the 1993 Tank Waste Technical Options Report, WHC-EP-0616, Rev. 0 (Boomer, et al. 1993). Because the Tank Waste Technical Options Report did not address the Tri-Party Agreement preferred alternative, a major focus of the 1995 waste processing alternatives trade study will be an evaluation of the technical risk and life-cycle cost of the Tri-Party Agreement preferred alternative.

The Tri-Party Agreement preferred alternative is the technical baseline in the Fourth Amendment of the Tri-Party Agreement of January 1994. This alternative consists of in-tank sludge washing and enhanced sludge washing (caustic leaching) and processes to separate the waste into HLW and LLW fractions. To provide a consistent basis for comparing waste processing alternatives, facility layouts, and costs in the 1993 Tank Waste Technical Options Report (Boomer et al, 1993) will be updated based on the recently completed Tank Waste Facility Configuration Study (Boomer 1994) and flowsheet data will be updated based on the recently completed TWRS Process Flowsheet (Orme 1994). Both the facility configuration study and the process flowsheet include technical aspects (i.e., sludge washing and enhanced sludge washing) of the Tri-Party Agreement preferred alternative. The 1996 trade study update will include the schedule and cost impacts of implementing advanced separation processes assuming that enhanced sludge washing does not result in a reasonable volume of HLW. 


\subsection{POLICY ISSUES}

Policy issues are factors that may have a major effect on the evaluation of enhanced sludge washing but are generally outside the control of the TWRS program. They may be budgetary, regulatory, configuration, timing, etc, in nature and can act as major constraints. Examples of policy issues that are recognized as having the potential for impacting the evaluation of enhanced sludge washing include:

- Funding levels

- Timing (e.g., how long must HLW be stored at Hanford - when will the CRWMS federal repository accept Hanford HLW?)

- NEPA (will the SST waste be retrieved?)

- Regulatory (will LLW be disposed of onsite, under what conditions?)

The above list is not intended to be all-inclusive, only illustrative. Other important policy issues are expected to be identified during the evaluation process

The criteria for what constitutes a "reasonable" volume of HLW in evaluating the adequacy of enhanced sludge washing is sometimes viewed as a policy issue. In fact, it represents a result of (rather than an input to) the evaluation process that must reflect consideration of all the relevant factors - policy issues, technical information, costs and stakeholder values. For example, what constitutes a "reasonable" volume of HLW might be significantly different for stakeholder values related to the shipment of HLW to the repository than for stakeholder values related to the interim storage of HLW at Hanford for an extended period. The FY 1995 decision basis development activity (see section 5.0) will focus on creating the capability to define the criteria for a reasonable HLW volume.

Participation in policy determinations that may have a major impact on the evaluation of enhanced sludge washing is recognized as being as important as gathering technical information. It is expected that the advanced conceptual design effort at the geological repository will result in improved definitions of the acceptable limits on HLW canister size and heat loading and associated waste disposal. It is intended that results from the enhanced sludge washing evaluation process will be used to provide input to and be helpful in formulating federal repository policy, TWRS - EIS decisions, and other policy actions, as appropriate. No milestones have been defined for policy issues. 


\section{WHC-EP-0805}

This page intentionally left blank. 


\subsection{EVALUATION PROCESS}

The evaluation process represents an integral part of the TWRS systems engineering process (WHC 1994a). Figure 5-1 shows the relationship of the evaluation process to other systems engineering process steps. The decision on the adequacy of enhanced sludge washing is only one of many important decisions that will guide the refinement of TWRS functions and requirements definition (DOE-RL 1994). The decision hierarchy for TWRS has been developed and documented (Johnson 1994) and this plan will guide the completion of Decision 4.2.2.1, "Determine Waste Separations Process."

\subsection{EVALUATION METHOD}

Central to the choice of an evaluation method for complex systems is the realization that most decisions are made with some uncertainty. The notion that all uncertainty can be resolved is unrealistic. Therefore a method must be chosen that can accommodate uncertainty, is rigorous and defensible, and that will result in the best decision at any given time under the uncertainty that exists. Further the evaluation method must enable the decision maker(s) to discern between important and irrelevant factors affecting the decision in a quantifiable way. If time is available before a decision must be made the evaluation methodology can be used to aid in the prioritization of resource allocation to reduce uncertainty in the most critical areas.

Decision analysis (Sage 1992) provides the required attributes for the evaluation of enhanced sludge washing and is the evaluation method of choice. Decision analysis combines systems engineering and statistical decision theory to create a methodology for rational choice in complex, dynamic, and uncertain situations.

The decision analysis procedure is made up of three steps: formulation, analysis, and appraisal. Formulation provides a formal model of the actual decision situation. This model is often a computer spreadsheet model. Analysis begins with a deterministic analysis and concludes with a probabilistic analysis. The deterministic analysis identifies the key uncertainties and drivers that affect the value measures. The probabilistic analysis assesses the key uncertainties as probability distributions and computes the probability of value measures for each alternative. Appraisal critically reviews the sensitivity of the results to 
Figure 5-1. Program Systems Engineering Process.

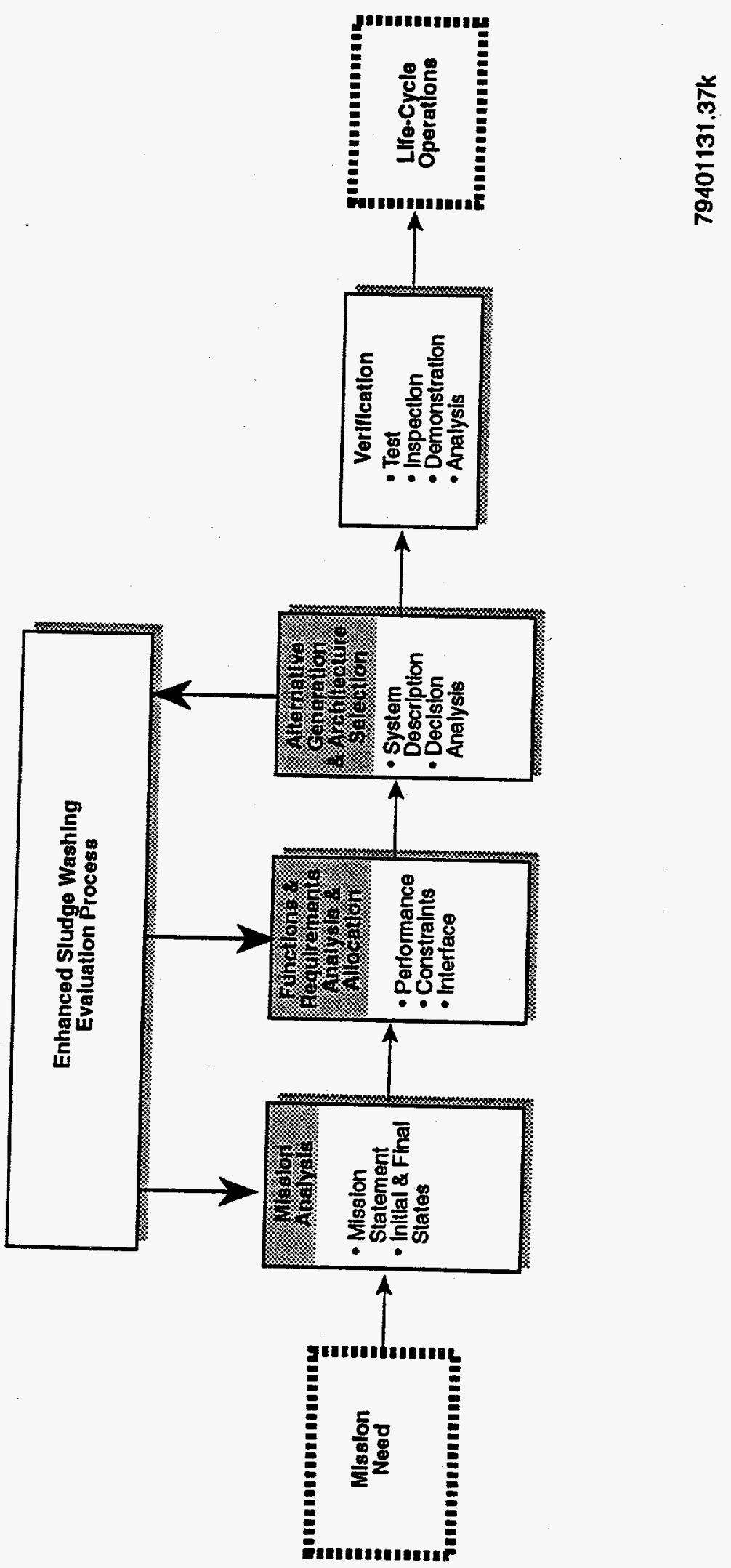


new alternatives, new information, different tradeoffs among values, and improved formulation or representation of the decision situation. If the appraisal proves satisfactory, then the recommendation of the decision analysis should lead to a clear decision.

During formulation, formal techniques for representing the decision situation and alternatives will be used, such as strategy tables, influence diagrams, decision trees, and decision hierarchies. During analysis, formal analytical techniques for system modeling, deterministic sensitivity, probabilistic assessment, and probabilistic analysis will be used as needed. During appraisal, formal techniques for the value of information, value of control, and level of decision quality will be used to focus any additional decision analysis needed for making a clear choice from among the alternatives.

\subsection{DECISION PROCESS}

The decision process for selecting the preferred TWRS sludge processing approach will conduct three iterations of development for the decision basis. Each iteration will rely on stakeholder contribution for relevant information and analysis, for clear value measures, and for a wide range of alternatives that should be considered before a decision is made. At the conclusion of each stage of iteration of decision basis development, stakeholder review and comment will identify the remaining issues that must be resolved before a clear choice will be selected.

The decision basis is the decision frame (which establishes the purpose, scope, and objectives of the decision), the set of alternatives, the value measures, and relevant information. Each stage of iteration will improve the decision basis from the available set of alternatives, value measures, information, and evaluation methodology. During the first stage of decision basis development, existing enhanced sludge washing information will be modeled. The decision analysis will be used to focus on the areas requiring additional work. For example, the review may identify that additional alternatives are needed to complete the evaluation of enhanced sludge washing. Information gaps that the next iteration in the following fiscal year must fill will be identified.

Three iterations will be conducted to complete the development of the final decision basis that will support the selection of the best alternative. At the end of each iteration, the decision basis will identify the best choice from the available information. New milestones are defined to coincide with the completion of each of the first three iterations on September 30, in 1995, 1996, and 1997, respectively. The information that would change this choice will then be identified to direct further activities toward specific results having the most impact on the decision. 
WHC-EP-0805

This page intentionally left blank. 


\subsection{MILESTONES}

A total of 44 enhanced sludge washing evaluation related milestones are summarized in Table 6-1. Fifteen milestones are existing Tri-Party Agreement Milestones and 29 are newly defined milestones. Totals for activities discussed in this plan are as follows: Waste Characterization - 4 existing, 5 new; Enhanced Sludge Washing - 4 existing, 3 new; tank AZ-101 Sludge Washing Test existing - 1 existing, 4 new; HLW Feed Composition and Waste Form Selection - 6 new; Blending Studies/Retrieval Sequence - 2 existing, 3 new; Flowsheet Development - 2 new; Trade Studies - 3 new; Evaluation Process -2 existing, 3 new. In addition, 2 existing milestones which illustrate the relationship between the enhanced sludge washing evaluation and the HLW pretreatment facility design are included in Table 6-1.

Milestones are listed in chronological order in Table 6-1. Milestone description sheets for all milestones are contained in Appendix B, also in chronological order.

The summary enhanced sludge washing evaluation schedule is shown on Figure 6-1. Detail schedules are shown in Appendix A. 
Table 61 . Enhanced Sludge Washing EValuation Related Mitestones. (2 pages)

\begin{tabular}{|c|c|c|c|}
\hline Qhentopt & atumptos? & Tites & Bie pate \\
\hline TDC-94-390 & TPA & $\begin{array}{l}\text { Define Additional Milestones for Waste Pretreatment Leading to the Decision } \\
\text { whether Advanced Sludge Separation Processes are Required }\end{array}$ & $09 / 30 / 94$ \\
\hline TW4-94-519 & $\begin{array}{c}\text { TPA } \\
(\mathrm{M}-44-05)\end{array}$ & $\begin{array}{l}\text { Issue } 20 \text { Tank Characterization Reports in Accordance with the Approved } \\
\text { TCP's }\end{array}$ & 09/30/94 \\
\hline T3A-95-101 & $\begin{array}{c}\text { TPA } \\
(\mathbf{M - 5 0 - 0 3 - T 0 1 )}\end{array}$ & Issue Report on Current Status of Tank Waste Enhanced Sludge Washing & $10 / 31 / 94$ \\
\hline T3A-95-148* & CONTRACTOR & Issue a Time-Phased Flowsheet Focusing on Feed Variability & $12 / 30 / 94$ \\
\hline T3C-95-104* & CONTRACTOR & Issue Feed Processability Assessment Report & $01 / 06 / 95$ \\
\hline T3A-95-146* & CONTRACTOR & Complete Decant and Fill of Tank AZ-101 & $01 / 31 / 95$ \\
\hline T3A-95-140* & CONTRACTOR & Issue Prototype Decision Model for Waste Pretreatment Alternatives & $06 / 01 / 95$ \\
\hline T3A-95-136* & DOE-RL & Determine Waste Processing Strategy and Waste Separations Process & $09 / 01 / 95$ \\
\hline T2D-95-135* & DOE-RL & Collect Rotary and Push Mode Core Samples from HLW Tanks & 09/28/95 \\
\hline T2D-95-136* & DOE-RL & Collect Auger Samples from HLW Tanks & $09 / 28 / 95$ \\
\hline T3A-95-102 & $\begin{array}{c}\text { TPA } \\
\text { (M-50-03-T2A) }\end{array}$ & $\begin{array}{l}\text { Submit Report Summarizing the Testing of Enhanced Sludge Washing and } \\
\text { Related Tank Waste Sludge Pretreatment Methods for Samples of Tank Waste } \\
\text { Shudge }\end{array}$ & 09/29/95 \\
\hline T3A-95-131* & CONTRACTOR & Issue Report on Laboratory Settling Tests of Tank C-107 Sludge & $09 / 29 / 95$ \\
\hline T3A-95-132* & CONTRACTOR & FY 1995 Sludge Washing/Alkaline Leach Tests Conducted at LANL & $09 / 29 / 95$ \\
\hline T3A-95-133* & CONTRACTOR & FY 1995 Sludge Washing/Alkaline Leach Tests Conducted at LANL & 09/29/95 \\
\hline T2D-95-102 & $\underset{(M-44-08)}{\text { TPA }}$ & $\begin{array}{l}\text { Issue } 30 \text { Tank Characterization Reports in Accordance with the Approved Tank } \\
\text { Characterization Plans. Complete Input of Characterization Information for } 30 \\
\text { HLW Tanis to Electronic Database(s) }\end{array}$ & 09/30/95 \\
\hline T3A-95-112* & DOE-RL & $\begin{array}{l}\text { Develop Decision Basis for Evaluation of Enhanced Sludge Washing to } \\
\text { Determine Whether Advanced Sludge Separation Processes are Required }\end{array}$ & $09 / 30 / 95$ \\
\hline T3C-96-114* & CONTRACTOR & Updated Estimates of Tank Waste Types, Compositions \& Quantities & $10 / 02 / 95$ \\
\hline T3C-96-107* & CONTRACTOR & Update Feed Processability Evaluation & $01 / 04 / 96$ \\
\hline T3A-96-132* & DOE-RL & Retrieval Sequence (a) Selected & $04 / 03 / 96$ \\
\hline T3A-96-131* & CONTRACTOR & TWRS Process Flowsheet, Rev. 2 & $08 / 30 / 96$ \\
\hline T3A-96-140* & CONTRACTOR & $\begin{array}{l}\text { Update of Determine Waste Processing Strategy and Waste Separations Process } \\
(4.2 .2 / 4.2 .2 .1)\end{array}$ & $08 / 30 / 96$ \\
\hline T2D-96-113* & DOE-RL & Collect Rotary and Push Mode Core Samples form HLW Tanks & $09 / 26 / 96$ \\
\hline T2D-96-114* & DOE-RL & Collect Auger Samples from HLW Tanks & $09 / 26 / 96$ \\
\hline T2D-96-102 & $\begin{array}{c}\text { TPA } \\
(\mathbf{M}-44-09)\end{array}$ & $\begin{array}{l}\text { Issue } 40 \text { Tank Characterization Reports in Accordance with the Approved Tank } \\
\text { Characterization Plans. Complete Input of Characterization Information for } 40 \\
\text { HLW Tanks to Electmonic Database(s) }\end{array}$ & $09 / 30 / 96$ \\
\hline T2E-96-101 & $\begin{array}{c}\text { TPA } \\
(\mathrm{M}-45-02 \mathrm{~A}) \\
\end{array}$ & $\begin{array}{l}\text { Submit Initial Single Shell Tank Retrieval Sequence Document for Ecology } \\
\text { Approval }\end{array}$ & 09/30/96 \\
\hline T2E-96-102* & DOE-RL & W-151 ORR/Start-Up Complete & $09 / 30 / 96$ \\
\hline
\end{tabular}




\section{WHC-EP-0805}

Table 6.1 . Enibanced Shudge Washing EValuation Related Millestones. (2 pages)

\begin{tabular}{|c|c|c|c|}
\hline $80,1+1,1$ & (1) & 110 & Doe oute \\
\hline T3A-96-100 & $\underset{\text { (M-50-03-T2B) }}{\text { TPA }}$ & $\begin{array}{l}\text { Submit Report Summarizing the Treating of Enhanced Sludge Washing and } \\
\text { Related Tank Waste Sludge Pretreatment Methods for Samples of Tank Waste } \\
\text { Sludge }\end{array}$ & $09 / 30 / 96$ \\
\hline T3A-96-110 & DOE-RL & $\begin{array}{l}\text { Preliminary Recommendation on Evaluation of Enhanced Sludge Washing to } \\
\text { Determine Whether Advanced Sludge Separation Processes are Required }\end{array}$ & $09 / 30 / 96$ \\
\hline T3C-97-109* & CONTRACTOR & Documentation of Potential Feed Composition Ranges Estimate & $10 / 01 / 96$ \\
\hline T2C-97-100 & $\underset{(\mathrm{M}-43-01)}{\text { TPA }}$ & Project W-030 Tank Farm Ventilation Upgrade & $12 / 31 / 96$ \\
\hline T3A-97-114* & CONTRACTOR & Initiate AZ-101 Sludge Washing Process Test & $01 / 02 / 976$ \\
\hline T3C-97-107* & CONTRACTOR & Recommend Design Basis Feeds for Conceptual Design & $01 / 03 / 97$ \\
\hline T3A-97-110* & CONTRACTOR & Retrieval Sequence (b) Selected & 04/03/97 \\
\hline T3A-97-111* & CONTRACTOR & $\begin{array}{l}\text { Update of Determine Waste Processing Strategy and Waste Separations Process } \\
(4.2 .2 / 4.2 .2 .1)\end{array}$ & $08 / 29 / 97$ \\
\hline T2D-97-109* & DOE-RL & Collect Rotary and Push Mode Core Samples form HLW Tanks & $09 / 25 / 97$ \\
\hline T3C-97-100* & CONTRACTOR & Incorporate Pretreatment CDR \& Shudge Wash Decision & $09 / 29 / 97$ \\
\hline T2D-97-102 & $\underset{(M-44-10)}{\text { TPA }}$ & $\begin{array}{l}\text { Issue } 40 \text { Tank Characterization Reports in Accordance with the Approved Tank } \\
\text { Characterization Plans. Complete Input of Characterization Information for } 40 \\
\text { HLW Tanks to Electronic Database(s) }\end{array}$ & $09 / 30 / 97$ \\
\hline T2E-97-104 & $\begin{array}{c}\text { TPA } \\
(\mathrm{M}-45-02 B)\end{array}$ & Submit Annual Update of SST Retrieval Sequence & 09/30/97 \\
\hline T3A-97-101 & $\begin{array}{c}\text { TPA } \\
(\mathbf{M - 5 0 - 0 3 - T 2 C )}\end{array}$ & $\begin{array}{l}\text { Submit Report Summarizing the Testing of Enhanced Sludge Washing and } \\
\text { Related Tank Waste Shudge Pretreatment Methods for Samples of Tank Waste } \\
\text { Sludge }\end{array}$ & $09 / 30 / 97$ \\
\hline T3A-97-105* & DOE-RL & $\begin{array}{l}\text { Issue Draft Recommendation on Evaluation of Enhanced Sludge Washing to } \\
\text { Determine if Advanced Sludge Separation Processes are Required }\end{array}$ & $09 / 30 / 97$ \\
\hline T3A-97-107* & DOE-RL & $\begin{array}{l}\text { Complete In-Tank Sludge Washing Process Test and Issue Report (Tank AZ- } \\
\text { 101) }\end{array}$ & $09 / 30 / 97$ \\
\hline T3A-98-100 & $\underset{(\mathbf{M}-50-03)}{\mathbf{T P A}}$ & $\begin{array}{l}\text { Complete Evaluation of Enhanced Sludge Washing to Determine if Advanced } \\
\text { Sludge Separation Processes are Required }\end{array}$ & $03 / 31 / 98$ \\
\hline T3A-98-101 & $\begin{array}{c}\text { TPA } \\
(\mathrm{M}-50-04-T 01)\end{array}$ & Submit Conceptual Design of HLW Pretreatment Facility & $03 / 31 / 98$ \\
\hline T3A-99-100 & $\begin{array}{c}\text { TPA } \\
\text { (M-50-04-T02) }\end{array}$ & Initiate Definitive Design of ELW Pretreatment Facility & $11 / 30 / 98$ \\
\hline
\end{tabular}

*Newly Defined Milestones 


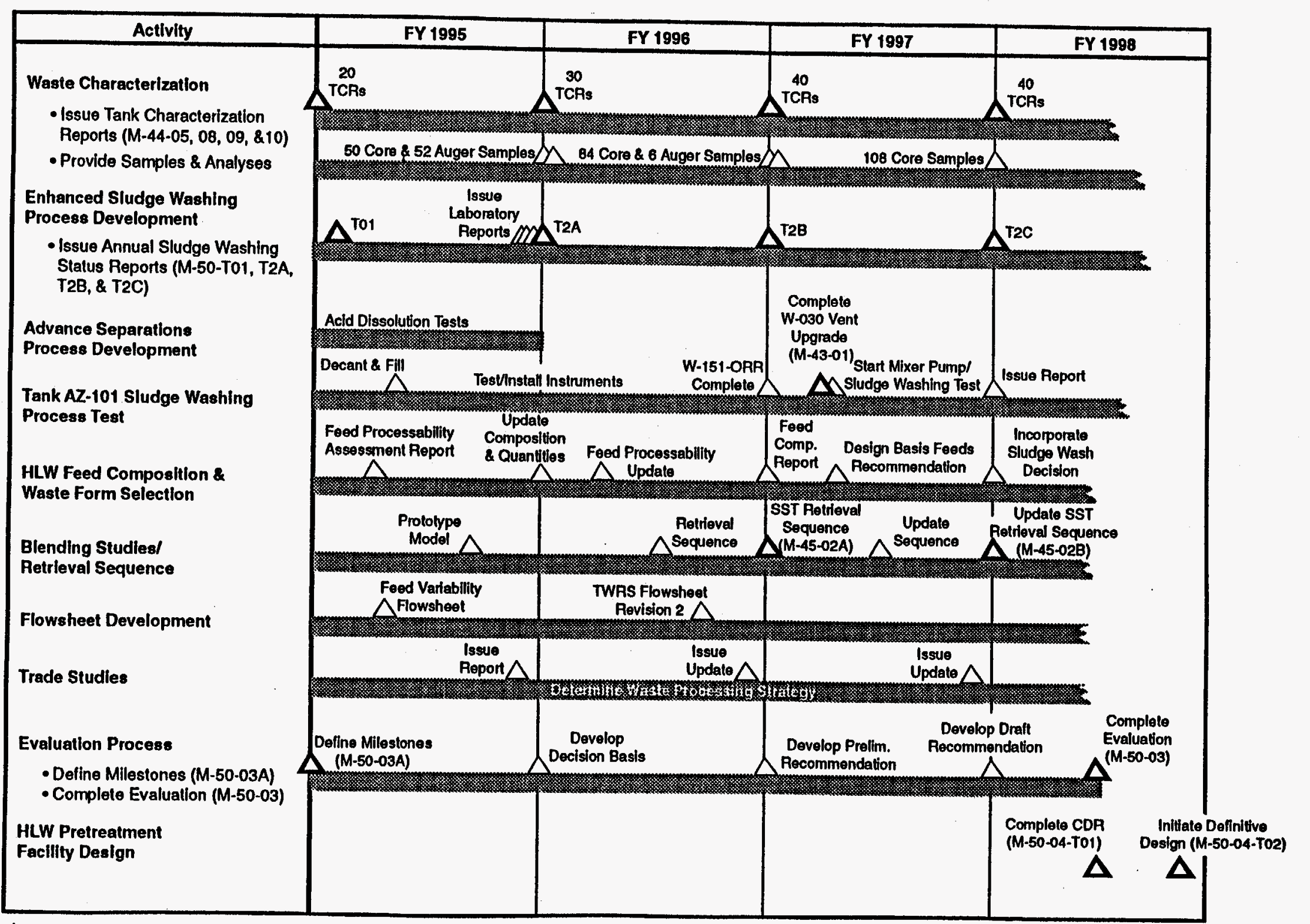


WHC-EP-0805

\subsection{REFERENCES}

10 CFR 61, 1992, "Licensing Requirements for Land Disposal of Radioactive Waste, ", Code of Federal Regulations, as amended.

Bernero, R. M., 1989, (Letter to A. J. Rizzo, U.S. Department of Energy, Richland Operations Office, Richland, Washington, September 26, 1989), U.S. Nuclear Regulatory Commission, Washington, D.C.

Bernero, R. M., 1993, (Letter to J. Lytle, U.S. Department of Energy, Richland Operations Office, Richland, Washington, March 2, 1993) U.S. Nuclear Regulatory Commission, Washington, D.C.

Boomer, K. D., 1994, Tank Waste Remediation System Facility Configuration Study, WHCSD-WM-ES-295, Rev. 0, Westinghouse Hanford Company, Richland, Washington.

Boomer et al., 1993, Tank Waste Technical Option Report, WHC-EP-0616, Rev. 0, Westinghouse Hanford Company, Richland, Washington.

Ecology, EPA, and DOE, 1994, Hanford Federal Facility Agreement and Consent Order, 2 vols., 4th amendment, Washington State Department of Ecology, U.S. Environmental Protection Agency, and U.S. Department of Energy, Olympia, Washington.

DOE-RL, 1994, Tank Waste Remediation System Functions and Requirements, DOE-RL-92-60. Draft, Westinghouse Hanford Company, Richland, Washington.

Geeting, J.G.H., and D.E. Kurath, 1993, Preliminary Assessment of Blending Hanford Tank Wastes, PNL-8589, Pacific Northwest Laboratory, Richland, Washington.

Johnson, M.E., 1994, Tank Waste Remediation System Program Decision and Risk Assessment, WHC-EP-0768 DRAFT, Westinghouse Hanford Company, Richland, Washington.

Orme, R. M., 1994, Tank Waste Remediation System Flowsheet, WHC-SD-WM-TI-613, Rev. 0, Westinghouse Hanford Company, Richland, Washington.

PNL, 1994, Public Values Related to Decision in the Tank Waste Remediation System Program, PNL-10107, Pacific Northwest Laboratory, Richland, Washington.

Powell, R. W., 1994, (Letter to L. Erickson, U.S. Department of Energy, Richland Operations Office, Richland, Washington, August 12, 1994), Westinghouse Hanford Company, Richland, Washington.

Sage, A. P., 1992, Systems Engineering, John Wiley \& Sons, Inc. New York, New York. 
Sheridan, T. R., 1994, (Letter to A. L. Trego, Westinghouse Hanford Company, Richland, Washington, June 23, 1994), U.S. Department of Energy, Richland Operations Office, Richland, Washington.

WHC, 1994a, Tank Waste Remediation System Systems Engineering Working Plan, WHC-SD-WM-WP-285, Rev. 0, Westinghouse Hanford Company, Richland, Washington.

WHC, 1994b, Tank Waste Remediation System Multi-Year Work Plan, WHC-SP-1101, 5 vols, Westinghouse Hanford Company, Richland, Washington. 
WHC-EP-0805

APPENDIX A

SCHEDULE OF TECHNICAL WORK SUPPORTING ENHANCED SLUDGE WASHING EVALUATION 
This page intentionally left blank. 


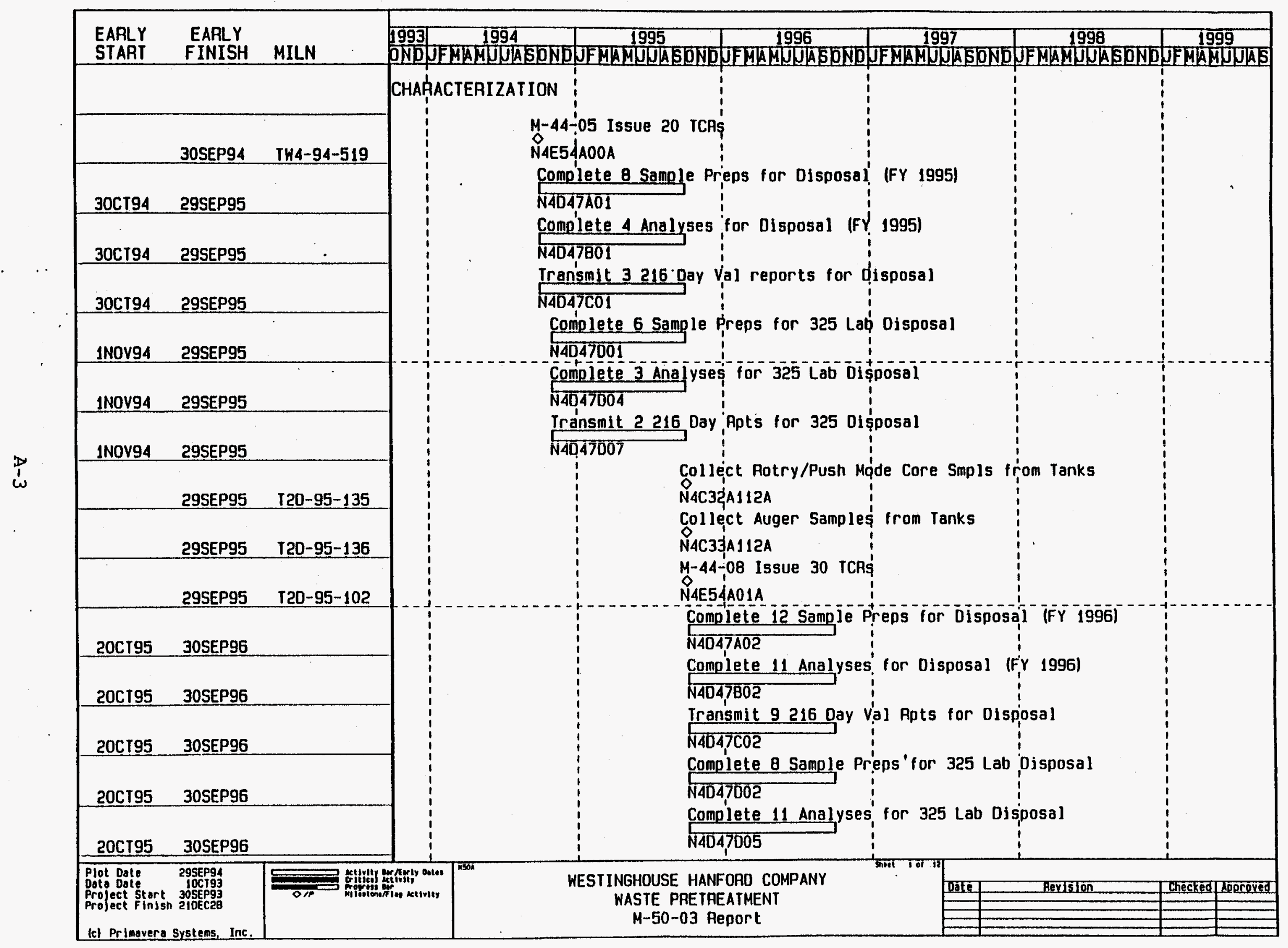




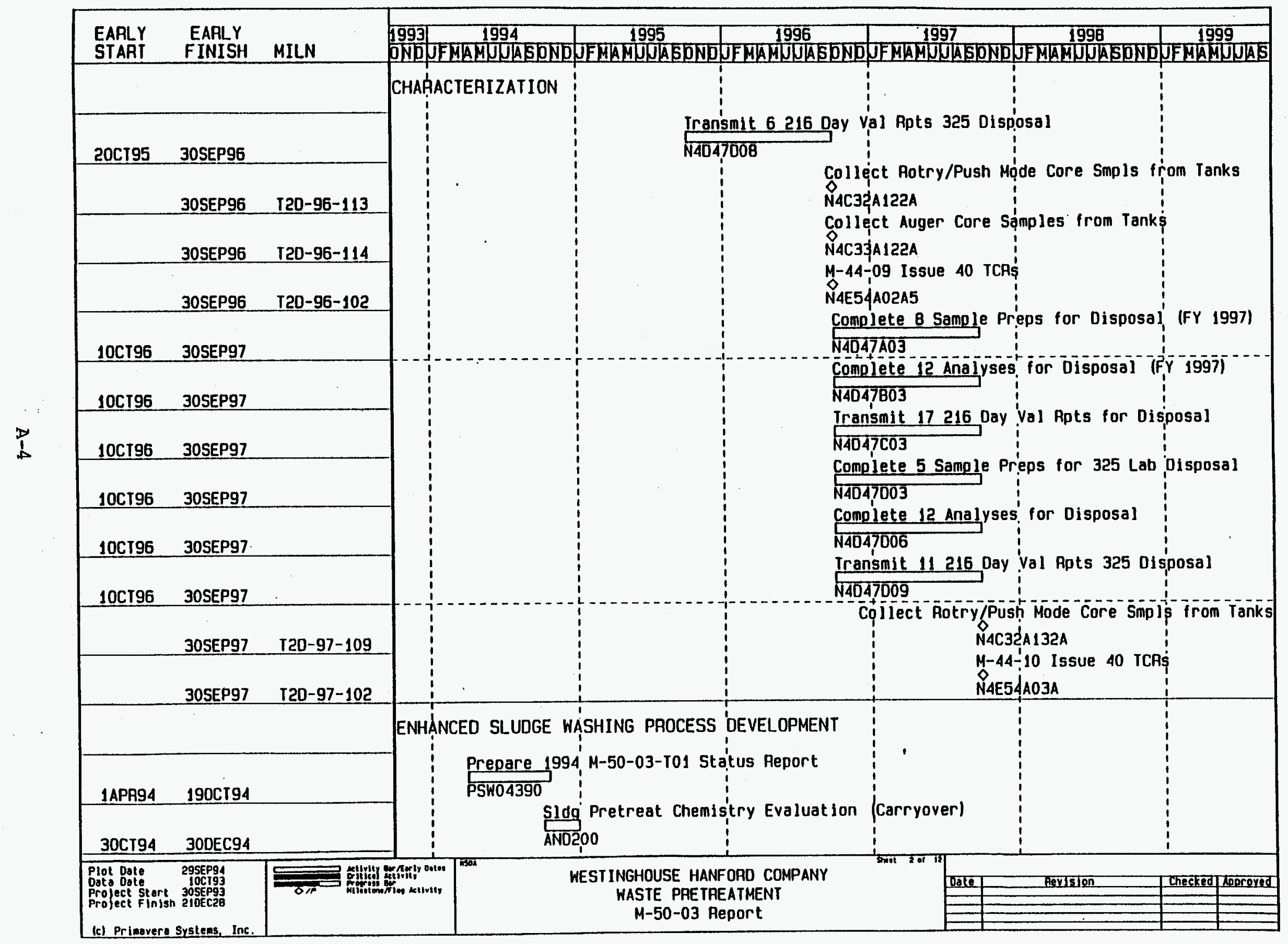




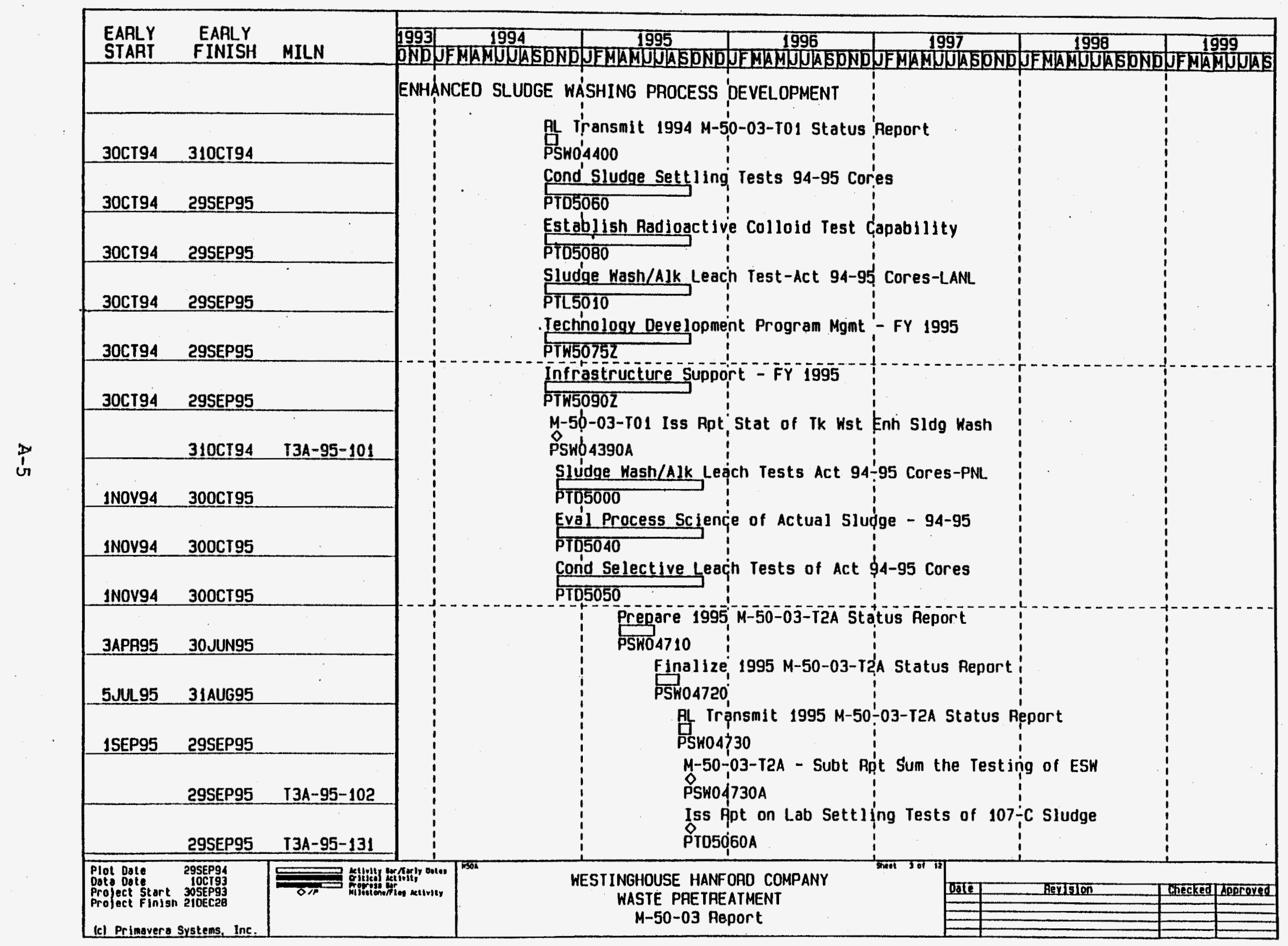




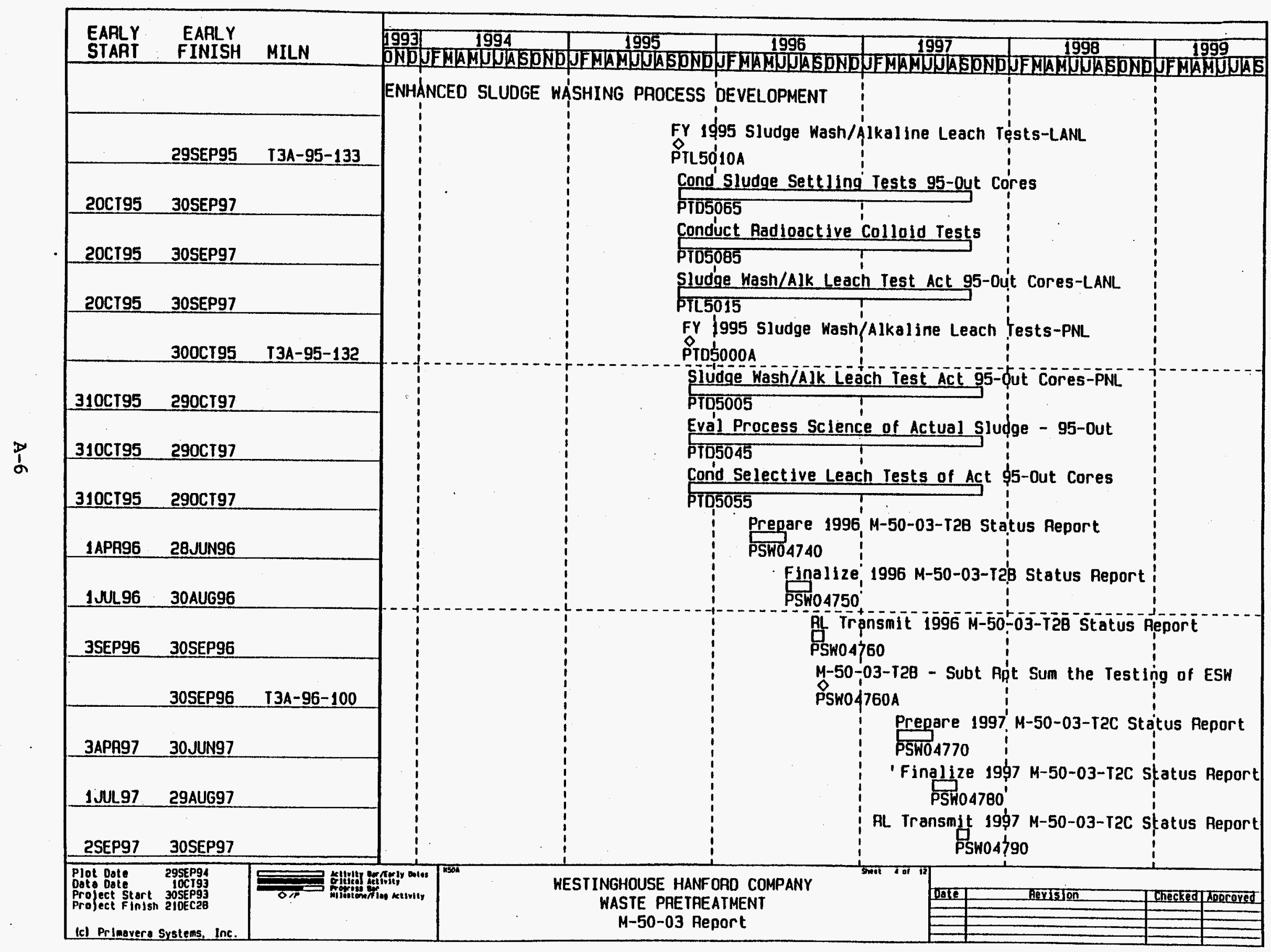




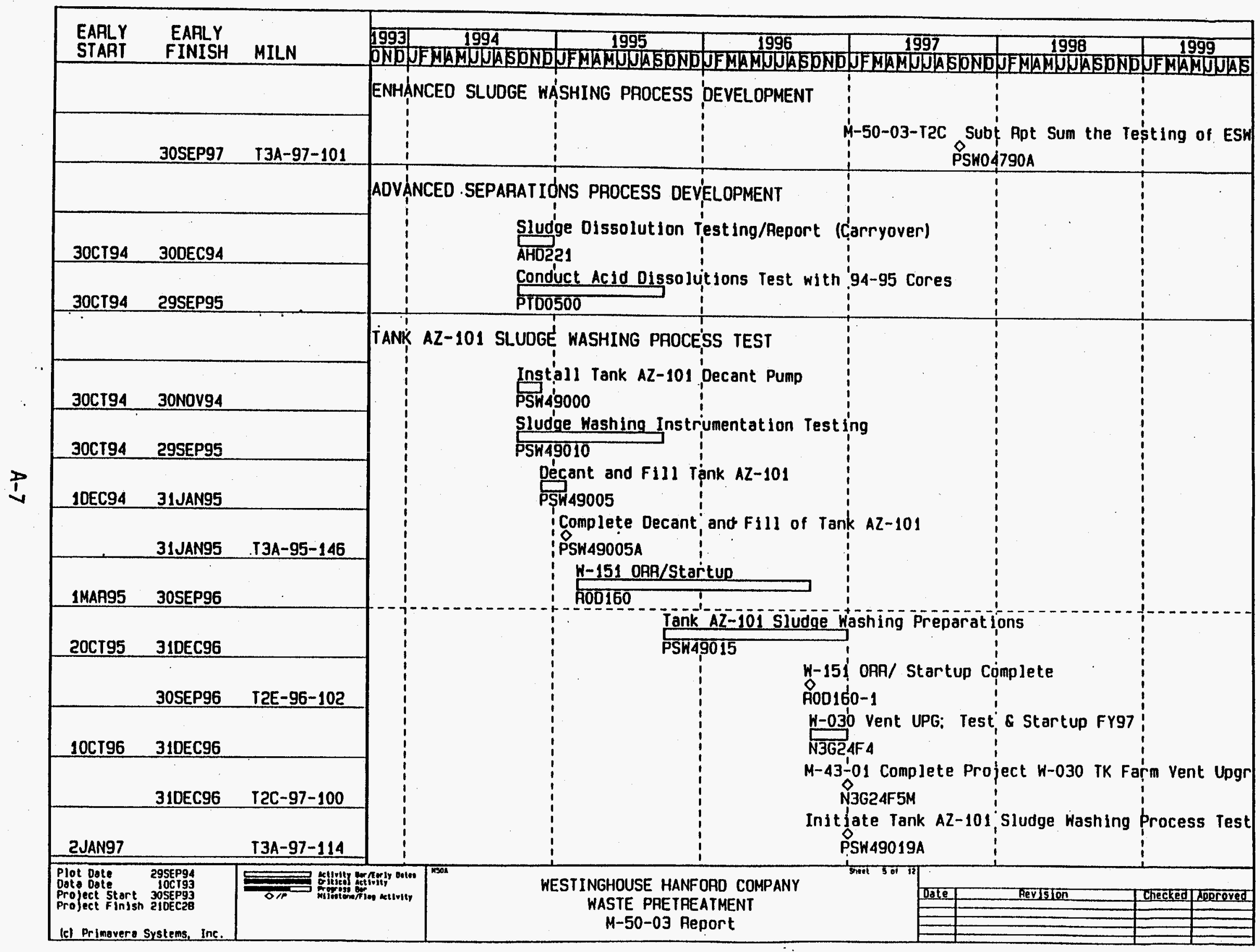




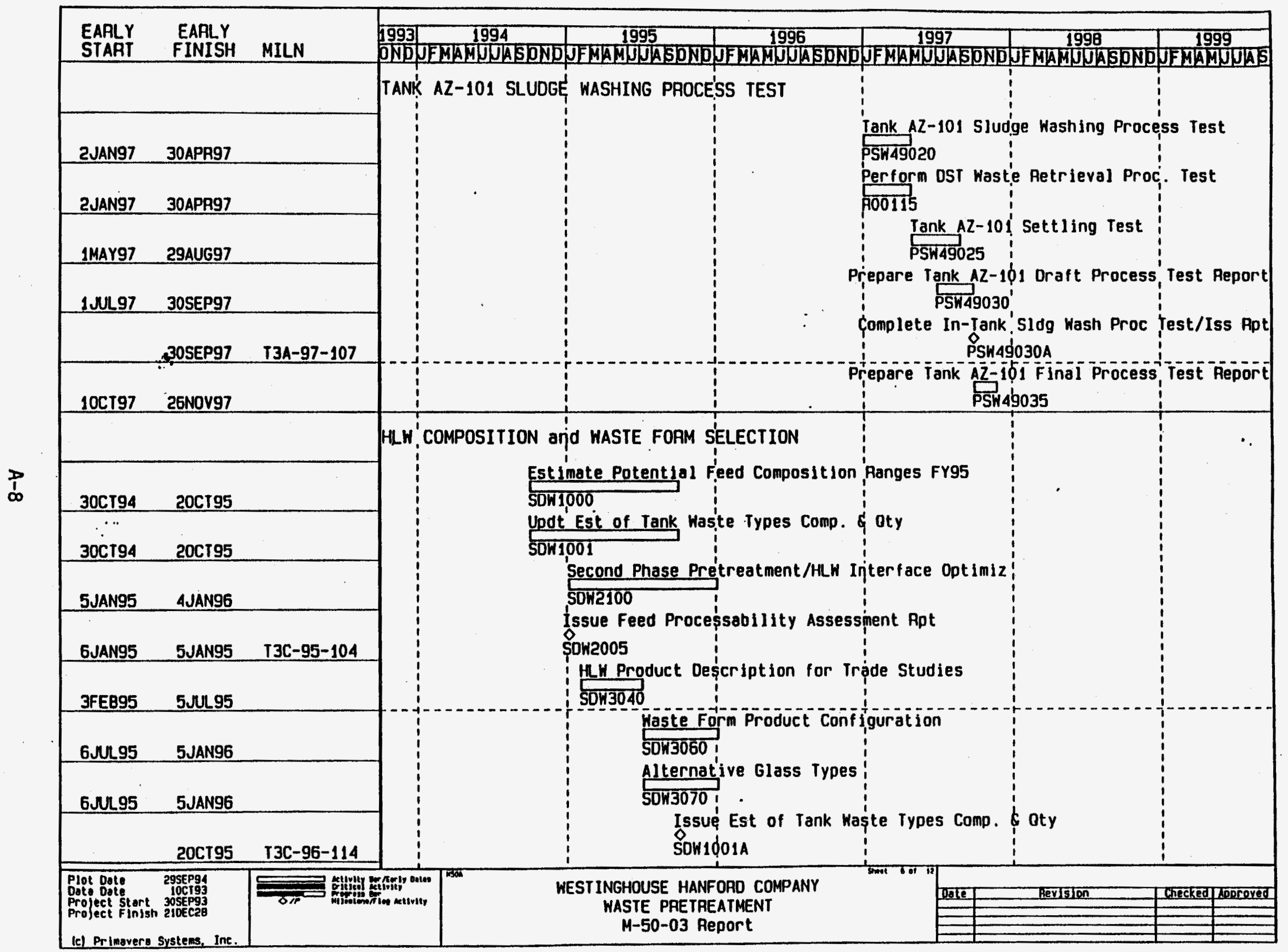




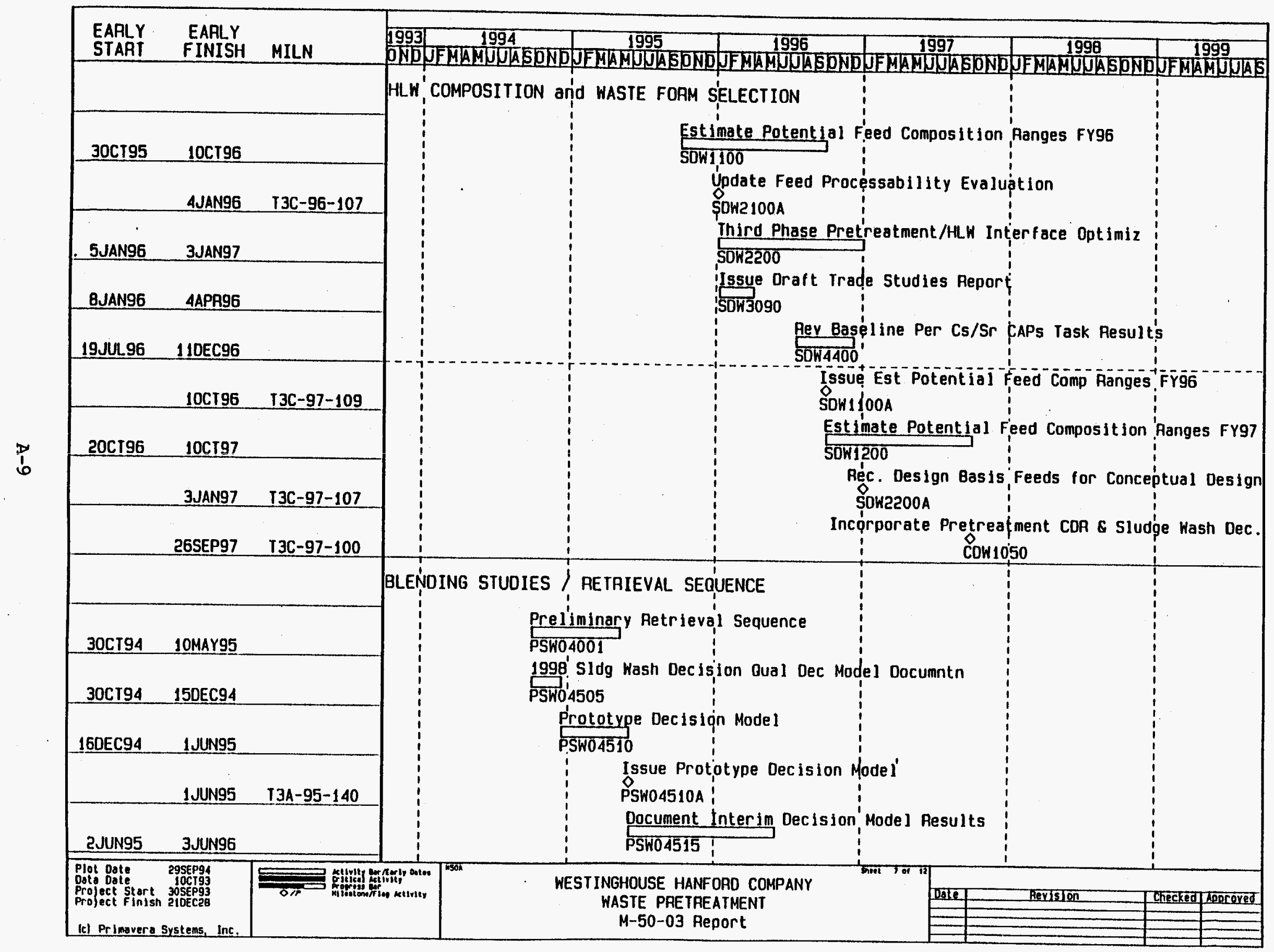




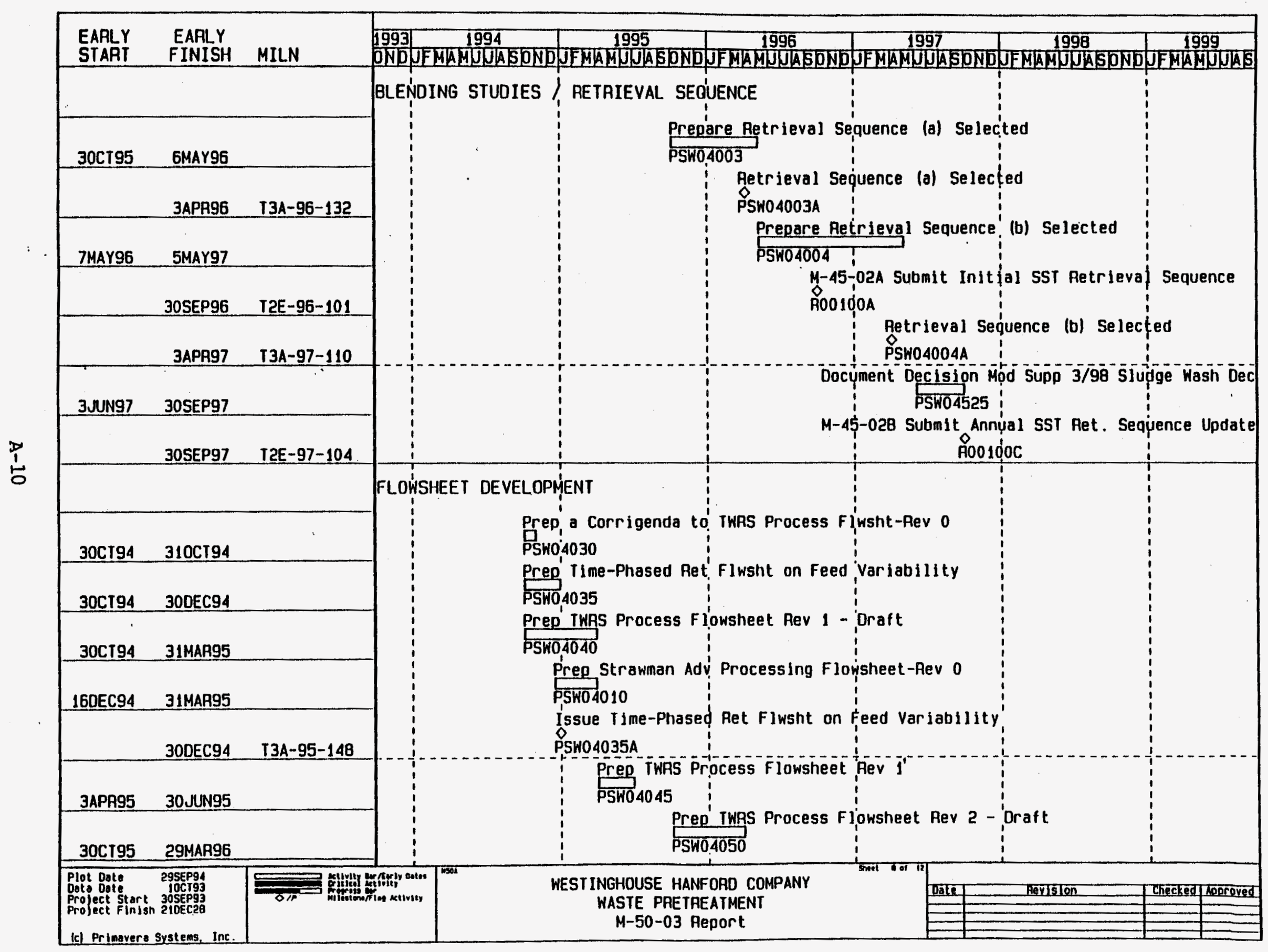




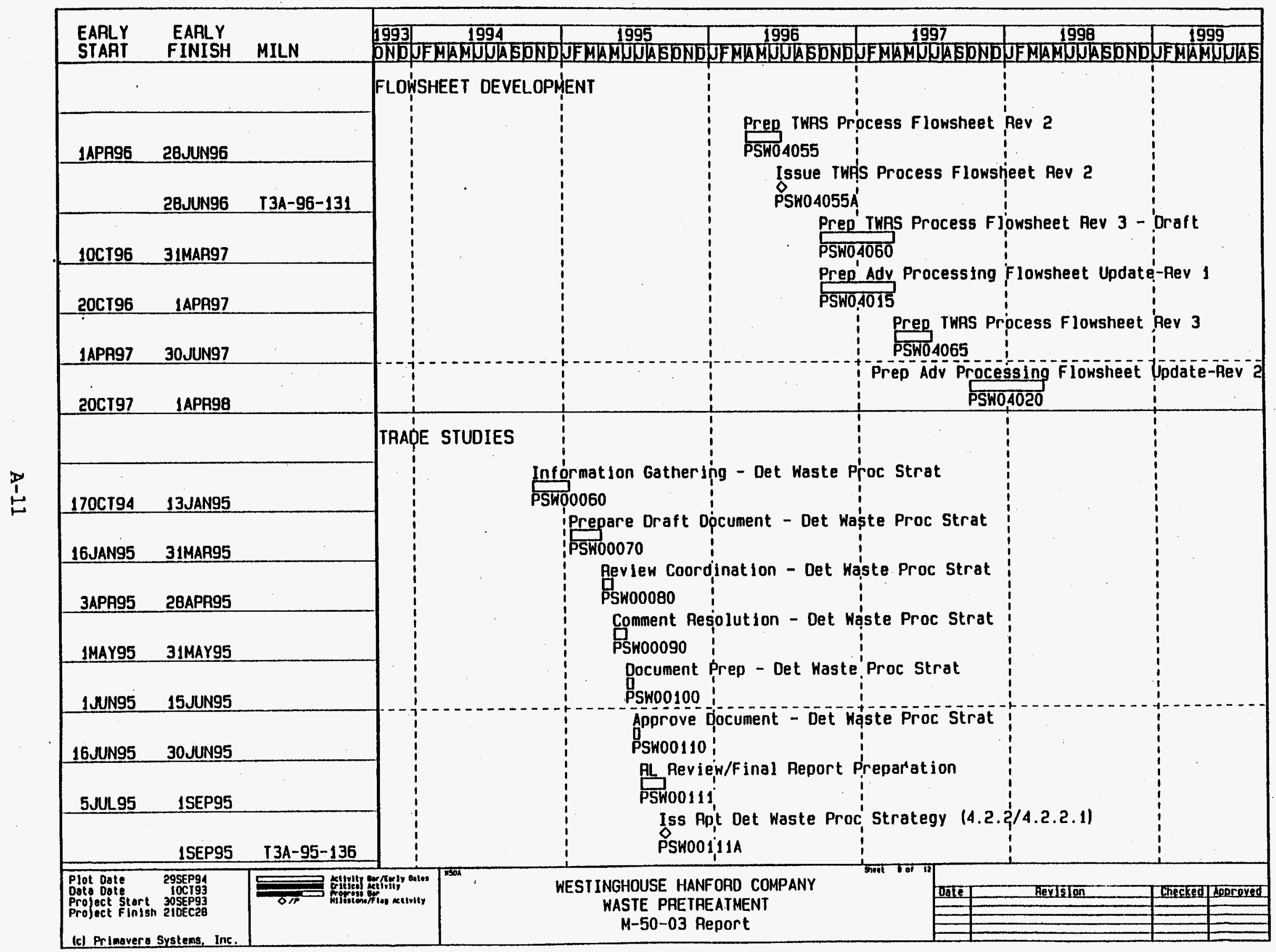




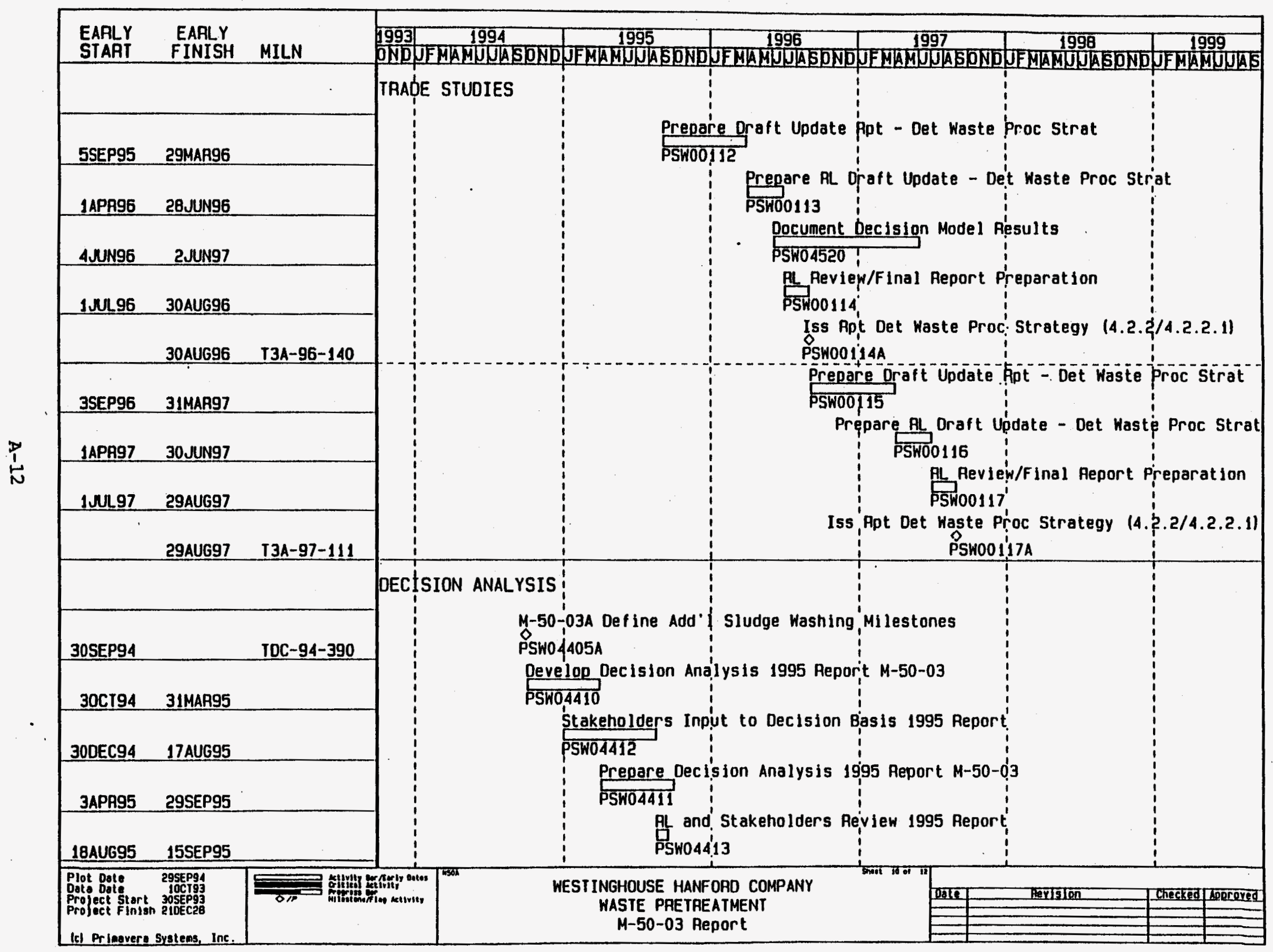




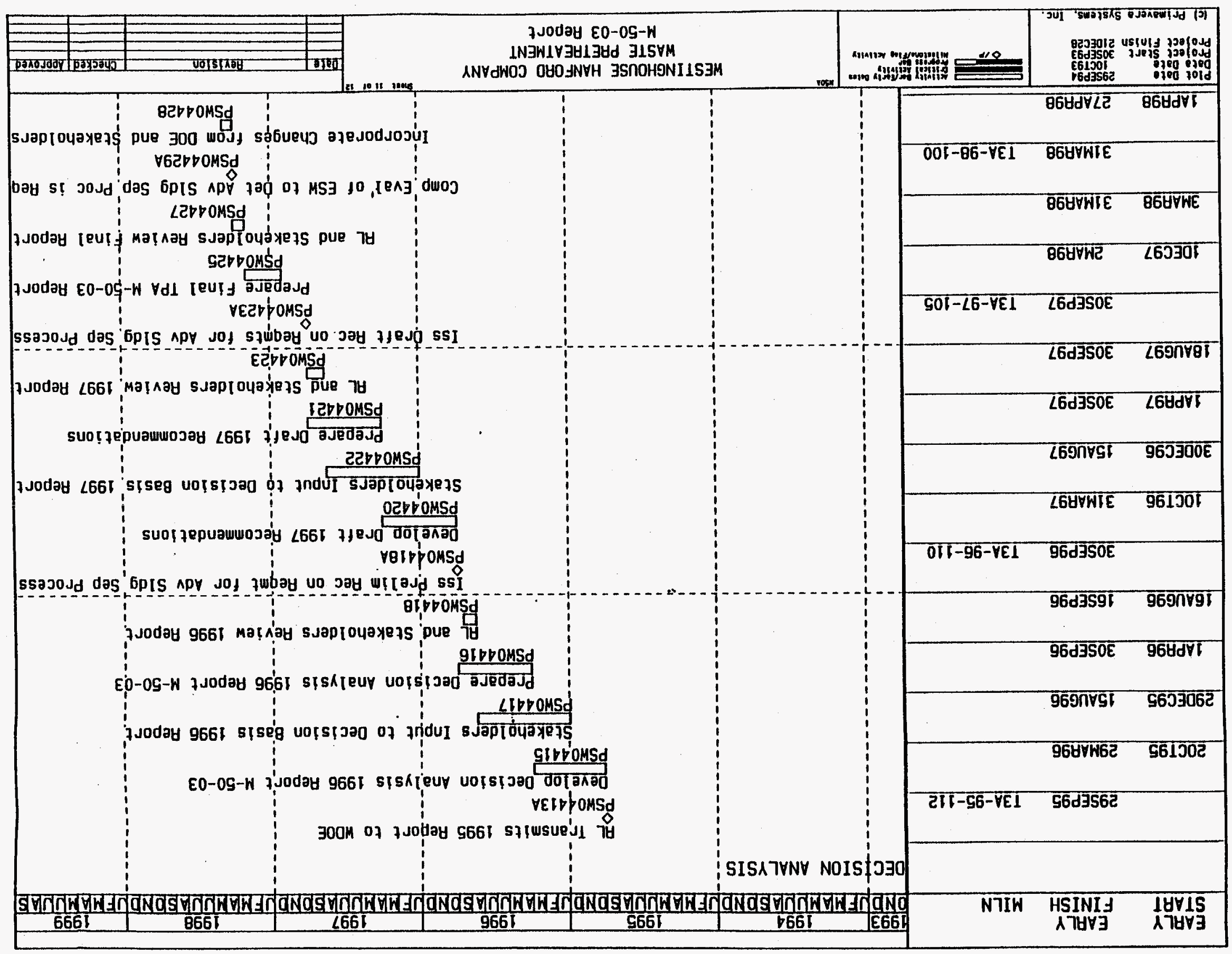




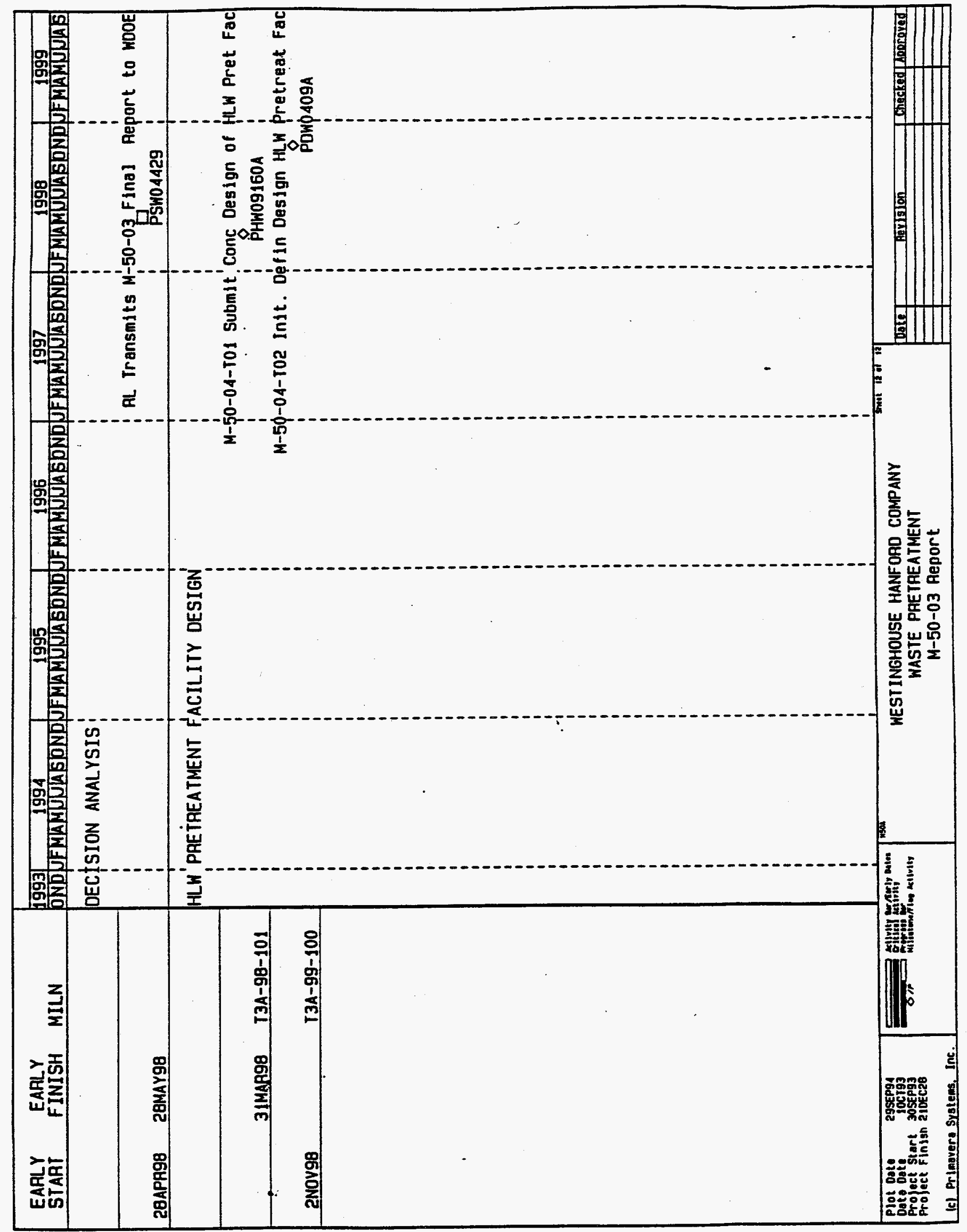


WHC-EP-0805

APPENDIX B

MILESTONE DESCRIPTION SHEETS

THE MILESTONE DESCRIPTION SHEETS ARE ORDERED CHRONOLOGICALLY

BY MILESTONE CONTROL NUMBER. 
This page intentionally left blank. 


\section{WHC TWRS Milestone Description Sheet}

Title:

\author{
Define Additional Milestones for Waste Pretreatment \\ Leading to the Decision whether Advanced Sludge \\ Separation Processes are required
}

Assigned to:

TWRS Strategic Analysis

WBS Designator:

1.1.1.3.01.04.03.33

Milestone Controi No.:

TDC-94-390

\author{
Schedule ID: \\ PSW04390A/ \\ PXW04-0A
}

Revision:

0

ADS No.:

1220-00-AF

Completion Date: $9 / 30 / 94$
Milestone Class:

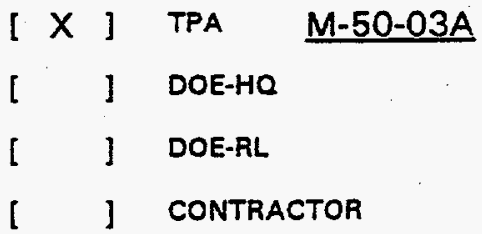

Deliverable:

\begin{tabular}{|c|c|c|}
\hline$x$ & 1 & REPORT \\
\hline & 1 & LETTER \\
\hline & ] & DRAWINGS \\
\hline & 1 & $\begin{array}{l}\text { Other } \\
\text { (Specify): }\end{array}$ \\
\hline
\end{tabular}

Addressed to:

$\left[\begin{array}{lll}{[} & ] & \text { DOE-HQ } \\ {\left[{ }^{*} \mathrm{X}\right.} & ] & \text { DOE-RL } \\ & ] & \begin{array}{l}\text { Other } \\ \text { (Specify): }\end{array}\end{array}\right.$

Description and what constitutes completion of this commitment:

The decision of whether advanced sludge separation processes are required will need the development of information from several TWRS Program Elements, (e.g. Waste Pretreatment, HLW Vitrification, LIW Vitrification, and Waste Retrievall, to determine if enhanced sludge separation processes are required. Some interim information to be included on this schedule may include the development of the decision-making methods. It will also include the schedule to evaluate the performance of enhance sludge washing, acceptance of criteria for making the decision encompassed in TPA Milestone M-50-03 and the decision method to be used.

Acceptance Criteria:

The acceptance criteria for accomplishing this milestone (M-50-03A) will be transmitted to DOE-RL approval three months in advance of the completion date. The Criteria will include the logic and strategy for Milestone M-50-03A. The milestone deliverable will be a contractor report approved for external publication and ready for transmittal to the WDOE by DOE-RL. The report will include a strategy plan and schedule defining additional milestones leading to the decision whether advanced sludge separation processes are required. This decision is encompassed in TPA Milestone M-50-03 scheduled for completion by 3/31/98. The schedule will be based on inputs received from stakeholder including DOE-RL, DOE-HQ, WDOE, and Waste Pretreatment Sub-Panel of Technical Advisory Panel.

Deliverables:

Acceptance criteria for this milestone (M-50-03A) will be transmitted to DOE-RL for approval by 6/30/94. A contractor approved draft report will be transmitted to DOE-RL by 8/15/94 for review by DOE-RL. The report will include a strategy plan and schedule for completing TPA Milestone M-50-03. A final contractor report incorporating DOE comments on the draft report and approved for external publication will be transmitted to DOE-RL by $9 / 15 / 94$ for transmittal to the WDOE by $9 / 30 / 94$.

W.B. Barton

Cost Account Manager
Date

I.E. Reep

Activity Manager

Date

L. Erickson

\section{K.A. Gasper}

Program Element Manager

Date

L. Erickson

DOE Manager (agreement)
Date
DOE Manager (acceptance)

Date 


\section{WESTINGHOUSE HANFORD COMPANY \\ TANK WASTE REMEDIATION SYSTEM DIVISION \\ WASTE TANK SAFETY AND OPERATIONS PROGRAM \\ FY94}

\section{MILESTONE DESCRIPTION SHEET}

TITLE: ISSUE 20 TANK CHARACTERIZATION REPORTS IN ACCORDANCE WITH THE APPROVED TCP'S.

\section{ASSIGNED TO: CHARACTERIZATION} PROGRAM

PROGRAM WBS DESIGNATOR: 1.1.1.4.4.02

MILESTONE CONTROL NO: TW4-94-519
DELIVERABLE:

[X] TPA

[ ] DOE-HQ

[ ] DOE-RL

[ ] WHC Key
[X] Report

[ ] Letter

[ ] Drawings

[ ] Other (Specify)
DATE: $11 / 18 / 93$

REVISION: 0

ADS NO: 1130

COMPLETION DATE: 09/30/94

FDS CODE: 1N4D42

\section{Description and what constitutes completion of this commitment:}

Statement of Work:

Generate and issue 20 tank characterization reports (TCR) in support of TPA milestone M-44-05. These TCRs will integrate historical knowledge concerning DSTs and SSTs with analytical and statistical data analysis from the characterization effort. TCRs will be issued as external publication (EP) documents. Delivery of final documents (cleared with either WHC or PNL concurrence) to DOE-RL for approval and release is considered completion of this milestone. This MDS is related to MDS 436, 437, and 520. Completion of the three MDSs fulfills TPA milestone M-44-05 for 20 TCRs by September 30, 1994 .

Deliverables:

1. 20 Tank Characterization Reports

A formal letter of notification, with the TCR attatched, will be sent to DOE-RL with the completion of each TCR. All of the 20 TCRs will be completed by $09 / 15 / 94$.
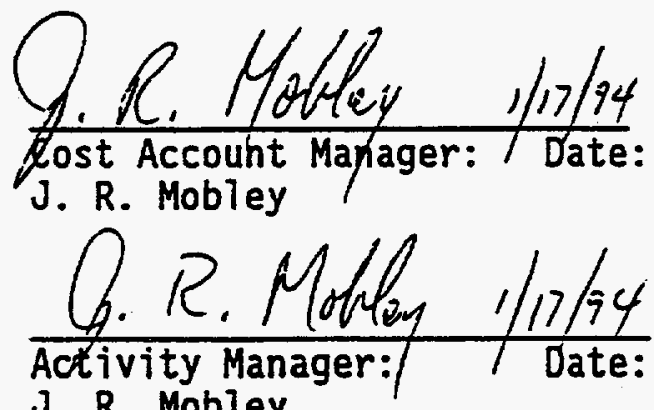

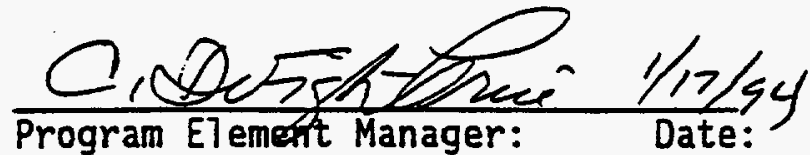

C. DeFigh-Price

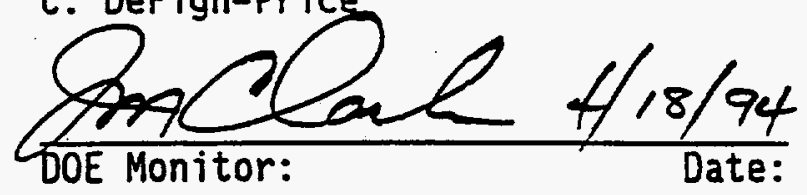


Tite: Issue Report on Current Status of Tank Waste Enhanced Sludge Washing

Assigned to:

Waste Pretreatment

WBS Designator:

1.1.1.3.01.04.03.33

Milestone Control No.:

T3A-95-101
Schedule 1D:

Revision:

ADS No.:

Completion Date: $10 / 31 / 94$
PSW04390B/PXW04-1A

0
Milestone Class:

$\begin{array}{lllll}{[} & X & ] & \text { TPA } & \text { M-50-03-TOI } \\ {[} & 1 & \text { DOE-HO } \\ {[} & 1 & \text { DOE-RL } \\ {[} & 1 & \text { CONTRACTOR }\end{array}$

\section{Deliverable:}

$\begin{array}{llll}{[} & ] & ] & \text { REPORT } \\ {[} & ] & \text { LETTER } \\ {[} & 1 & \text { DRAWINGS } \\ {[} & ] & \begin{array}{l}\text { Other } \\ \text { (Specify): }\end{array}\end{array}$

Addressed to:

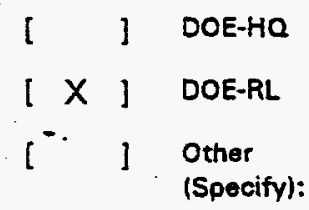

Description and what constitutes completion of this commitment:

This milestone will report on Hanford progress in enhanced sludge washing. Included in the scope of this milestone will be the issuance of a plan that will define the tests to be performed on Hanford tank sludges. In addition, the enhanced siudge washing laboratory test results on Hanford sludges completed through the third quarter of the fiscal year will be presented with expected impacts on HLW vitrification. These impacts will be illustrated in a summary of HLW glass volume projections for all Hanford waste types. Finally, the status and results of computer modeling of sludge washing of tank wastes will be presented.

Acceptance Criteria:

The report will include data from all actual tests completed through the third quarter of FY 1994 on sludge washing and enhanced sludge washing and the expected impacts on HLW glass volume. (Because of delay of testing at $325 \mathrm{Lab}$ only two the originally scheduled five tank sample tests have been completed, Tanks 241-B-101 and 241-U-110).

\section{Excellent}

The Programmatic issues associated with the test results are fully addressed. Models converge and predict duplicate lab results.

\section{Satisfactory}

Programmatic issues are identified, but not fully discussed. Models work and predict results which are compared to lab results and variances explained.

\section{Unsatisfactory}

Planned tests are not completed due to management or operator deficiencies. Programmatic issues are not clearly identified.

Basis of Measurement: Fulfillment of the requirements identified in the MYWP MOSs. 


\section{WHC TWRS Milestone Description Sheet}

Deliverables:

The deliverables are:

- Letter of transmittal by 09/30/94 with the following documents attached:

- "Laboratory Development of Sludge Washing and Alkaline leaching Processes: Test Plan for Fy 1994, PNL-998 Hanford Tank Sludges: A Status Report," PNL-10078 previously submitted to fuifill Milestone TDC-94-332

- Modeling Report (WHC approved document transmittal to DOE for review and approval)

- "Computer Simulation of Laboratory Leaching and Washing of Tank Waste Sludges" (WHC-SD-XXX), Milestc TDC-94-326

- Final transmittal to RL by $10 / 24 / 94$.

The letter of transmittal will also contain a summary of HLW glass volume projections for all Hanford Waste type

W.B. Barton

Cost Account Manager

Date

I.E. Reep

Activity Manager

Date
K.A. Gasper

Program Element Manager

Date

L. Erickson

DOE Manager (agreement)

L. Erickson

DOE Manager (acceptance)

Date 


\section{WHC TWRS Milestone Description Sheet}

Titte: Issue a Time-Phased Flowsheet Focusing on Feed Variability

Assigned to:

WBS Designator:

TWRS Process Engineering

1.1.1.3.01.04.03.02

Milestone Control No.: $\quad$.T3A-95-148

Milestone Class:

$\begin{array}{llll}{[} & & ] & \text { TPA } \\ {[} & 1 & \text { DOE-HO } \\ {[} & & ] & \text { DOE-RL } \\ {[} & X & ] & \text { CONTRACTOR }\end{array}$

Deliverable:

[ $X$ ] REPORT

[ ] LETTER

[ ] DRAWINGS

[ 1 Other
Schedule ID:

Revision:

ADS No.:

Completion Date:

1220-00-AF

$12 / 30 / 94$

PSW04035A

0
Addressed to:

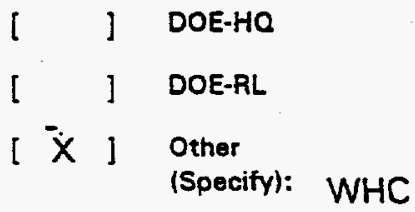

Description and whot constitutes completion of this commitment:

This work is a precursor to the FY 1995 update of the TWRS Process Flowsheet. Rev. 0 of the flowsheet issued in 1994 assumed that the feed was a uniform blend of all tank waste. The next step is to begin considering retrieval sequences. An early retrieval sequence report will be available at the end of FY 1994. The early retrieval sequence report will provide an ordering of tanks that will be inputted to the TWRS Process Flowsheet to provide a feed composition range for pretreatment.

Acceptance Criteria:

Deliverables:

The deliverable is an internally approved document showing the variability of retrieved waste composition for the duration of tank retrieval operations.

W.B. Barton

Cost Account Manager

I.E. Reep

Activity Manager

Date
K.A. Gasper

Program Element Manager

Date

L. Erickson

DOE Manager lagreement)
Date

L. Erickson 


\section{WESTINGHOUSE HANFORD COMPANY}

\section{Tank Waste Remediation System Division \\ Milestone Description Sheet}

Title: Issue Feed Processability Assessment Report

Assigned To: High Level Waste

WBS Designator: 1.1.1.3.03.04

Milestone Control No.: T3C-95-104

Milestone Class:

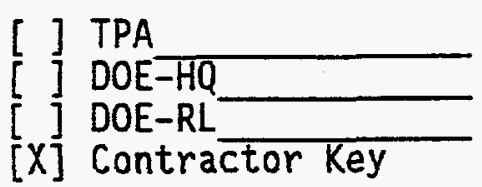

Deliverable

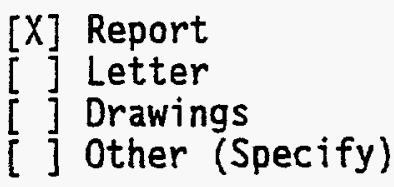

Schedule ID: SDW2005

Revision: 0

ADS No.: 1240-0

Comp Tetion Date: 01/06/95

\section{Description:}

Addressed to:

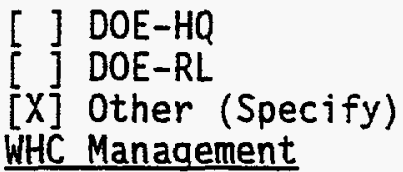

Review available data from Pretreatment/Characterization and provide an evaluation of glass formulations, process compatibility, and melter operational performance characteristics for each waste. Develop estimates of total glass production ranges based on different blending, pretreatment and glass composition.

Acceptance Criteria:

Issuance of report to WHC management.

Deliverables:

Report on potential range of feed compositions.

Signatures:

Cost Account Manager Date

T. W. Crawford

Activity Manager

R. W. Powel]
Program Element Manager R. W. Powell

DOE Manager (Agreement)

J. C. Peschong 
Titie: Complete Decant and Fill of Tank AZ-101

Assigned to:

WBS Designator:

TWRS Process Design

Milestone Control No.:

1.1.1.3.01.04.02.15

T3A-95-146
Schedule ID:

Revision:

ADS No.:

Completion Date:

PSW49010A

0

$$
\text { 1220-00-AF }
$$

$01 / 31 / 95$

Addressed to:

Milestone Class:

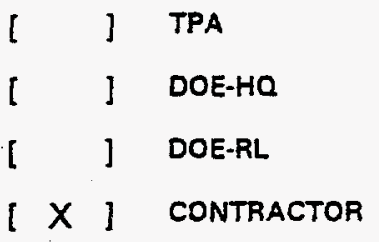

Deliverable:

\begin{tabular}{|c|c|}
\hline ! & REPORT \\
\hline [ & LETTER \\
\hline f & DRAWINGS \\
\hline$[x$ & $\begin{array}{l}\text { Other } \\
\text { (Specify\}: }\end{array}$ \\
\hline
\end{tabular}

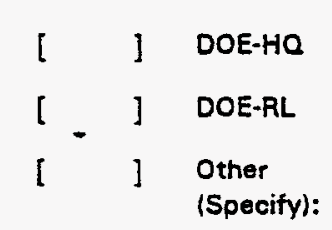

Description and what constitures completion of this commitment:

The first step in preparing AZ-101 for mixer pump installation and sludge washing is to decant the suparnatant liquid and refill the tank with dilute waste. This requires the installation and operation of a decant pump, instrumentation, and a computer control system. This milestone commitment will be met when the decanting of AZ-101 has been completed.

\section{Acceptance Criteria:}

Tank has been decanted to a level $\leq 2$ feet above the solid/liquid interface.

Deliverables:

A nearly empty tank ready to be refilled.

\section{W.B. Barton}

Cost Account Manager

Date

I.E. Reep

Activity Managor

Date

L. Erickson

DOE Manager (acceptance)

\section{K.A. Gasper}

Program Element Manager

Dato

L. Erickson

DOE Manager (agreement)

Date 


\section{WHC TWRS Milestone Description Sheet}

Title: Issue Prototype Decision Model for Waste Pretreatment Alternatives
Assigned to:
TWRS Process Technology
WBS Designator:
1.1 .1 .3 .01 .04 .03 .40
Milestone Control No.:
T3A-95-140

Schedule ID:

PSW04510A

Revision:

0

$\begin{array}{ll}\text { ADS No.: } & 1220-00-A F \\ \text { Completion Date: } & 06 / 01 / 95\end{array}$

Milestone Class:

[ ] TPA

[ ] DOE-HO

[ ] DOE-RL

$[X]$ CONTRACTOR
Deliverable:

\begin{tabular}{|c|c|c|}
\hline$x$ & ] & REPORT \\
\hline & & LETTER \\
\hline & & DRAWINGS \\
\hline & & $\begin{array}{l}\text { Other } \\
\text { (Specify): }\end{array}$ \\
\hline
\end{tabular}

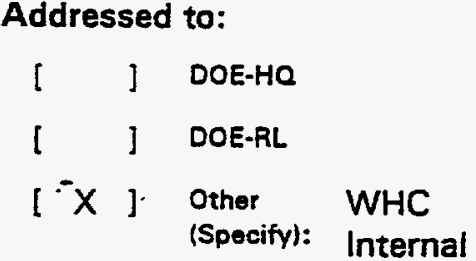

Addressed to:

Description and what constitutes completion of this commitment:

Background: In FY-94, a decision model for pretreatment was developed. The work scope can be broken into seve phases for purposes of discussion:

Prototype model supporting sludge wash decision - limited to pretreatment

integrate $\mathrm{WW}$ vitrification decision model with pretreatment model

integrate $H L W$ vitrification decision model with previous models.

Use model to support evaluation of alternatives for the sludge wash decision.

Scope: The scope of this milestone description sheet is limited to the first phase (Prototype model). Prepare the sludg wash-decision criteria to be used by the model, build a prototype decision model that incorporates these criteria, a use the model to evaluate at least two alternatives, one of which will be consistent with the emerging TWRS baselir

Acceptance Criteria:

The prototype decision model report shall:

- Be approved by appropriate organizations within WHC,

- Be cleared for public release,

- Document the decision analysis process/methodology/criteria used, and

- Evaluate at least two alternatives as described in the scope section, above. 
Deliverables:

The deliverable is one or more supporting documents, that taken together as a set meet the requirements in the acceptance criteria section. An example of such a set is:

- A report documenting the prototype decision model, including the decision criteria

- A report documenting the results of using the model to evaluate two or more pretreatment alternatives.

W.B. Barton

Cost Account Manager

Date

I.E. Reep

Activity Manager

Date

L. Erickson

DOE Manager (acceptance)

\section{K.A. Gasper}

Program Ejement Manager

Date

L. Erickson

DOE Manager (agreement)

Date 
Titlo: Determine Waste Processing Strategy and Waste Separations Process

$(4.2 .2 / 4.2 .2 .1)$

\author{
Assigned to: TWRS Process Design \\ WBS Designator: $\quad$ 1.1.1.3.01.04.02 \\ Milestone Control No.: $\quad$ T3A-95-136
}

Milestone Class:

[ ] TPA

l $]$ DOE-HO

$\left[\begin{array}{l}X\end{array}\right]$ DOE-RL

l ] CONTRACTOR
Deliverable:

[ $\mathrm{X}]$ REPORT

l $]$ LetTER

[ ] DRAWINGS

[ ] Other

(Specify):
Schedule ID: $\quad$ PSW00111A

Revision:

0

Completion Date: 09/01/95

Addressed to:

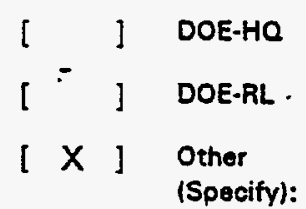

WHC-

internal

Description and what constitutes completion of this commitment:

This activity will provide technical justification (via a trade study) for the "case Beta" separations strategy (i.e. slud washing and enhanced sludge washingl and establish the basis for additional development work for advance separations. The study will assess four categories of separations alternatives consistent with environmental impa statement (EIS) preparation including no pretreatment, treatment of waste to an intermediate form, enhanced slude washing and extensive pretreatment separations (e.g. CLEAN). A trade study report will be prepared which includ information gathering, draft document preparation, WHC review, and WHC approval. The commitment will be comple with WHC appoval of the study document according to the appropriate Impact Level (assumed to be N/A or level

\section{Acceptance Criteria:}

Acceptance will be provided by WHC approval of the study document.

Deliverables:

One study document will be prepared which addresses the alternatives given above.

W.B. Barton

\begin{tabular}{ll}
\hline Cost Account Manager & Date \\
l.E. Reep & \\
\hline Activity Manager & Date \\
L. Erickson & \\
\hline DOE Manager (acceptance) & Date
\end{tabular}

\section{K.A. Gasper}

Program Element Manager

Date

L. Erickson

DOE Manager (agreement)

Date 


\section{Westinghouse Hanford Company \\ Tank Waste Remediation System \\ Milestone Description Sheet}

Title:

Collect Rotary and Push Mode

Core Samples from High Level

Waste Tanks

Schedule D:

N4C32A112A

Revision:

Assigned to: Waste Tank Sampling Engineering

ADS No.:

$1130-0 C$

Program WBS Designator: 1.1.1.2.04.03.02

Completion Date:

09-28-95

Milestone Control No.: T2D-95-135

Milestone Class:

[ ] TPA

[ ] DOE-HQ

[ X ] DOE-RL

[ ] CONTRACTOR
Deliverables:

[ ] Report

[ X ] Letter

[ ] Drawings

[ ] Other(Specify)

Addressed To:

[ ] DOE-HQ

[ ] DOE-RL

[ ] Other(Specify):

Description and what constitutes completion of this commitment (What work is specifically going to be done to accomplish this milestone):

High level tank waste surface to tank bottom core samples will be collected using the Push and Rotary mode coring systems. The number of core samples identified for Push mode sampling is 22 (based on 2 cores/tank). The number of core samples idennified for Rotary mode sampling is 28 (based on 2 cores/tank). Waste samples will be transported and relinquished to an onsite laboratory. Relinquishment of all required* waste samples to the laboratory via a transportation chain of custody document constirutes completion of the sampling commiment. In the event any of the above tanks cannot be sampled, contingency tanks will be selected.

The cost requirement for these sampling events is $\$ 5.7 \mathrm{M}$ for push and $\$ 8.4 \mathrm{M}$ for rotary. This is based on rotary truck 2 deploying to the field on 10/03/94 and working days and swings, five days a week, through July 1995. Also assumed is the deployment of trucks 3 and 4 by 06/01/95. Deployment is defined as the truck availability to take samples in tank farms. At present, there are no flammable gas tanks to be rotary sampled in FY 1994/5. Before any flammable gas tank can be added to the schedule for FY 1995, truck 3 or 4 must be available and the safery-reiated documentation complete. Prior to the rotary truck being deployed into a tank with a hard siudge crust that requires rotary sampling, the ability to have some rotation without nitrogen flow must be present. This will require a change to the safety analysis.

* See acceptance criteria below.

Acceptance Criteria:

Waste sampling in direct accordance with an approved (WHC) Tank Characterization Plan. 
Deliverables (Describe the specific products or conditions):

Quarterly performance reports will be transmitted by the Characterization Program Element manager to DOERL manager as part of the DNFSB 93-5 Commiment 1.10. The reports will identify sampling performance based on a quarterly and fiscal year-to-date percent complete scheme. Additionally, any non-recoverable schedule variance will be reported and consequential impacts identified.

P. A. Young

Cost Account Manager

G. A. Stanton

Activity Manager

Date

Date
R. E. Gerton

DOE Manager (acceptance)
C. DeFigh-Price

Program Element Manager Date

R. E. Gerton

DOE Manager (agreement)
Date 


\section{Westinghouse Hanford Company \\ Tank Waste Remediation System \\ Milestone Description Sheet}

Title:

Collect Auger Samples from

High Level Waste Tanks

Assigned to: Waste Tank Sampling Engineering

Program WBS Designator: 1.1.1.2.04.03.03

Milestone Control No.: T2D-95-136
Deliverables:

[ ] Report

[X] Letter

[X] DOE-RL

[ ] CONTRACTOR
[ ] Drawings

[ ] Other(Specify)
Schedule ID:

N4C33A112A

Revision:

ADS No.:

0

1130-0C

Completion Date:

09-28-95

Description and what constitutes completion of this commitment (What work is specifically going to be done to accomplish this milestone):

High level tank waste surface samples will be collected using an auger sampling system. The number of auger samples identified for auger sampling is 52 (assumes 2 samples/tank) based on sampling schedule 3.0. Waste samples will be transported and relinquished to an onsite laboratory. Relinquishment of all required* waste samples to the laboratory via a transportation chain of custody document constitutes completion of the sampling commitment. In the event any of the above tanks cannot be sampled, contingency tanks will be selected. The 20 inch auger is required for field deployment on 10/13/94.

The 52 augers will require $\$ 2.4 \mathrm{M}$ of available funding.

* See acceptance criteria below.

\section{Acceptance Criteria:}

Waste sampling in direct accordance with an approved (WHC) Tank Characterization Plan.

Deliverables (Describe the specific products or conditions):

Quarerly performance reports will be transmitted by the Characterization Program Element manager to DOE$R L$ manager as part of the DNFSB 93-5 Commitment 1.10. The reports will identify sampling performance based on a quartexly and fiscal year-to-date percent complete scheme. Additionally, any non-recoverable schedule variance will be reported and consequential impacts identified.

\section{P. A. Young}

Cost Account Manager

Dare

G. A. Stanton

Activity Manager

Date

R. E. Gerton

DOE Manager (acceptance) Date

\section{DeFigh-Price}

Program Element Manager Date

R. E. Gerton

DOE Manager (agreement) Date 


\section{WHC TWRS Milestone Description Sheet}

Title: Submit Report Summarizing the Testing of Enhanced Sludge Washing and Related Tank Waste Sludge Pretreatment Methods for Samples of Tank Waste Sludge

Assigned to:

Process Technology

WBS Designator:

1.1.1.3.01.04.03.33

Milestone Control No.: T3A-95-102
Schedule ID: $\quad$ PSW04730A/PXW04-1B

Revision:

0

ADS No.:

1220-00-AF

Completion Date: 09/29/95

Addressed to:

$\begin{array}{llll}{[} & ] & \text { REPORT } \\ {[} & ] & \text { LETTER } \\ {[} & ] & \text { DRAWINGS } \\ {[} & ] & \begin{array}{l}\text { Other } \\ \text { (Specify): }\end{array}\end{array}$

\author{
[ ] DOE-HO \\ $\left[{ }^{\circ} X\right]$ DOE-RL \\ [ $]$ Other \\ (Specify):
}

Description and what constitutes completion of this commitment:

Perform testing of enhanced sludge washing and related tank waste sludge pretreatment methods using actual ta waste samples. Document and issue results of testing completed to that time. This annual report will also docume preliminary candidate tank waste pretreatment sequence and tank blending strategies. Goals for both early progress waste immobilization and minimization of the production of high level glass will be addressed in these strategies.

These preliminary strategies will be utilized to predict the production of high level waste glass associated with candida enhanced sludge washings and related tank waste sludge pretreatment methods. The prediction of the HLW gla volume production will be updated.

\section{Acceptance Criteria:}

The report will include the latest laboratory data available on sludge washing and enhanced sludge washing, and expected impacts on HLW glass volume will be provided. 


\section{WHC TWRS Milestone Description Sheet}

Deliverables:

The deliverables are:

- Contractor approved report to DOE-RL for review and comment by 08/15/95.

- Final WHC-approved report for external release and transmittal by $9 / 15 / 95$.

\section{W.B. Barton}

Cost Account Manager

Date

I.E. Reep

Activity Manager

Date

L. Erickson

DOE Manager (acceptance)
K.A. Gasper

Program Element Manager

Date

L. Erickson

DOE Manager (agreement)

Date 
Title: Issue Report on Laboratory Settling Tests of Tank C-107 Sludge

Assigned to:

Waste Pretreatment - TDPO

WBS Designator:

1.1.1.3.01.02.03.08

Milestone Control No.:

T3A-95-131
Schodule ID:

Revision:

ADS No.:

$1220-00-A B$

Completion Date:

$09 / 29 / 95$
Milestone Class:

[ ] TPA

[ 1 DOE-HO

[ ] DOE-RL

$[\times]$ CONTRACTOR
Deliverable:

$\begin{array}{llll}{[} & \mathrm{X} & ] & \text { REPORT } \\ {[} & & ] & \text { LETTER } \\ {[} & & ] & \text { DRAWINGS } \\ {[} & & ] & \begin{array}{l}\text { Other } \\ \text { [ }\end{array}\end{array}$

Addressed to:

$$
\begin{aligned}
& \text { l }] \text { DOE-HO } \\
& \text { [ ] DOE-RL } \\
& {[\mathrm{X}] \text { Other }} \\
& \text { (Specify): WHC }
\end{aligned}
$$

Description and what constitutes compietion of this commitment:

This milestone will report on settling tests conducted on tank C-107 actual sludge by PNL. The report will include da on settling rate, compaction and quality of the supernate for sludge washed with inhibited water, with alkaline solutio and again with inhibited water. Tests will be initiated with approximately one liter of sludge.

\section{Acceptance Criteria:}

This draft report will include laboratory data completed on at least one cycle of enhanced sludge washing similar to $t$ latest integrated flowsheet for an actual core of tank C-107.

\section{Deliverables:}

The deliverable is a draft report issued for WHC review on settling tests of tank C-107.

\section{J.N. Appel}

Cost Account Managor
Date

Date
Activity Manager

L. Erickson

DOE Manager (acceptance)
Date

\section{K.A. Gasper}

Program Element Manager

Date

Performing Manager (Other)

Date

L. Erickson

DOE Manager (agreement) 
Title: FY 1995 Siudge Washing/Alkaline Leach Tests Conducted at PNL

$\begin{array}{ll}\text { Assigned to: } & \text { Waste Pretreatment - TDPO } \\ \text { WBS Designator: } & 1.1 .1 .3 .01 .02 .03 .01 \\ \text { Milestone Control No.: } & \text { T3A-95-132 }\end{array}$

Milestone Class:

I 1 TPA

[ ] DOE-HO

[ ] DOE-RL

$[X]$ CONTRACTOR
Deliverable:

$\begin{array}{llll}{[} & X & ] & \text { REPORT } \\ {[} & ] & \text { LETTER } \\ {[} & 1 & \text { DRAWINGS } \\ 1 & 1 & \begin{array}{l}\text { Other } \\ \text { (Specify): }\end{array}\end{array}$

Schedule ID:

Revision:

ADS No.:

Completion Date:
PTD5000A

0

$1220-00-A B$

$09 / 29 / 95$

Description and what constitutes completion of this commitment:

This milestone will report progress in sludge washing and alkaline leach tests completed during FY 1995 . These tests will consist of small scale batch washing and leaching of approximately 5 gram samples of actual sludges. Eight cores of actual waste will be tested. Chemical analysis of washing and leaching solutions and sludges prior to and after each step will be performed so that component material balances can be included in the report. These component balances will facilitiate the estimation of the high level waste (HLW) glass volume.

Acceptance Criteria:

The draft report will include laboratory data of small scale sludge wash/alkaline leach test on eight cores of actual waste. The data will consist of elemental material balances so that HLW glass volumes may be projected based on composition.

\section{Deliverables:}

The deliverable is a draft report issued for WHC review on sludge washing/alkaline leaching tests conducted in FY 1995 by Pacific Northwest Laboratory (PNL).

\section{J.N. Appel}

Cost Account Manager

Date

Date

$\frac{\text { Activity Manager }}{\text { Ac. Reep }}$

L. Erickson

DOE Manager (acceptance)

\section{K.A. Gasper}

Program Element Manager

Date

Performing Manager (Other)

Date

L. Erickson

DOE Manager (agreement)

Date 


\section{WHC TWRS Milestone Description Sheet}

Title: FY 1995 Sludge Washing/Alkaline Leach Tests Conducted at LANL

Schedule ID:

PTL5010A

Revision:

0

$\begin{array}{ll}\text { Assigned to: } & \text { Waste Pretreatment - TDPO } \\ \text { WBS Designator: } & 1.1 .1 .3 .01 .02 .03 .02 \\ \text { Milestone Control No.: } & \text { T3A-95-133 }\end{array}$

ADS No.:

1220-00-AB

Milestone Control No.: · T3A-95-133

Completion Date: 09/29/95

Milestone Class:

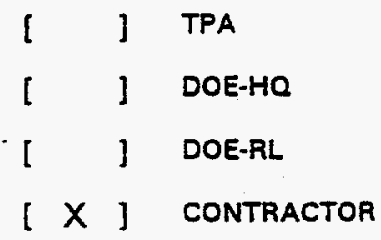

Deliverable:

$\begin{array}{llll}{[} & ] & \text { REPORT } \\ {[} & ] & \text { LETTER } \\ {[} & ] & \text { DRAWINGS } \\ {[} & ] & \begin{array}{l}\text { Other } \\ \text { (Specify): }\end{array}\end{array}$

Addressed to:

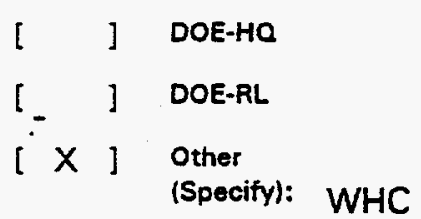

Description and what constitutes completion of this commitment:

This milestone will report progress in sludge washing and alkaline leach tests completed during FY 1995 . These te will consist of small scale batch washing and leaching of approximately 5 gram samples of actual sludges. Eight co of actual waste will be tested. Chemical analysis of washing and leaching solutions and sludges prior to and after $e^{2}$ step will be performed so that component material balances can be included in the report. These component balan will facilitiate the estimation of the high level waste (HLW) glass volume.

Acceptance Criteria:

The draft report will include laboratory data of small scale sludge wash/alkaline leach test on eight cores of actu waste. The data will consist of elemental material balances so that HLW glass volumes may be projected based composition.

\section{Deliverables:}

The deliverable is a draft report issued for WHC review on sludge washing/alkaline leaching tests conducted in FY 15 by Los Alamos National Laboratory (LANL).

\section{J.N. Appel}

Cost Account Manager

I.E. Reep

Activity Manager

\section{Erickson}

DOE Manager (acceptance)
Date

Date

Date
K.A. Gasper

Program Element Manager

Dare

Performing Manager (Other)

Date

L. Erickson

DOE Manager

Date 


\section{WHC-SP-1101 \\ WESTINGHOUSE HANFORD COMPANY \\ TANK WASTE REMEDIATION SYSTEM DIVISION \\ MILESTONE DESCRIPTION SHEET}

TITLE: ISSUE 30 TANK CHARACTERIZATION REPORTS IN

ACCORDANCE WITH THE APPROVED TANK

CHARACTERIZATION PLANS. COMPLETE INPUT OF

CHARACTERIZATION INFORMATION FOR 30 HLW TANKS TO

ELECTRONIC DATABASE(S) (M-44-08)

ASSIGNED TO: Characterization Support

WBS DESIGNATOR: 1.1.1.2.04.05.04

SCHEDULE ID: NAES4AOIA REYISION:

MILESTONE CONTROL NO: T2D-95-102

\section{MILESTONE CLASS: DELIVERABLE:}

$[X]$ TPA $M-44-08$
[] DOE-HQ
[] DOE-RL
[] CONTRACTOR
[X] REPORT

[ ] LETTER DRAWINGS

] OTHER (SPECIFY)
ADS NO:

$1130-0-0 E$ COMPLETION DATE: $9 / 30 / 95$
ADDRESSED TO:

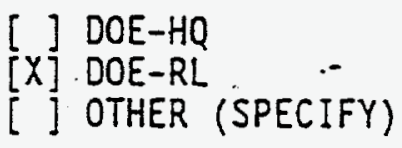

Description and what constitutes completion of this commitment:

Generate and issue 30 Tank Characterizacion Reports (TCRs) (in accordance with the approved Tank Characterization P(ans) in support of TPA milestone M-44-08. ihese icRs will integrate rank wasze historical data with tank waste analytical data. Updare previously issued TCRs as necessary co incorporate new information. TCRs will be cleared for public release.

Acceptance Criteria:

1) The Tank Characterizacion Reports must include both the relevant hiszorical dara and the information obtained by the characterization effor: in acsordance with the approved Tank Characterizatjon plans. ihe TCRs will be simitar in content and format to that prepared for tank 241-AP-101 and issued as supporting documents. One copy of each TCR will be transmitred to RL for formal submitral ro Ecology. ALl other internal and external distribution of the TCRs will be performed by the Characterization Program.

2) Characterization data for all 30 ranks must be accessible by onsite and offsite szakeholders through the Tank Characterization Database.

Deliverables: (Deseribe the specific products or condition)

1) Provide a draft to DOE-RL during review process so RL can perform concurrent review.

2) Transmit each nex or revised TCR to DOE-RL as it is issued. Provide with each TCR a draft transmittal letter which DOE-RL may use to forward the document to EPA and Ecology.

3) Provide a final letter after transmission of all TCRs to DOE-RL, indicating completion of the milestone and the date that each rCR was transmitred.

Fox

$\frac{\text { C. S. Hailer Ubed Grom } 9 / 19 / 74}{\text { Cost Account Manager }}$

$\frac{\text { S. J. Eberiein Ele } \frac{9-19-94}{\text { Activity Manager }}}{\text { Date }}$
C. Defiah-Price

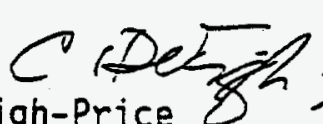

Program ETement Manager

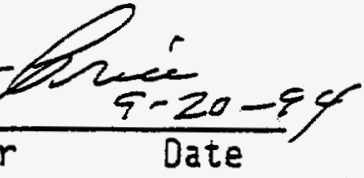

R. E. Gerton

DOE Monitor

R. E. Gerton

DOE Manager (acceptance) Date


Title: Develop Decision Basis for Evaluation of Enhanced Sludge Schedule ID: Washing to Determine Whether Advanced Sludge Separation Processes are Required

\author{
Revision:
}

ADS No.:

Completion Date:
PSW04413A

0

1220-00-AF

$09 / 30 / 95$
Milestone Class:

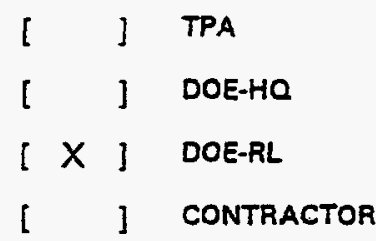

Deliverable:

$\begin{array}{llll}{[} & ] & \text { REPORT } \\ {[} & ] & \text { LETTER } \\ {[} & ] & \text { DRAWINGS } \\ {[} & ] & \begin{array}{l}\text { Other } \\ \text { (Specify): }\end{array}\end{array}$

Addressed to:

\begin{tabular}{|c|c|c|}
\hline & & DOE-HQ \\
\hline$x$ & & DOE-RL \\
\hline & & $\begin{array}{l}\text { Other } \\
\text { (Specify) }\end{array}$ \\
\hline
\end{tabular}

Description and what constitutes completion of this commitment:

A decision basis will be developed which implements decision methodology and decision criteria developed with stakehoider participation for TPA $M-50-03$ "Complete evaluation of enhanced sludge washing to determine wheth advanced siudge separation processes are required" by 03/31/98. The performance of sludge washing and related tar waste sludge pretreatment methods will be evaluated as part of the decision basis verification process using data available in FY 1995. The initial evaluation results will be used to :

- Provide a basis for a decision on the need for advanced sludge separations if a decision is required earlier than $t$ planned date of $3 / 31 / 98$.

- Provide programmatic guidance to prioritize testing, engineering, and development efforts required to reduce $t$ uncertainty of factors affecting the decision.

Acceptance Criteria:

The acceptance criteria, including the plan for accomplishing this milestone, will be documented in the deliverabl submitted to DOE-RL to fulfill TPA Milestone M-50-03A by 09/30/94. A draft of the deliverable will be submitted thr months prior to the completion date for review by DOE and stakeholders. A final report approved for external publication will be transmitted to DOE-RL one month prior to the completion date for transmittal to WDOE by the completion date.

Excellent

Decision basis is developed utilizing input from the technical community, management and other stakeholders. Qual products are provided fully addressing programmatic issues and requiring minimal rework. Report is effective in providing guidance in prioritizing test and supporting other program decision making.

\section{Satisfactory}

Decision basis is developed based on input from the technical community management and input from stakeholde Products identify programmatic issues. Report can be used for prioritizing tests. Draft recommendation may regu considerable rework, and is accepted by DOE by the end of FY 1995. With effort, products provide FY $1996 \mathrm{MU}$ Year Program Planning activity support.

\section{Unsatisfactory}

Decision basis is developed, but required rework, and is not accepted by DOE by the end of FY 1995 . Products do adequately support FY 1996 Multi-Year Program Planning activities in a timely manner.

Basis of Measurement: Fulfillment of the requirements identified in the MYWP MDSs. 


\section{WHC TWRS Milestone Description Sheet}

Deliverables:

The deliverables are:

- A contractor approved draft report transmitted to DOE-RL for review by 06/30/95.

- A final report approved for external publication transmitted to DOE-RL by 08/31/95.

W.B. Barton

Cost Account Manager

I.E. Reep

Activity Manager

Date

L. Erickson
K.A. Gasper

Program Element Manager

Date

L. Erickson

DOE Manager (agreement)

Date

DOE Manager lacceptancel

Date 


\section{WESTINGHOUSE HANFORD COMPANY}

Tank Waste Remediation System Division

Milestone Description Sheet

Title: Updated Estimates of Tank Waste

Types, Compositions \& Quantities

Assigned To: High Level Waste

WBS Designator: 1.1.1.3.03.04

Milestone Control No.: T3C-96-114

Milestone Class:

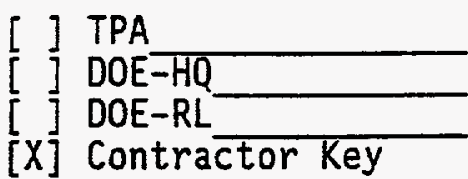

Deliverable

[X] Report

[ ] Letter

[ ] Drawings

[ ] Other (Specify)
Schedule ID: SDW1001

Revision: 0

ADS No.: 1240-0

Completion Date: 10/02/95

\section{Description:}

Addressed to:

[ ] DOE-HQ

[ ] DOE-RL

[X] Other (Specify)

WHC Management

Critically review available data. Consider uncertainties in tank waste inventory, pretreatment performance, and biending alternatives. Provide estimates of the potential range of feed compositions to the HLW vitrification plant.

Acceptance Criteria:

Issuance of the report to WHC senior management.

Deliverables:

Report detajing estimates of potential feed composition ranges.

Signatures:

Cost Account Manager Date

T. W. Crawford

Activity Manager

R. W. Powe 17
Program Element Manager

R. W. Powe 11

DOE Manager (Agreement)

J. C. Peschong 


\section{WESTINGHOUSE HANFORD COMPANY}

\section{Tank Waste Remediation System Division Milestone Description Sheet}

Title: Update Feed Processability Evaluation

Schedule ID: SDW2100 Revision: 0

Assigned To: High Level Waste

ADS No.: 1240-0

WBS Designator: 1.1.1.3.03.04

Completion Date: 01/04/96

Milestone Control No.: T3C-96-107

Milestone Class:

Deliverable

Addressed to:

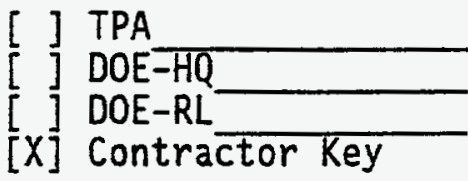

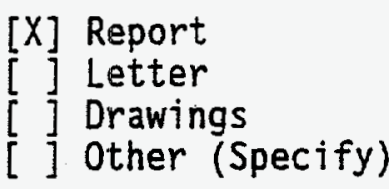

[ ] DOE-HQ

[ ] DOE-RL

[X] Other (Specify)

WHC Management

\section{Description:}

Identify and develop strategies for controlling critical components through blending, pretreatment or glass formulation and dilution to maximize the waste oxide loading and optimize melter and plant performance. Issue updated feed processability assessment report.

\section{Acceptance Criteria:}

Transmittal of report to WHC management.

Deliverabies:

Feed Processability Report.

Signatures:

Cost Account Manager Date

T. W. Crawford

Activity Manager

R. W. Powe 11
Program Element Manager Date

R. W. Powe11

DOE Manager (Agreement)

J. C. Peschong 


\section{WHC TWRS Milestone Description Sheet}

Titie: Retrieval Sequence (a) Selected

Assigned to:

WBS Designator:

TWRS Process Technology

Milestone Control No.:

1.1 .1 .3 .01 .04 .02 .25

T3A-96-132
Schedule ID:

Revision:

ADS No.:

1220-0-AF

Completion Date:
PSW04003A

0

\section{Milestone Class:}

[ $]$ TPA

[ ] DOE-HO

$[\mathrm{X}]$ DOE-RL

[ ] CONTRACTOR
Deliverable:

$\begin{array}{llll}{\left[\begin{array}{ll}\mathrm{X} & ]\end{array}\right.} & \text { REPORT } \\ {[} & & ] & \text { LETTER } \\ {[} & & ] & \text { DRAWINGS } \\ {[} & & ] & \begin{array}{l}\text { Other } \\ \text { (Specify): }\end{array}\end{array}$

Addressed to:

\begin{tabular}{|c|c|}
\hline 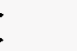 & 1 \\
\hline 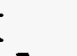 & ] \\
\hline$x$ & נ \\
\hline
\end{tabular}

WHCInternal

Description and what constitutes completion of this commitment:

Background: TPA milestone number M-45-02A "Initial Retrieval Sequence Report" calls for the transmittal of the init SST retrieval sequence to Ecology for their approval by September 30, 1996. Although not required by the TPA milestone, the report will include the retrieval sequence of all 177 SSTs and DSTs. The preparation of that report is $t$ responsibility of the Retrieval Program. The technical basis for that report is the subject of this milestone descripti sheet.

The sequence selected for this milestone is an update of the preliminary retrieval sequence to be established circa $M$ 1995 and documented in the Preliminary Retrieval Sequence Report to be issued circa September 1995 . This sequen shall be selected from alternatives based upon the metrics estimated by a computer simulation of the TWRS. in $t$ event that the computer simulation is not ready on time, the retrieval sequence (a) can be based upon manual estimation of a subset of the metrics. The selected sequence shall be documented in a report.

\section{Acceptance Criteria:}

The retrieval sequence shall:

\footnotetext{
- Be approved by appropriate organizations within WHC,

Be cleared for public release.

Provide the order and estimated timing of the retrieval of all 177 SSTs and DSTs,

Be based upon the metrics estimated by a computer simulation of the behavior of the Tank Waste Remediati System (TWRS) to alternative retrieval sequences and blending strategies, or manual estimates thereof,

- Be developed using assumptions consistent with the current TWRS baseline.
} 


\section{WHC TWRS Milestone Description Sheet}

Deliverables:

The deliverable is one or more supporting documents, that together meet the above acceptance criteria.

W.B. Barton

Cost Account Manager

Date

Date

Activity Manager

L. Erickson

DOE Manager (acceptance)

Date

\section{K.A. Gasper}

Program Element Manager

Date

L. Erickson

DOE Manager (agreement)

Date 
Title: Issue TWRS Process Flowsheet, Rev. 2

\section{Assigned to:}

WBS Designator:

Milestone Control No.:

TWRS Process Technology

1.1.1.3.01.04.03.02

T3A-96-131

\author{
Schedule ID: \\ Revision: \\ PSW04055A \\ 0
}

ADS No.:

1220-00-AF

Completion Date:

$06 / 28 / 96$

\section{Milestone Class:}

[ ] TPA

[ ] DOE-HO

[ ] DOE-RL

$[X]$ CONTRACTOR
Deliverable:

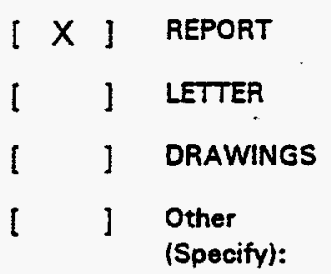

Addressed to:

[ ] DOE-HO

[- $]$. DOE-RL

[ $\mathrm{X}$ ] Other

(Specify): WHCInternal

Description and what constitutes completion of this commitment:

Using the latest process requirements, processing sequences development results, and information from vendors, revis the previous year's issue of the Tank Waste Remediation System (TWRS) Process Flowsheet.

Acceptance Criteria:

Deliverables:

A completed internal supporting document (SD) will be issued for reference use within the TWRS Process Engineerir organization.

W.B. Barton

Cost Account Manager

Date

I.E. Reep

Activity Manager

Date

L. Erickson

DOE Manager (acceptance)
K.A. Gasper

Program Element Manager

Date

L. Erickson

DOE Manager (agreement)

Date 


\section{WHC TWRS Milestone Description Sheet}

Title: Update of Determine Waste Processing Strategy and Waste Separations Process $(4.2 .2 / 4.2 .2 .1)$

Assigned to:

WBS Designator:

TWRS Process Design

$$
\text { 1.1.1.3.01.04.02 }
$$

Milestone Control No.: T3A-96-140

Milestone Class:

$\begin{array}{llll}{[} & & ] & \text { TPA } \\ {[} & & ] & \text { DOE-HQ } \\ {[} & & ] & \text { DOE-RL } \\ {[} & \mathrm{X} & ] & \text { CONTRACTOR }\end{array}$

Deliverable:

\begin{tabular}{|c|c|c|}
\hline$[x$ & ] & REPORT \\
\hline l & 1 & LETTER \\
\hline & & DRAWINGS \\
\hline & & $\begin{array}{l}\text { Other } \\
\text { (Specify): }\end{array}$ \\
\hline
\end{tabular}

\author{
Schedule ID: \\ PSW00114A \\ Revision: \\ 0 \\ ADS No.: \\ 1220-00-AF \\ Completion Date: \\ $08 / 30 / 96$
}

Addressed to:

$\begin{array}{lll}{[} & ] & \text { DOE-HO } \\ {[=1} & \text { DOE-RL } \\ {[X]} & \begin{array}{l}\text { Other } \\ \text { (Specify): }\end{array} \\ & & \begin{array}{l}\text { WHC- } \\ \text { Internal }\end{array}\end{array}$

Description and what constitutes completion of this commitment:

This activity will provide for the first update to the current technical justification (via a trade study) for the "case Beta" separations strategy and establish the basis for additional development work for advance separations. The study assessed separations alternatives consistent with environmental impact statement (EIS) preparation including no pretreatment, treatment of waste to an intermediate form, enhanced sludge washing, and extensive pretreatment separations (e.g., CLEAN). A trade study report was prepared in FY 1995 which included information gathering, draft document preparation. WHC review, and WHC approval. This update to that document will be complete with WHC approval of the updated study document according to the appropriate Impact Level. The study will also include the cost and schedule impacts of implementing advanced separations processes assuming that enhanced siudge washing will not result in an acceptably low volume of HLW.

Acceptance Criteria:

Acceptance will be provided by WHC approval of the update to the study document.

Deliverabies:

Annual update to previous study document which incorporates latest data.

W.B. Barton

\begin{tabular}{ll}
\hline Cost Account Manager & Date \\
I.E. Reep & Date \\
\hline Activity Manager & \\
L. Erickson & Date
\end{tabular}

\section{K.A. Gasper}

\begin{tabular}{ll}
\hline Program Element Manager & Date \\
L. Erickson & \\
\hline DOE Manager (agreement) & Date
\end{tabular}




\section{Westinghouse Hanford Company Tank Waste Remediation System Milestone Description Sheet}

Title:

Collect Rotary and Push Mode

Core Samples from High Level

Waste Tanks

Assigned to: Waste Tank Sampling Engineering

Program WBS Designator: 1.1.1.2.04.03.02

Milestone Control No.: T2D-96-113

Milestone Class:

Deliverables:

[ ] Report

[X] Letrer

[ X ] DOE-RL

[ ] Drawings

[ ] CONTRACTOR

[ ] Other(Specify)
Schedule D:

N4C32A122A

Revision:

ADS No.:

$1130-0 \mathrm{C}$

Completion Date:

09-26-96

Description and what constitutes completion of this commitment (What work is specifically going to be done to accomplish this milestone):

High level tank waste surface to tank bottom core samples will be collected using the Push and Rotary mode coring systems. The number of cores identified for Push mode sampling is 36 (based on 2 cores/tank). The number of cores identified for Rotary mode sampling is 48 (based on 2 cores/tank). Waste samples will be transported and relinquished to an onsite laboratory. Relinquishment of all required* waste samples to the laboratory via a transportation chain of custody document constinutes completion of the sampling commitment. In the event any of the above taniks cannot be sampled, contingency tanks will be selected.

This assumes $\$ 11.0 \mathrm{M}$ of funding for rotary and $\$ 6.8 \mathrm{M}$ for push sampling. This requires all 4 trucks deployed and working in the field. The safery issues for rotary in a flammable gas tanks will need to be resolved by $2 / 14 / 96$ (U-107). As of 9/22/94 the first flammable rotary tanks.

* See acceptance criteria below.

Acceptance Criteria:

Waste sampling in direct accordance with an approved (WHC) Tank Characterization Plan.

Deliverables (Describe the specific products or conditions):

Quarterly performance reports will be transmitted by the Characterization Program Element manager to DOERL manager as part of the DNFSB 93-5 Commiment 1.10. The reports will identify sampling performance based on a fiscal year-to-date percent complete scheme. Additionally, any non-recoverable schedule variance will be reported and consequential impacts identified.

\section{P. A. Young}

Cost Account Manager

Date

G. A. Stanton

Activity Manager

Date

R. E. Gerton
C. DeFigh-Price

Program Element Manager Date

R. E. Gerton

DOE Manager (agreement) Date
Addressed To:

\section{[ ] DOE-HQ}

[ X ] DOE-RL

[ ] Other(Specify): 


\section{Westinghouse Hanford Company \\ Tank Waste Remediation System Milestone Description Sheet}

Title: Collect Auger Samples from High Level Waste Tanks

Assigned to: Waste Tank Sampling Engineering

Program WBS Designator: 1.1.1.2.04.03.03

Milestone Control No.: T2D-96-114

Milestone Class:

Deliverables:

[ ] TPA

[ ] Report

[ ] DOE-HQ

[ X ] Letter

[ X] DOE-RL

[ ] Drawings

[ ] CONTRACTOR
Schedule ID:

N4C33A122A

Revision:

ADS No.:

$1130-0 C$

Completion Date:

Description and what constitutes completion of this commitment (What work is specifically going to be done to accomplish this milestone):

High level tank waste surface samples will be collected using an auger sampling system. Six cores will be sampled by auger method. Waste samples will be transported and relinquished to an onsite laboratory. Relinquishment of all required* waste samples to the laboratory via a transportation chain of custody document constitutes completion of the sampling commitment. In the event any of the above tanks cannot be sampled, contingency tanks will be selected.

This requires $\$ .3 \mathrm{M}$ of funding.

* See acceptance criteria below.

Acceptance Criteria:

Waste sampling in direct accordance with an approved (WHC) Tank Characterization Plan.

Deliverables (Describe the specific products or conditions):

Quarterly performance reports will be transmitted by the Characterization Program Element manager as part of the DNFSB 93-5 Commitment 1.10. The reports will identify sampling performance based on a quarteriy and fiscal year-to-date percent complete scheme. Additionally, any non-recoverable schedule variance will be reported and consequential impacts identified.

P. A. Young

Cost Account Manager

Date

G. A. Stanton

Activity Manager

Date

R. E. Gerton

DOE Manager (acceptance) Date
C. DeFigh-Price

Program Element Manager Date

R. E. Gerton

DOE Manager (agreement) Date 
TITLE: ISSUE 40 TANK CHARACTERIZATION REPORTS IN ACCORDANCE WITH THE APPROVED TANK

CHARACTERIZATION PLANS. COMPLETE INPUT OF CHARACTERIZATION INFORMATION FOR 40 HLW TANKS TO ELECTRONIC DATABASE(S) (M-44-09)

ASSIGNED TO: Characterization Support

WBS DESIGNATOR: 1.1.1.2.04.05.04
SCHEDULE ID: N4E54AO2A REVISION:

MILESTONE CONTROL NO: T2D-96-102

\section{MILESTONE CLASS: DELIVERABLE:}

[X] TPA M-44-09

[ ] DOE-HQ

[ ] DOE-RL

[ ] CONTRACTOR

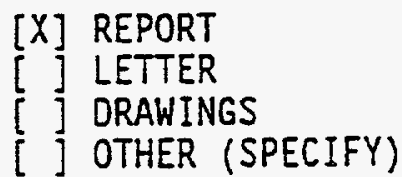

ADDRESSED TO:

[ ] DOE-HQ

[X] DOE-RL

[ ] OTHER (SPECIFY)

Description and what constitutes completion of this commitment:

Generate and issue 40 Tank Characierization Reports (TCRs) (in aceordance with the approved Tank Characterization Plans) in suppori of TPA milestone M-64-09. These TCRs will integrate tank waste historical data with tank waste anatytical data. Uodate previousty issued TCRs as necessary to incorporate new information. TCRs will be cteared for puolic release.

\section{Acceptance Criteria}

1) The Tank Characterization Resoris must include both the relevant historical data and the information obrained by the characierization effort in accordance with the approved iank Characterization Plans. The TCRs will be similar in content and format to that prepared for tank 241-AP-101 and issued as supporting documents. One copy of each TCR will be transmitzed to RL for formal submittal to Ecology. All other internal and externat distribution of the TCRs will be performed by the characterization Program.

2) Characzerization data for all 40 tanixs must be accessible by onsite and offsize stakeiolders through the Tank Characzerization Database.

Deliverables: (Describe the specific products or condition)

1) Provide a draft to DOE-RL during review process so RL can perform concurrent review.

2) Transmit each ney or revised TCR to DOE-RL as it is issued. Provide with each TCR a draft transmittal letter which DOE-RL maY use to forward the document to EPA and Ecology.

3) Provide a final letter after transmission of all TCRS to DOE-RL, indicating eampletion of the milestone and the date that each TCR was iransmitred.

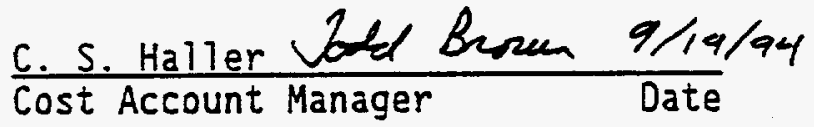

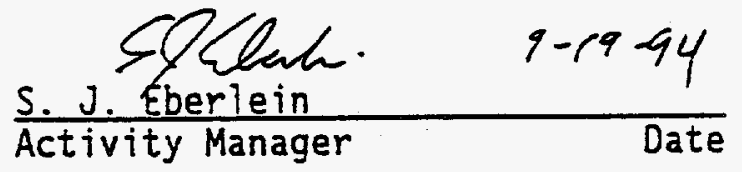

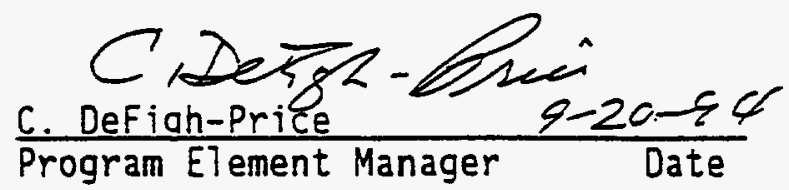

R. E. Gerton

DOE Monitor Date

R. E. Gerton

DOE Manager (acceptance) Date




\section{WESTINGHOUSE HANFORD COMPANY \\ TANK WASTE REMEDIATION SYSTEM DIVISION \\ MILESTONE DESCRIPTION SHEET}

TITLE: SUBMIT INITIAL SINGLE SHELL TAINK RETRIEVAL SEQUENCE DOCUMENT FOR ECOLOGY APPROVAL.

ASSIGNED TO: Waste Retrieva]

WBS DESIGNATOR: 1.1.1.2.05

MILESTONE CONTROL NO: T2E-96-101
SCHEDULE ID: R00100A REVISION: 0

ADS NO: $1210-0$

COMPLETION DATE: $9-30-96$
MILESTONE CLASS:

DELIVERABLE:

[X] TPA M-45-02A

[ ] DOE-HQ

[ ] DOE-RL

[ ] CONTRACTOR

\section{[X] REPORT}

LETTER

DRAWINGS

OTHER (SPECIFY)
ADDRESSED TO:

[] $\mathrm{DOE}-\mathrm{HQ}$

[X] DOE-RL

[ ] OTHER (SPECIFY)

Description and what constitutes completion of this commitment:

Based on the TWRS flow sheet and system models, provide a single-shell tank retrieval sequence document that defines the tank selection criteria, tank selection rationale, reference retrieval methods for each tank, and the estimated retrieval schedules

Acceptance Criteria

The retrieval sequence document will reflect the latest revision of the TWRS

flow sheet and provide a basis for retrieval project and operations schedules.

Deliverables:

Submit the single-shell tank retrieval document to DOE-RL for approval by Ecology.

L. A. Fort

Cost Account Manager: Date:

K. E. McKinney

Activity Manager:

W. R. Wrzesinski

DOE Manager (acceptance)

\section{G. A. Meyer}

Program Element Manager: Date:

W. R. Wrzesinski 
Titie: W-151 ORR/STARTUP COMPLETE

$\begin{array}{lc}\text { Assigned to: } & \text { Waste Retrieval } \\ \text { WBS Designator: } & 1.1 .1 .2 .05 \\ \text { Milestone Control No.: } & \text { T2E-96-102 }\end{array}$

Milestone Class:

$\begin{array}{llll}{[} & & \text { TPA } \\ {[} & & ] & \text { DOE-HO } \\ {[} & X & ] & \text { DOE-RL } \\ 1 & 1 & \text { CONTRACTOR }\end{array}$

\author{
Schedule ID: ROD160-1 \\ Revizion: \\ 0
}

ADS No.:

$1210-2$

Completion Date: 30 SEP96

Deliverable:

[. ] REPORT

$[X]$ LETTER

[ ] DRAWINGS

[ ] Other

(Specify):
Addressed to:

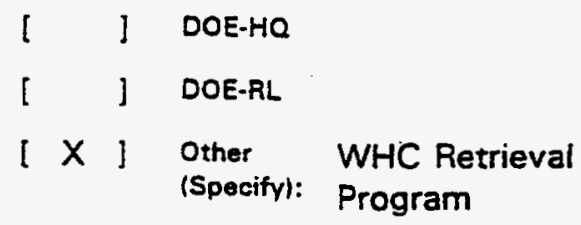

Description and what constitutes completion of this commitment:

This activity includes all work necessary to prepare for startup of the mixer pumps in tank 101-AZ, including readiness reviews, procedures, etc..

\title{
Auceptance Criteris:
}

Completion of the Operation Readiness Review and approval to begin operations.

\section{Deliverabies:}

Issue a letter to the Waste Retrieval Program Office documenting completion of the ORR/Starting activities.

E. M. Nordquist

Cost Account Manager

L. A. Fort

Date

Activity Manages

W. R. Wrzesinski

DC' Manager (acceptance)
G. A. Meyer

Date

Program Element Manager

W. R. Wrzesinski

Date

DOE Manager (agreement) 
Title: Submit Report Summarizing the Testing of Enhanced Sludge Washing and Related Tank Waste Sludge Pretreatment Methods for Samples of Tank Waste Sludge

Assigned to:

WBS Designator: Process Technology

Milestone Control No.:

T3A-96-100
Milestone Class:

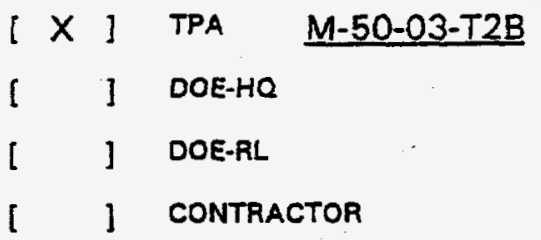

Deliverable:

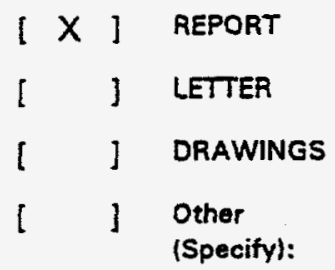

Schedule ID:

Revision:

ADS No.:

Completion Date: 09/30/96

0
PSW04760A/PXW04-2A

\author{
1220-00-AF
}

Addressed to:

$\begin{array}{lll}{[} & ] & \text { DOE-HQ } \\ {[\times} & ] & \text { DOE-RL } \\ {[=} & ] & \begin{array}{l}\text { Other } \\ \text { (Specify): }\end{array}\end{array}$

Description and what constitutes completion of this commitment:

Perform testing of enhanced sludge washing and related tank waste sludge pretreatment methods using actual tank waste samples. Document and issue results of testing completed to that time. This annual report will also document preliminary candidate tank waste pretreatment sequence and tank blending strategies. Goals for both early progress on waste immobilization and minimization of the production of high level giass will be addressed in these strategies.

These preliminary strategies will be utilized to predict the production of high level waste glass associated with candidate enhanced sludge washings and related tank waste sludge pretreatment methods. The prediction of the HLW glass volume production will be updated.

\section{Acceptance Criteria:}

The report will include the latest laboratory data available on sludge washing and enhanced sludge washing through second quarter of FY 1996 and the expected impacts on HLW glass volume will be provided. 


\section{WHC TWRS Milestone Description Sheet}

Deliverabies:

The deliverables are:

- Contractor approved report to DOE-RL for review and comment by 07/31/96.

- Final WHC-approved report for external publication and transmittal by 09/01/96.

W.B. Barton

Cost Account Manager

Date

I.E. Reep

Activity Manager

Date

L. Erickson

\section{K.A. Gasper}

Program Element Manager

Date

L. Erickson

DOE Manager (agreement)

Date

DOE Manager (acceptance)

Date 
Title: Preliminary Recommendation on Evaluation of Enhanced Sludge Washing to Determine Whether Advanced Sludge Separation Process are Required

Assigned to:

TWRS Strategic Analysis

WBS Designator:

$$
1.1 .1 .3 .01 .04
$$

Milestone Control No.:

T3A-96-110

\author{
Schedule ID:
}

Revision:

ADS No.:

Completion Date:
PSW04418A

0

1220-00-AF

$09 / 30 / 96$
Milestone Class:

\begin{tabular}{|c|c|c|}
\hline & 1 & TPA \\
\hline & ] & DOE-HO \\
\hline$x$ & ] & DOE-RL \\
\hline & 1 & CONTRACTOR \\
\hline
\end{tabular}

Deliverable:

$\begin{array}{llll}{[} & X & ] & \text { REPORT } \\ {[} & & ] & \text { LETTER } \\ {[} & & \text { D } & \text { DRAWINGS } \\ {[} & & ] & \begin{array}{l}\text { Other } \\ \text { (Specify): }\end{array}\end{array}$

Addressed to:

$\begin{array}{lll}{[} & ] & \text { DOE-HO } \\ {[=X} & ] & \text { DOE-RL } \\ {[} & ] & \begin{array}{l}\text { Other } \\ \text { (Specify): }\end{array}\end{array}$

Description and what constitutes completion of this commitment:

This milestone supports completion of TPA M-50-03 "Complete evaluation of enhanced sludge washing to determine whether advanced siudge separation processes are required" by $03 / 31 / 98$. The performance of sludge washing and related tank waste sludge pretreatment methods will be evaluated to determine if these processes will be capable of satisfying criteria which will be established during FY 1995. A decision methodology will be developed with stakeholder participation and implemented. A preliminary recommendation will be developed based on data available during FY 1996 which will:

- Provide a basis for a decision on the need for advanced sludge separations if a decision is required earlier than the planned date of $03 / 31 / 98$.

- Provide programmatic guidance to prioritize testing, engineering, and development efforts required to reduce the uncertainty of factors affecting the decision.

\section{Acceptance Criteria:}

The acceptance criteria, including the plan for accomplishing this milestone, will be documented $i$ the deliverable submitted to DOE-RL to fulfill TPA Milestone M-50-03A by 09/30/94. A draft of the deliverable will be submitted three months prior to the completion date for review by DOE and stakeholders. A final report approved for external publication will be transmitted to DOE-RL one month prior to the completion date for transmittal to WDOE by the completion date. 


\section{WHC TWRS Milestone Description Sheet}

Deliverables:

The deliverable are:

- A contractor approved draft report transmitted to DOE-RL for review b 06/30/96.

- A final report approved for external publication transmitted to DOE-RL by 08/31/96.

W.B. Barton

Cost Account Manager

Date

Date

Date
I.E. Reep

Activity Manager

L. Erickson
DOE Manager (acceptance)

\section{K. A. Gasper}

Program Element Manager

Date

L. Erickson

DOE Manager (agreement)

Date 


\section{WESTINGHOUSE HANFORD COMPANY \\ TANK WASTE REMEDIATION SYSTEM DIVISION \\ MILESTONE DESCRIPTION SHEET}

TITLE:

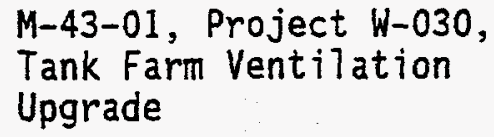

ASSIGNED TO: Tank Farm Upgrades

PROGRAM WBS DESIGNATOR:

1.1.1.2.03.10.01

MILESTONE CONTROL NO: T2C-97-100

MILESTONE CLASS:

DELIVERABLE:

[X] TPA

[ ] DOE-HQ

[] Report

[ ] DOE-RL

$[X]$ Letter**

[ ] Drawings

[ ] WHC Key
SCHEDULE ID: N3G24F5M

REVISION: 0

ADS NO: $1120-2$

COMPLETION DATE: $12 / 31 / 96$

Description and what constitutes completion of this commitment:

Project $W-030$ will replace the ventilation system for the $A Y$ and $A Z$ Tank Farm. This project will provide the essential safety class systems for the $A Y$ and $A Z$ Tank Farms to provide safe and efficient storage of radioactive liquid highlevel waste. Upgrades and improvements will be made to the ventilation and cooling, electrical standby power and instrumentation/control systems.

Acceptance Criteria:

Completion of M-43-01C, "Begin Operations". This last interim milestone will complete the requirements of $M-43-01$.

Deliverables:

Complete Definitive Design, Start Construction, Complete Construction, Begin Operations

** One letter will be written to document completion of M-43-01C, "Begin operations. Included in this letter, will be notification of completion of the entire milestone M-43-01, "Project W-030 Tank Farm Ventilation Upgrade"

K. A. Colosi

Cost Account Manager: Date:

K. L. Morris

Activity Manager: Date:
J. D. Thomson Program Element Manager: Date:

A. Hon

DOE Monitor:
Date:

$\overline{\text { DOE Manager (acceptance) Date }}$

Seprember 28, 1994 


\section{WESTINGHOUSE HANFORD COMPANY}

Tank Waste Remediation System Division

Milestone Description Sheet

Title: Documention of Potential Feed Composition Ranges Estimate

Assigned To: High Level Waste

WBS Designator: 1.1.1.3.03.04

Milestone Control No.: T3C-97-109

Milestone Class:

$\begin{array}{ll}{[} & \text { TPA } \\ {[} & \text { DOE-HQ } \\ {[} & \text { DOE-RL } \\ {[X]} & \text { Contractor Key }\end{array}$
Deliverabie

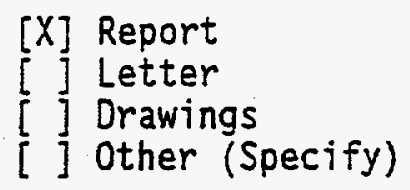

Schedule ID: SOW1100

Revision: 0

ADS No.: 1240-0

Completion Date: 10/01/96
Addressed to:

[] DOE-HQ
$[$ ]
$[X]$ ODE-RL
WHC Management
WHC Mafify)

Description:

Critically review available data. Consider uncertainties in tank waste inventory, pretreatment performance, and blending alternatives. Provide estimates of the potential range of feed compositions to the HLW vitrification plant.

Acceptance Criteria:

Issuance of the report to WHC senior management.

Deliverables:

Report detailing estimates of potential feed composition ranges.

Signatures:

Cost Account Manager Date

T. W. Crawford

Activity Manager

R. W. Powe11
Program Element Manager

R. W. Powe 11

DOE Manager (Agreement)

J. C. Peschong 
Title: Initiate Tank AZ-101 Sludge Washing Process Test

WBS Designator:

TWRS Process Design

Milestone Control No.:

1.1.1.3.01.04.02.15

T3A-97-114

Milestone Class:

[ ] TPA

[ ] DOE-HQ

[ ] DOE-RL

[ $X$ ] CONTRACTOR
Deliverable:

$\begin{array}{lll}{[X} & ] & \text { REPORT } \\ {[} & ] & \text { LETTER } \\ {[} & ] & \text { DRAWINGS } \\ {[} & ] & \begin{array}{l}\text { Other } \\ \text { (Specify): }\end{array}\end{array}$

Schedule 1D: $\quad$ PSW49019A

Revision:

0

ADS No.:

1220-00-AF

Completion Date:

$01 / 02 / 97$

Addressed to:

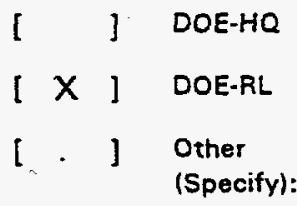

Description and what constitutes completion of this commitment:

The first test of sludge washing tank waste will be conducted in tank AZ-101. This test will be a joint effort between the Waste Retrieval and Waste Pretreatment program elements. Waste Retrieval will install two mixer pumps in the tank. Waste Pretreatment will install additional instrumentation, e.g. turbidity profilers, some interface analyzers, and thermal dispersion probes. In addition, the computer control system installed to support the decanting operation will be expanded to support the new instrumentation. The pumps will be tested and simultaneously the sludge washing process test will be carried out. Process Design will measure waste suspended solids and dissolved solids concentrations before and after the operation of the mixer pumps. This milestone commitment will be completed when the measurements have been made and the tank is ready for mixer pump operation.

\section{Acceptance Criteria:}

Suspended solids measurements have been made and samples have been taken to measure dissolved solids concentrations.

Deliverables:

A transmittal letter documenting readiness to initiate the mixer pump (supplied by Project W-151, DST Retrieval Pumps) and sludge washing tests.

W.B. Barton

\begin{tabular}{ll}
\hline Cost Account Manager & Date \\
I.E. Reep & \\
\hline Activity Manager & Date \\
L. Erickson & \\
\hline DOE Manager (acceptance) & Date
\end{tabular}

K.A. Gasper

\begin{tabular}{ll}
\hline Program Element Manager & Date \\
L. Erickson & \\
\hline DOE Manager (agreement) & Date
\end{tabular}


Title: Recommend Design Basis Feeds for Conceptual Design

Assigned To: High Level Waste WBS Designator: 1.1.1.3.03.04

Milestone Control No.: T3C-97-107

Milestone Class:

$\left[\begin{array}{ll}] & \mathrm{TPA} \\ {[} & \mathrm{DOE}-\mathrm{HQ} \\ {[} & \mathrm{DOE}-\mathrm{RL} \\ {[x]} & \text { Contractor Key }\end{array}\right.$
Deliverable

$[X]$ Report

[ ] Letter

[ ] Drawings

[ ] Other (Specify)
Scheduie ID: SDW2200 Revision: 0

ADS No.: 1240-0

Completion Date: 01/03/97

Addressed to:

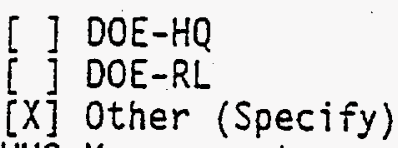

WHC. Manaoement

\section{Description:}

Identify and develop strategies for controlling critical components through blending pretreatment or glass formulation and dilution to maximize the waste oxide loading and optimize melter and plant performance characteristics.

Produce specific recommendations for design basis feeds for Conceptual Design.

\section{Acceptance Criteria:}

Issuance of recommended design basis feed specifications to WHC management.

Deliverabies:

Recommended design basis feed specifications to WHC management.

Signatures:

Cost Account Manager. Date

T. W. Crawford

Activity Manager

R. J. Powe11
Program Element Manager

R. H. Powell

DOE Manager (Agreement). Date

J. C. Peschong 
Titie:

Retrieval Sequence

(b) Selected

Assigned to:

TWRS Process Technology

WBS Designator:

1.1.1.3.01.04.02.25

Milestone Control No.:

T3A-97-110
Schedule ID:

Revision:

ADS No.:

1220-0-AF

Completion Date: 04/03/97

0
Milestone Class:

\begin{tabular}{|c|c|}
\hline ] & TPA \\
\hline 1 & DOE-HO \\
\hline ] & DOE-RL \\
\hline
\end{tabular}

Deliverable:

\begin{tabular}{|c|c|c|}
\hline$x$ & ] & REPORT \\
\hline & & LETTER \\
\hline & & DRAWINGS \\
\hline & & $\begin{array}{l}\text { Other } \\
\text { (Specify): }\end{array}$ \\
\hline
\end{tabular}

PSW04004A

Addressed to:

$\begin{array}{lll}{[} & ] & \text { DOE-HQ } \\ {[} & ] & \text { DOE-RL } \\ {[. X} & ] & \begin{array}{l}\text { Other } \\ \text { (Specify): }\end{array}\end{array}$

WHC-

Internal

Description and what constitutes completion of this commitment:

Background: TPA milestone number M-45-02B "Initial Retrieval Sequence Report" calls for the transmittal of the initial SST retrieval sequence to Ecology for their approval by September 30, 1997. Although not required by the TPA milestone, the report will include the retrieval sequence of all 177 SSTs and DSTs. The preparation of that report is the responsibility of the Retrieval Program. The technical basis for that report is the subject of this milestone description sheet.

The sequence selected for this milestone is an update of the retrieval sequence to be established circa May 1996 (Retrieval Sequence (a) Selected) and documented in the Retrieval Sequence Report to be issued by the Retrieval Program circa September 1996. This sequence shall be selected from alternatives based upon the metrics estimated by a computer simulation of the TWRS. In the event that the computer simulation is not ready on time, the retrieval sequence (b) can be based upon manual estimation of a subset of the metrics. The selected sequence shall be documented in a report.

Acceptance Criteria:

The retrieval sequence shall:

- Be approved by appropriate organizations within WHC,

- Be cleared for public release,

- Provide the order and estimated timing of the retrieval of all 177 SSTs and DSTS,

Be based upon the metrics estimated by a computer simulation of the behavior of the Tank Waste Remediation

System (TWRS) to alternative retrieval sequences and blending strategies, or manual estimates thereof,

- Be developed using assumptions consistent with the current TWRS baseline. 


\section{WHC TWRS Milestone Description Sheet}

Deliverables:

The deliverable is one or more supporting documents, that together meet the above acceptance criteria.

\section{W.B. Barton}

Cost Account Manager

Date

1.E. Reep

Activity Manager

Date

L. Erickson

DOE Manager (acceptance)

Date

\section{K.A. Gasper}

Program Element Manager

Date

L. Erickson

DOE Manager (agreement)

Date 
Tive:

Update of Determine Waste Processing Strategy and Waste Separations Process (4.2.2/4.2.2.1)

Assigned to: TWRS Process Design

$$
1.1 .1 .3 .01 .04 .02
$$

Milestone Control No.:

T3A-97-111
WBS Designator:

\author{
Schedule ID: \\ Revision: \\ PSW00117A \\ 0
}

ADS No.:

1220-00-AF

Compietion Date: 08/29/97

Addressed to:

Miiestone Class:

Deliverable:

[ ] TPA

l ] DOE-HO

[ $X]$ REPORT

[ ] DOE-RL

l ] LETTER

[ $X$ ] CONTRACTOR

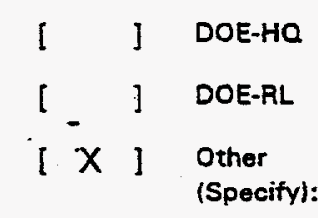

Other

(Specify):
WHCInternat

Description and what constitutes completion of this commitment:

This activity will provide for the second update to the current technical justification (via a trade study) for the "case Beta" separations strategy and establish the basis for additional development work for advance separations. The study assessed four categories of separations alternatives consistent with environmental impact statement (ElS) preparation including no pretreatment, treatment of waste to an intermediate form, enhanced sludge washing, and extensive pretreatment separations (e.g., CLEAN). A trade study report was prepared in FY 1995 , and updated in FY 1996 , which included information gathering, draft document preparation, WHC review, and WHC approval. This update to that document will be complete with WHC appoval of the updated study document according to the appropriate impact Level (assumed to be N/A or level 4).

Acceptance Criteria:

Acceptance will be provided by WHC approval of the update to the study document.

Deliverables:

Annual update to previous study document which incorporates latest data.

\section{W.B. Barton}

\begin{tabular}{ll}
\hline Cost Account Manager & Date \\
l.E. Reep & Date \\
\hline Activity Manager & \\
L. Esickson & Date
\end{tabular}

K.A. Gasper

\begin{tabular}{ll}
\hline Program Element Manager & Date \\
L. Erickson & \\
\hline DOE Manager (agreement) & Date
\end{tabular}




\section{Westinghouse Hanford Company Tank Waste Remediation System Milestone Description Sheet}

Title: Collect Rotary and Push Mode Core Samples from High Level Waste Tanks

Assigned to: Waste Tank Sampling Engineering

Program WBS Designator: 1.1.1.2.04.03.02

Milestone Control No.: T2D-97-109
Schedule ID:

N4C32A132A

Revision:

ADS No.:

$1130-0 \mathrm{C}$

Completion Date:
Milestone Class:

[ ] TPA

[ ] DOE-HQ

[ X ] DOE-RL

[ ] CONTRACTOR
Deliverables:

[ ] Repor

[X] Leater

[ ] Drawings

[ ] Other(Specify)

Addressed To:

[ ] DOE-HQ

[X] DOE-RL

[ ] Other(Specify): -

Description and what constitutes completion of this commitment (What work is specifically going to be done to accomplish this milestone):

High level tank waste surface to tank bottom core samples will be collected using Push and Rotary mode coring systems. The number of cores idenrified for Rotary mode sampling is 88 (assumes 2 cores/tank). The number of cores identinied for Push mode sampling is 20 (assumes 2 cores/tank). However, other tanks can be substinured via appropriate WHC change confrol to the integrated operations schedule. Waste samples will be transported and relinquished to an onsite laboratory. Relinquishment of all required* waste samples to the laboratory via a transportation chain of custody documenr constirutes completion of the sampling commiment. In the event any of the above tanks cannor be sampled. coningency tanks will be selected.

This assumes \$19.7M for Rotary and \$4.0M for Push sampling. All 4 trucks are required with 6 crews of operators.

* See acceptance criteria below.

\section{Acceptance Criteria:}

Waste sampling in direct accordance with an approved (WHC) Tank Characterization Plan (TCP). Sampling must meet recovery requirements specified in the TCP.

Deliverables (Describe the specific products or condirions):

Quarteriy performance reports will be transmitted by the Characterization Program Element manager to DOERL manager as part of the DNFSB 93-5 Commiment 1.10. The reports will identify sampling performance based on a fiscal year-to-date percent complete scheme. Additionally, any non-recoverable schedule variance will be reported and consequential impacts identified.

\section{P. A. Young}

Cost Account Manager

Date

G. A. Stanron

Activiry Manager

Date
C. DeFigh-Price

Program Element Manager Dare

R. E. Gerron

DOE Manager (agrement) Date

R. E. Genton

DOE Manager (acceptance) Date 


\section{WESTINGHOUSE HANFORD COMPANY}

\section{Tank Waste Remediation System Division \\ Milestone Description Sheet}

Tit7e: Incorporate Pretreatment CDR \& Sludge Wash Decision

Assigned To: High Level Waste

WBS Designator: 1.1.1.3.03.05.04

Milestone Control No.: T3C-97-100

Milestone Class:

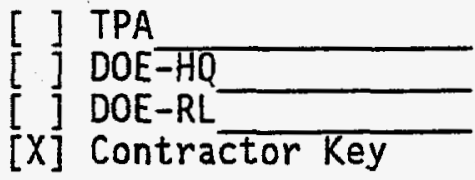

Deliverable

[ ] Report

$[X]$ Letter

\section{] Drawings}

] Other (Specify)
Schedule ID: CDW1050

Revision: 0

ADS No.: 1240-0

Completion Date: 09/29/97

Addressed to:

[ ] DOE-HQ

[ ] DOE-RL

[X] Other (Specify)

A-E contractor

\section{Description:}

An interface with the Pretreatment program detailing final selection of pretreatment processes to be used in the HLW facility Conceptual Design.

\section{Acceptance Criteria:}

Transmittal of the pretreatment process selection decision to the HLW facility A-E contractor.

Deliverables:

Letter transmitting the pretreatment CDR and sludge wash decision to the $A-E$ contractor.

Signatures:

$\overline{\text { Cost Account Manager Date }}$

Activity Manager

R. W. Powe Il
Program Element Manager Date

R. W. Powe 11

DOE Manager (Agreement) Date

J. Peschang 
TITLE: ISSUE 40 TANK CHARACTERIZATION REPORTS IN ACCORDANCE WITH THE APPROVED TANK

CHARACTERIZATION PLANS. COMPLETE INPUT OF CHARACTERIZATION INFORMATION FOR 40 HLW TANKS TO ELECTRONIC DATABASE(S) $(M-44-10)$

ASSIGNED TO: Characterization Support

WBS DESIGNATOR: 1.1.1.2.04.05.04

MILESTONE CONTROL NO: T2D-97-102

\section{MILESTONE CLASS: DELIVERABLE:}

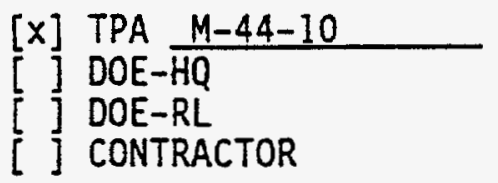

$\begin{array}{ll}{[x]} & \text { REPORT } \\ {[]} & \text { LETTER } \\ {[]} & \text { DRAWINGS } \\ {[j]} & \text { OTHER (SPECIFY) }\end{array}$

SCHEDULE ID: N4E54A03A REYISION:

Description and what constitutes completion of this commitment:

Generate and issue 40 Tank Characterization Reports (TCRs) (in accordance with the aporoved Tank Characterization P(ans) in support of TPA milestone M-44-10. These TCRs will incegrate tank waste historical data with tank waste analytical data. Update previously issued TCRs as necessary to incorporate nex information. TCRs will be cieared for public release.

\section{Acceptance Criteria}

1) The Tank Characterization Reports must include both the relevant historical data and the information obtained by the characterization effort in accordance with the approved Tank Characterization plans. ihe TCRs will be similar in content and format to that prepared for tank 241-AP-101 and issued as suoporting documents. One copy of eaci $\mathrm{iCR}$ vill be transmitted to RL for formal submitral so Ecology. All other internal and external distribution of the TCRS will be performed by the Characterization Program.

2) Characierization data for all 40 tanks must be actessible by onsite and offsite stakenoloers through the Tank Characterization Database.

Deliverables: (Describe the specific products or condition)

1) Provide a draft to DOE-RL during reviex process so RL can perform concurrent review.

2) Transmit each ney or revised TCR to OOE-RL as it is issued. Provide with each TCR a draft transmittal letter which DOE-RL may use to forward the dociment to EPA and Ecology.

3) Provide a final letter after transmission of all TCRs to OOE-RL, indicating completion of the milestone and the dace that each $i C R$ was transmitted.
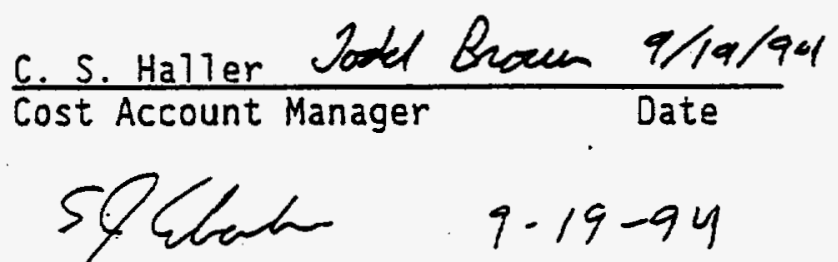

S. 0. Eberlein Activity Manager

$$
9 \cdot 19-94
$$

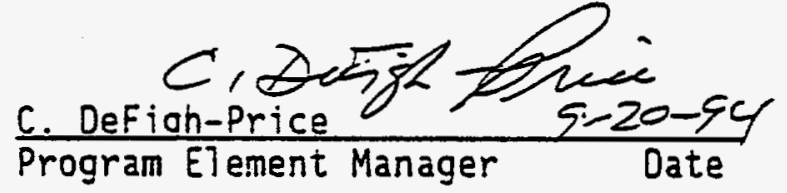

R. E. Gerton DOE Monitor

R. E. Gerton

DOE Manager (acceptance) Date




\section{WESTINGHOUSE HANFORD COMPANY \\ TANK WASTE REMEDIATION SYSTEM DIVISION \\ MILESTONE DESCRIPTION SHEET}

TITLE: SUBMIT ANNUAL UPDATE OF SINGLE SHELL TANK RETRIEVAL SEQUENCE DOCUMENT FOR ECOLOGY APPROVAL.

ASSIGNED TO: Waste Retrieval

WBS DESIGNATOR: 1.1.1.2.05

MILESTONE CONTROL NO: T2E-97-104
SCHEDULE ID: ROO100C REVISION: 0
ADS NO: $1210-0$

COMPLETION DATE: $9-30-97$

\section{MILESTONE CLASS: DELIVERABLE: ADDRESSED TO:}

$\begin{array}{ll}{[X]} & \text { TPA } M-45-02 B \\ {\left[\begin{array}{l}1 \\ {[}\end{array}\right] \text { DOE-HQ }} \\ {[] \text { DOE-RL }} \\ {[]} & \text { CONTRACTOR }\end{array}$
[ ] DOE-HQ

[X] DOE-RL

[ ] OTHER (SPECIFY)

Description and what constitutes completion of this commitment:

Based on the TWRS flow sheet and system models, provide a single-shell tank retrieval sequence document that defines the tank selection criteria, tank selection rationale, reference retrieval methods for each tank, and the estimated retrieval schedules.

\section{Acceptance Criteria}

The retrieval sequence document will reflect the latest revision of the TWRS flow sheet and provide a basis for retrieval project and operations schedules.

Deliverables:

Submit the singie-shel1 tank retrieval document to DOE-RL for approval by Ecology.

L.A. Fort

Cost Account Manager: Date:

K. E. McKinney

Activity Manager:

W. R. Wrzesinski

DOE Manager (acceptance)
G. A. Meyer

Program Element Manager: Date:

W. R. Wrzesinski

DOE Manager (agreement): Date: 


\section{WHC TWRS Milestone Description Sheet}

Title: Submit Report Summarizing the Testing of Enhanced Sludge Washing and Related Tank Waste Sludge Pretreatment Methods for Samples of Tank Waste Sludge

Assigned to:

Process Technology

WBS Designator:

$$
\text { 1.1.1.3.01.04.03.44 }
$$

Milestone Control No.:

T3A-97-101

Milestone Class:

Deliverable:

$\left[\begin{array}{lll}X & ]\end{array}\right.$ TPA

$M-50-03-T 2 C$

$[\mathrm{X}$

REPORT

l $]$ DOE-HO

[ ] DOE-RL

l ] CONTRACTOR
Schedule ID:

Revision:

ADS No.:

Completion Date:
PSW04790A/PW05-0A

0

1220-00-AF

$09 / 30 / 97$
Addressed to:

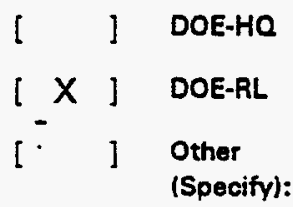

Description and what constitutes completion of this commitment:

Perform testing of enhanced sludge washing and related tank waste sludge pretreatment methods using actual tar waste samples. Document and issue results of testing completed to that time. This annual report will also docume preliminary candidate tank waste pretreatment sequence and tank blending strategies. Goals for both eariy progress waste immobilization and minimization of the production of high level glass will be addressed in these strategies.

These preliminary strategies will be utilized to predict the production of high level waste glass associated with candida enhanced sludge washings and related tank waste sludge pretreatment methods. The prediction of the HLW glas volume production will be updated.

\section{Acceptance Criteria:}

The report will include the latest laboratory data available on sludge washing and enhanced sludge washing (throus second quarter of FY 1997) and the expected impacts on HLW glass volume will be provided. 


\section{WHC TWRS Milestone Description Sheet}

Deliverables:

The deliverables are:

- Contractor approved report to DOE-RL for review and comment by 07/31/97.

- Final WHC-approved report for external publication and transmittal by 09/01/97.

\section{W.B. Barton}

Cost Account Manager

\section{K.A Gasper}

Program Element Manager

Date

L. Erickson

DOE Manager (agreement)

Date

L. Erickson

DOE Manager (acceptance)

Date 


\section{WHC TWRS Milestone Description Sheet}

Page 1 of

Titie: Issue Draft Recommendation on Evaluation Sludge Washing To Determine if Advanced Siudge Separation Process are Required

Assigned to:

TWRS Strategic Analysis

WBS Designator:

1.1 .1 .3 .01 .04 .02 .22

Milestone Control No.:

T3A-97-105

Schedule ID: $\quad$ PSWO4423A

Revision:

0

ADS No.:

1220-00-AF

Completion Date:

$09 / 30 / 97$

Addressed to:

Milestone Class:

[ ] TPA

l 1 DOE-HO

$\left[\begin{array}{lll}X & 1 \\ \text { DOE-RL }\end{array}\right.$

[ ] CONTRACTOR
Deliverable:

[ $X$ ] REPORT

l $]$ LETTER

[ ] DRAWINGS

[ ] Other

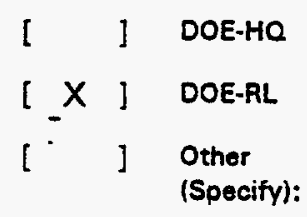

(Specify):

Description and what constitutes completion of this commitment:

This milestone provides the basis for completing TPA M-50-03 "Complete evaluation of enhanced sludge washing determine whether advanced sludge separation processes are required" by 03/31/98. The performance of sludge washing and related tank waste siudge pretreatment methods will be evaluated to determine if these processes will established during FY 1995. A decision methodology will be developed with stakeholder participation and implement A draft recommendation will be developed based on data available during FY 1997 which will:

- Provide a basis for a decision on the need for advanced sludge separations if a decision is required earlier than $t$ planned date of $03 / 31 / 98$.

- Be revised consistent with resuits from all testing, engineering, and development efforts completed during FY 195 and serve as the review and comment draft for the Final Recommendation.

Acceptance Criteria:

The acceptance criteria, including the plan for accomplishing this milestone, will be documented in the deliverable submitted to DOE-RL to fulfill TPA Milestone M-50-03A by 09/30/94. A draft of the deliverable will be submitted thr months prior to the completion date for review by DOE and stakeholders. A final report approved for external publication will be transmitted to DOE-RL one month prior to the completion date for transmittal to WDOE by the completion date. 


\section{WHC TWRS Milestone Description Sheet}

\section{Deliverables:}

The deliverables are:

- A contractor approved draft report transmitted to DOE-RL for review by 06/30/97.

- A final report approved for external publication transmitted to DOE-RL by 08/31/97.

\section{W.B. Barton}

Cost Account Manager

\section{I.E. Reep}

Activity Manager

Date

L. Erickson

DOE Manager (acceptance)

\section{K.A. Gasper}

Program Element Manager

Date

L. Erickson

DOE Manager (agreement)

Date 


\section{WHC TWRS Milestone Description Sheet}

Title: Complete In-Tank Sludge Washing Process Test and Issue Report (Tank AZ-101)

Schedule ID: PSW49030A

Revision:

0

$\begin{array}{ll}\text { Assigned to: } & \text { TWRS Process Design } \\ \text { WBS Designator: } & 1.1 .1 .3 .01 .04 .02 .15 \\ \text { Milestone Control No.: } & \text { T3A-97-107 }\end{array}$

ADS No.:

1220-00-AF

Completion Date:

$09 / 30 / 97$

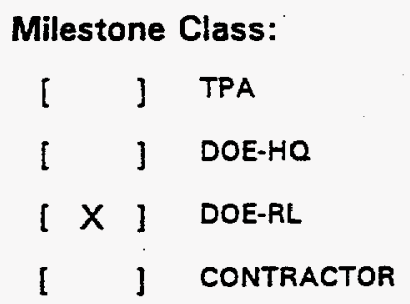

Deliverable:

Addressed to:

Description and what constitutes completion of this commitment:

The solids/liquids separation will be done by decanting off liquid from DSTs (including salt cake which has been dissolved in SSTs and transferred to the DSTs). The solids treatment will consist of ln-Tank Processing (sludge washing with water and sodium hydroxide solution) to remove solubles including some of the aluminum and zirconium) to reduce the volume of solids going to the HLW immobilization facility.

A sludge washing test will be conducted to determine if sludge can be adequately mobilized with two mixer pumps, and if the sludge can be washed and separated from the waste solution as assumed in the Hanford Federal Facility Agreement and Consent Order (Tri-Party Agreement).

Completion of this activity includes accomplishing the following activities in Tank 241-AZ-101:

- Installation of a decant pump and control system

- Decanting the neutralized current acid waste (NCAW) supernatant to another tank

- Adding dilute low-activity supernatant from another tank

- Installing and testing mixer pumps supplied by Project W-151, Tank 241-AZ-101 Waste Retrieval System (performed by others)

- Allowing the washed solids to settle

- Measuring the suspended solids profile before and after the mixer pump/sludge washing test

- Sampling and analyzing the supernatant before and after the mixer pump/sludge washing test

- Updating computer model for simulating solid-liquid separation and leaching based on analytical results

- Preparing a report documenting efficiency of a single sludge wash of NCAW 


\section{WHC TWRS Milestone Description Sheet}

\section{Acceptance Criterie:}

The acceptance criteria includes issuing a contractor approved test plan describing the planned waste retrieval mixer pump and sludge washing process tests prior to initiating the process tests. Status report documenting activities accomplished and planned accomplistments will be submitted in FY 1995 and FY 1996 . A contractor approved report documenting the results of the sludge washing demonstration in Tank 241-AZ-101 will be transmitted to DOE-RL on the completion date.

Deliverables:

The deliverables are:

- Contractor approved test plan by 04/30/95

- Sludge washing test status report by 09/30/95

- Sludge washing test status report by 09/30/96

- Contractor approved report documenting results of the siudge washing test in Tank 241-AZ-101 by $09 / 30 / 97$

\section{W.B. Barton}

Cost Account Manager
K.A. Gasper

Program Element Manager

Date

L. Erickson

I.E. Reep

Activity Manager

Date

DOE Manager (agreement)

Date

L. Erickson

DOE Manager (acceptance)

Date 


\section{WHC TWRS Milestone Description Sheet}

Title: Complete Evaluation of Enhanced Sludge Washing to Determine if Advanced Sludge Separation Processes are Required
Schedule ID:

PSW04429A/ PHW26F

Revision:

0

ADS No.:

1220-00-AF

Completion Date:
Milestone Class:

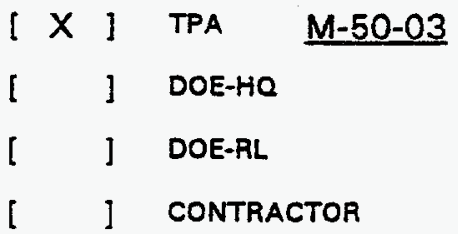

Deliverable:

$\begin{array}{llll}{[} & X & \text { REPORT } \\ {[} & & ] & \text { LETTER } \\ {[} & ] & \text { DRAWINGS } \\ {[} & ] & \begin{array}{l}\text { Other } \\ \text { (Specify): }\end{array}\end{array}$

Addressed to:

$\begin{array}{lll}{[-} & ] & \text { DOE-HQ } \\ {[} & ] & \text { DOE-RL } \\ {[} & ] & \begin{array}{l}\text { Other } \\ \text { (Specify): }\end{array}\end{array}$

Description and what constitutes completion of this commitment:

The performance of sludge washing and related tank waste sludge pretreatment methods will be evaluated to determine if these processes will be capable of satisfying criteria which will be established by the three parties prior to the milestone date. The criteria will include such items as volume of HLW resulting from pretreatment, compatibility with HLW and LLW vitrification processes, and processing rates. For example, sludge washing and enhanced sludge washing must result in the production of a "reasonable" volume of $H L W$ requiring repository disposal such that other established sludge treatment processes will not result in overall cost savings or schedule improvements. If the predicted performance does not meet the criteria, the need for more advanced sludge separations processes will be re-examined and changes to the HLW Program will be proposed accordingly. Key elements of this evaluation include:

- Pretreatment process testing using actual tank waste. These tanks will be chosen to represent the expected range of sludge composition. Candidate processes are those, such as water washing, caustic washing, and selective leaching, which do not require complex processing systems and which can be impiemented within tanks or relatively simple facilities.

- Developing candidate tank treatment and blending sequences to minimize the volume of immobilized HLW.

- Modeling systems performance to predict the volumes of immobilized HLW produced and processing rates for candidate pretreatment processes.

- $\quad$ Assessing the uncertainties related to the HLW volume predictions.

- Issuing annual reports summarizing the status of testing of enhanced sludge washing and advanced separations methods.

- Decision analysis process based on inputs from stakeholders.

Acceptance Criteria:

The acceptance criteria, including the decision analysis process and plan for achieving this milestone will be documented in the deliverable submitted to DOE-RL to fulfill Milestone M-50-03A by $9 / 30 / 94$. The deliverable will contractor report approved for extemal publication. The report must be ready for transmittal to the WDOE by DOEAll comments received from reviewers of this report will be addressed. A decision analysis process based on inp from stakeholders and approved by DOE-RL will be used to explain the decision documented in the report. 
Deliverables:

- A contractor approved report will be transmitted to DOE-RL by $12 / 31 / 97$ for review by DOE-RL and Stakeholders.

- A final contractor report approved for external publication will be transmitted to DOE-RL by $02 / 28 / 98$ for DOE-RL transmittal to WDOE by $03 / 31 / 98$.

W.B. Barton

Cost Account Manager

I.E. Reep

Activity Manager

Date

Date

K.A. Gasper

Program Element Manager

Date

L. Erickson

DOE Manager (agreement)

Date

L. Erickson

DOE Manager (acceptance)

Date 


\section{WHC TWRS Milestone Description Sheet}

Tite: Submit Conceptual Design of HLW Pretreatment Facility

Schedule ID:

Revision:

ADS No.:

Completion Date:

Milestone Class:

Deliverable:

\begin{tabular}{|c|c|c|c|}
\hline$x$ & J & TPA & M-50-04-T01 \\
\hline & 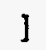 & DOE-HQ & \\
\hline & 1 & DOE-RL & \\
\hline & & CONTRAC & CTOR \\
\hline
\end{tabular}

\begin{tabular}{|c|c|}
\hline$\left[\begin{array}{ll}x & X\end{array}\right]$ & REPORT \\
\hline$\left[\begin{array}{ll}x & 1\end{array}\right.$ & LETTER \\
\hline ] & DRAWINGS \\
\hline$\times 1$ & $\begin{array}{l}\text { Other } \\
\text { (Specify): }\end{array}$ \\
\hline
\end{tabular}

1220-00-AC

$03 / 31 / 98$

Addressed to:

PHW09160A/PDW0400A 0

\begin{tabular}{|c|c|}
\hline I & DOE-HO \\
\hline$x$ & DOE-RL \\
\hline & $\begin{array}{l}\text { Other } \\
\text { (Specify }\end{array}$ \\
\hline
\end{tabular}

Description and what constitutes completion of this commitment:

To the extent that additional facilities are needed for the solids treatment beyond In-Tank Processing (sludge wast with water and sodium hydroxide solution), they will be provided by a. HLW pretreatment facility, WBS element 1.1 .1 .3 .01 .06 , which may be a stand-alone facility or may be combined with the LLW pretreatment facility or with HLW immobilization facility. This capability is scheduled to be operational by June, 2008, TPA Milestone 50-04 support the HLW immobilization activity.

A Conceptual Design Report (CDR) will be prepared to support a Request for Project Authorization for design an construction of the HLW pretreatment facility.

\section{Acceptance Criteria:}

The acceptance criteria includes issuing a Conceptual Design Plan (CDP) in accordance with RL 4700.1, Project Management System, which identifies the work elements and schedule required to achieve project validation. I criterion for completion of this milestone is a contractor approved CDR for the HLW pretreatment facility. 


\section{Deliverables:}

The deliverables are:

- Contractor approved CDP by 04/30/96

- Contractor approved CDR by 03/31/98

K.A. Gasper

Cost Account Manager Date

K.A. Gasper

Activity Manager

Date

Date

\section{Erickson}

K.A. Gasper

Program Element Manager

Date

L. Erickson

DOE Manager (agreement)

Date 
Title: Initiate Definitive Design of HLW Pretreatment Facility

Assigned to:

WBS Designator:

TWRS Projects

Milestone Control No.:

1.1 .1 .3 .01 .06

T3A-99-100
Schedule ID: $\quad$ PDW0409A

Revision: $\quad 0$

ADS No.:

1220-00-AC

Completion Date: $11 / 30 / 98$
Milestone Class:

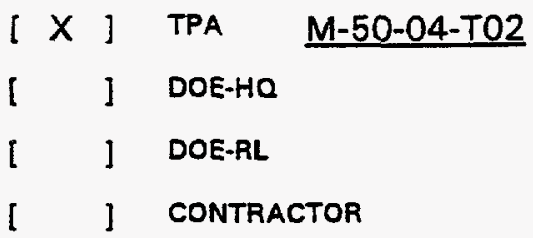

Defiverable:

$\left[\begin{array}{ll}X & \text { REPORT }\end{array}\right.$

$[\mathrm{X}]$ LETTER

[ ] DRAWINGS

$[\times]$
Other Validation

(Specify): Package
Addressed to:

$\begin{array}{lll}{[} & ] & \text { DOE-HO } \\ {[\times} & 1 & \text { DOE-RL } \\ {[:} & ] & \begin{array}{l}\text { Other } \\ \text { (Specify): }\end{array}\end{array}$

Description and what constitutes completion of this commitment:

To the extent that additional facilities are needed for the solids treatment beyond In-Tank Processing (sludge washi with water and sodium hydroxide solution), they will be provided by a HLW pretreatment facility, WBS element 1.1.1.3.01.06, which may be a stand-alone facility or may be combined with the LLW pretreatment facility or with $t$ HLW immobilization facility. This capability is scheduled to be operational by June, 2008, TPA Milestone 50-04, support the HLW immobilization activity.

A Conceptual Design Report (CDR), Justification for New Start documentation and project validation package are prepared and submitted to support Key Decision 1, Approve New Start. Following budget approval, a request fo Project Authorization is submitted to DOE-RL for approval to initiate definitive design.

A sludge washing test will be conducted if sludge can be adequately mobilized with two mixer pumps, and if the slud can be washed and separated from the waste solution as assumed in the Hanford Federal Facility Agreement ano Consent Order (Tri-Party Agreement).

\section{Acceptance Criteria:}

The acceptance criteria includes issuing a Conceptual Design Plan (CDP) in accordance with RL 4700.1, Project Management System, which identifies the work elements and schedule required to achieve project validation. Th criterion for completion of this milestone is DOE approval of the CDR; completion of Key Decision 1, Approve Ne Start; and, approval of Project Authorization to commence Title I design of the HLW pretreatment facility. To achie this milestone, A-E staff must be mobilized and working on definitive design of HLW pretreatment facility. 


\section{WHC TWRS Milestone Description Sheet}

Deliverables:

The deliverables are:

- Contractor approved CDR by 03/31/98.

- Project validation package by $04 / 30 / 98$.

- DOE-RL approval of the CDR by 04/30/98.

- Approval of the Project Authorization to proceed with Title I design by 10/31/98.

- Letter to DOE-RL documenting mobilization of A-E and initiation of Title I by $11 / 30 / 98$.

\section{K.A. Gasper}

Cost Account Manager

Date

K.A. Gasper

Activity Manager

Date

L. Erickson

DOE Manager (acceptance)

Date

\begin{tabular}{lc} 
K.A. Gasper & - \\
\hline Program Element Manager & Date \\
L. Erickson & \\
\hline DOE Manager (agreement) & Date
\end{tabular}


This page intentionally left blank. 


\section{DISTRIBUTION}

\section{U.S. Department of Energy - Headquarters}

EM-35, Trevion II

Washington, D.C. 20585

C. A. Myler

E. I. Rizkalla

D. J. Wynne

Brookhaven National Laboratory

Upton, NY 11973

K. K. Bandyopadhyay

M. Reich

Lawrence Livermore National Laboratory

202 North Ridge Court

Lindsborg, KS. 37456

B. C. Hudson

Los Alamos National Laboratory

P. O. Box 1663

Los Alamos, NM 87545

S. F. Agnew

M. Attrep.

T. Hyrons

D. Sweetin

D. J. Temer

R. Villarreal

Oak Ridge National Laboratory

P. O. Box 2008

Bethel Valley Rd. Building 4501

Oak Ridge, TN 37831-6223

J. T. Bell

E. D. Collins

A. G. Croff

C. P. McGinnis 


\section{DISTRIBUTION (CONT.)}

U. S. Department of Energy Richland Operations Office

C. Sohn

L. Erickson

S. T. Burnum

J. M. Clark

P. T. Furlong

R. A. Gilbert

P. E. Lamont

B. L. Nicoll

J. C. Peschong

G. A. Sanders

D. E. Trader

Public Reading Room

Pacific Northwest Laboratory

G. A. Beeman

G. H. Bryan

L. K. Holton, Jr.

B. M. Johnson, Jr.

W. L. Kuhn

G. J. Lumetta

G. B. Mellinger

V. P. Ostrander

M. J. Quadrel

R. K. Quinn

B. M. Rapko

J. T. Slankas

J. L. Straalsund

D. M. Strachan

J. L. Swanson

PNL Technical Files
S7-53

R3-74

S7-53

R3-72

S7-52

S7-53

S7-53

S7-53

S7-53

S7-53

K8-50

A1-65

B1-40

P7-25

P7-43

K1-78

K2-21

P7-25

K1-78

B1-40

K1-73

K1-73

P7-25

B $1-40$

B1-40

K2-44

P7-25

K1-11 


\section{DISTRIBUTION (CONT.)}

Westinghouse Hanford Company

H. Babad

S7-30

C. DeFigh-Price

R2-31

W. T. Alumkal

S7-85

J. N. Appel

G3-21

V. L. Armstrong

G3-21

B. A. Austin

B2-30

D. L. Banning

G2-20

S. A. Barker

G3-20

W. B. Barton

H5-27

M. L. Bell

T6-07

J. B. Blethen

G3-21

A. L. Boldt

H5-49

K. D. Boomer

H5-49

P. J. Certa

H5-27

C. H. Delegard

T6-09

T. L. Denton

S4-54

S. J. Eberlein

S7-31

R. R. Gadd

G3-20

J. S. Garfield

H5-49

K. A. Gasper

R2-08

K. D. Gibson

H4-61

M. L. Grygiel

B1-58

D. W. Hendrickson

L5-31

R. L. Hibbard Jr.

L6-25

J. O. Honeyman

S7-81

B. K. Horsager

G3-20

R. D. Jensen

B1-59

M. E. Johnson

B1-58

K. N. Jordan

S7-83

L. K. Kelly

S7-03

R. A. Kirkbride

H5-27

M. J. Klem

H5-27

M. J. Kupfer

H5-49

G. A. Meyer

S4-54

R. J. Murkowski

R4-01

R. M. Orme

H5-27

R. W. Powell

H4-14

G. W. Reddick Jr.

H5-49

I. E. Reep

G3-21 


\section{DISTRIBUTION (CONT.)}

Westinghouse Hanford Company

R. C. Roal

H5-27

P. S. Schaus

H4-14

G. A. Stanton Jr.

S7-31

M. W. Stevenson

B2-35

J. D. Thomson

R2-76

T. K. Stone

G3-21

D. J. Washenfelder

H5-27

P. R. Weinman

G3-21

D. D. Wodrich

S7-84

R. D. Wojtasek

S7-84

Correspondence Control

B5-24

President's Office

A3-01

TFIC

R1-20

Information Release Administration

A2-24

Document Processing and Distribution

L8-15

Central Files

L8-04

Environmental Data Management Center

H4-22

D. O. Campbell

102 Windham Road

Oak Ridge, TN 37830

C. H. Drummond III

4771 Watts Hall

2041 College Rd.

Columbus, Ohio 43210

J. L. Kovach

NUCON

P.O. Box 29246

Columbus, OH 43229

D. A. Orth

124 Vivion Drive

Aiken, SC 29803

R. G. Wymer

188-A Dr.

Oak Ridge, TN 37830 
WHC-EP-0805

DISTRIBUTION (CONT.)

Savannah River Laboratory

P. O. Box 616, Building 773-A, C-140

Aikens, SC 29802

M. C. Thompson

WDOE

R. C.H. King

State of Washington Department of Ecology

P. O. Box 47600

Olympia, WA. $98504-7600$

A. D. Huckaby

Washington State Department of Ecology,

Nuclear Waste Program

P. O. Box 1386

Richland, WA 99352

M. Gordon

Washington State Department of Ecology, Regulatory and Technical Support Program

P. O. Box 47600

Olympia, WA. $98504-7600$ 